\title{
A ERG
}

\section{Estimating the Economic Impact of Increases in the Minimum Wage}

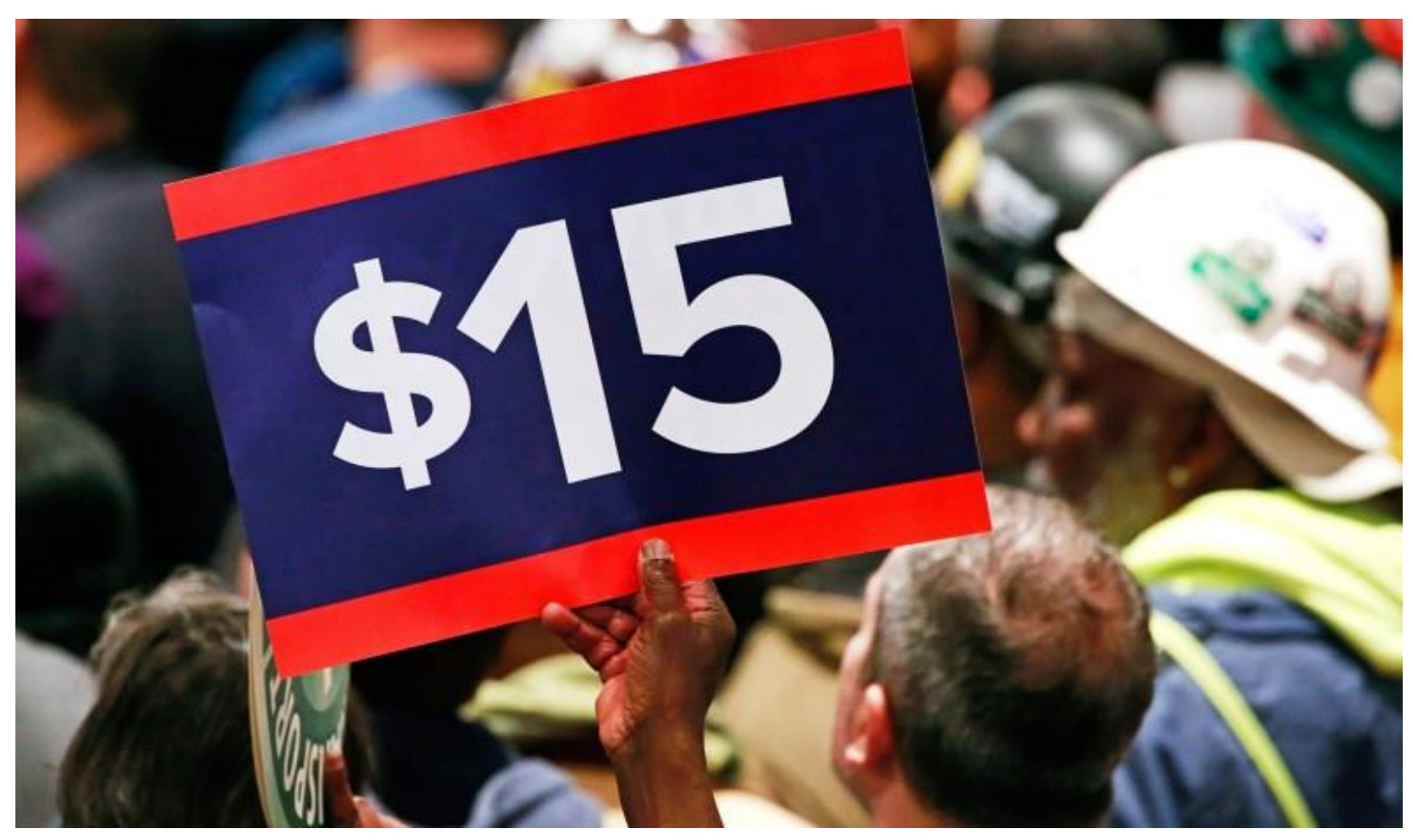

Kory Fenstemacher $\mid$ Jared Fisher $\mid$ Zerina Hadzalic | Brenda Hillebrandt

July 2019 


\section{DISCLAIMER:}

This is a project performed by M.S. students in Applied Economics. The Applied Project course is the capstone course for the degree of M.S. in Economics. The course is a threemonth consulting project that takes the student from the proposal stage through the final presentation and final report.

The students are "hired" as associates in a fictitious consulting company called Applied Economics Research Group (AER Group). The consulting company is fictitious, and is only mentioned to enhance the realism of the project.

To further enhance the realism of the projects, we sometimes use hypothetical client requests for proposals with actual client names. However, the client requests may not be real. Please contact the Director of the Applied Master's program at Florida State University to find out if a client request is real or not.

Although every effort has been made to verify the accuracy of the student projects, Florida State University makes no claims, promises, or guarantees about the accuracy, completeness, or adequacy of the projects, and disclaims liability for errors and omissions of content, statements and conclusions of the projects. In addition, note that these projects are the work of students, and do not necessarily reflect the views of the Department of Economics or Florida State University.

Please do not quote, cite or distribute this project without written consent by the Director of the Applied Master's program at Florida State University. 


\section{Estimating the Economic Impact of Increases in the Minimum Wage: Executive Summary}

\section{Background}

Florida's latest Minimum Wage

Initiative (Initiative \#18-01) is

highly likely to appear on November's voting ballot. This amendment proposes raising the current minimum wage of $\$ 8.46$ to $\$ 10.00$ per hour beginning September 30th, 2021. Each year following the initial increase, the minimum wage would increase another $\$ 1.00$ per hour until it reaches the goal of $\$ 15.00$ per hour by the year 2026 , which is marked by the dotted red line in Figure 1. Based on this information, the Florida Legislature has tasked AERG with a multi-stage economic analysis that involves estimating employment effects, as well as tax revenue and social services expenditures.
Figure 1. Florida's final proposed minimum wage increase, $\$ 15$ per hour, is indicated by the red dashed line.

\section{Hourly Wage Distributions in Florida}

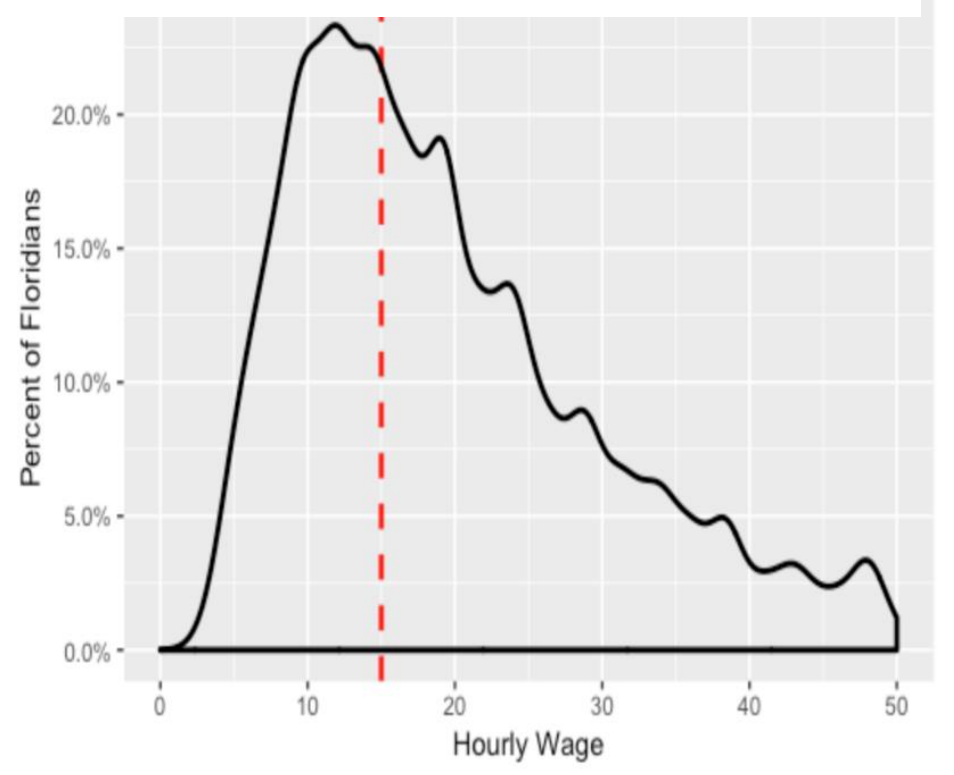

\section{Methodology}

The first step in our analysis was to construct an hourly wage distribution using Integrated Public Microdata Series (IPUMS) data, the world's largest individual-level population database. This

Percent of Floridians Making $\$ 15$ or Less Per Hour

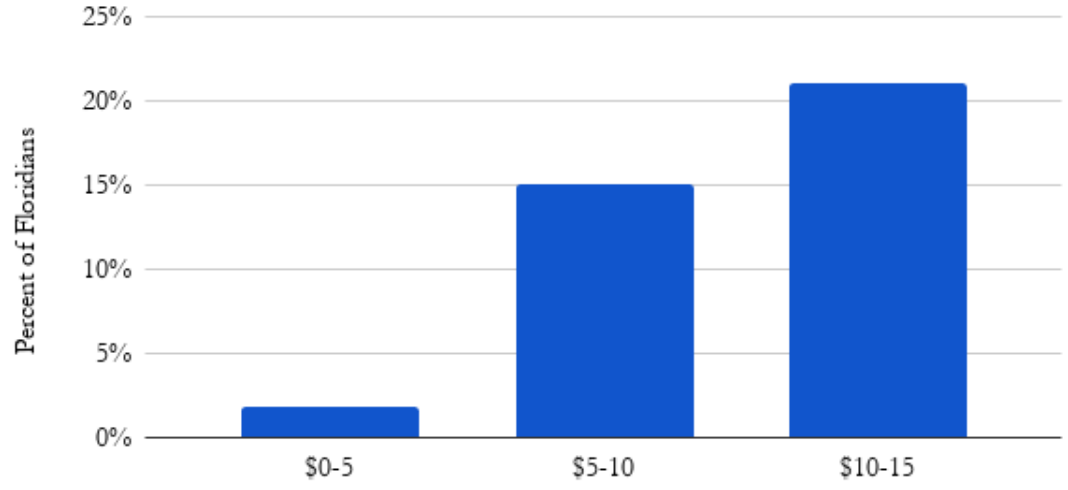

Figure 2. A closer look at the wage distribution. distribution is aggregated at the state level, as the data contains information on hourly wages of workers from all 67 counties in Florida. As observed in Figure 2, our distribution shows over $15 \%$ of Floridians make $\$ 10$ per hour or less, while over $35 \%$ of the Floridian working population make $\$ 15$ per hour or less. 
Since the effects of the minimum wage on employment have been well examined in prior research, much of our analysis will be based on the estimates found in the literature. One of our key tasks is to critically assess the wage elasticities presented therein. We choose to estimate employment using elasticities reflecting low, medium, and high disemployment effects. The majority of the literature we reviewed revolves around lowskilled workers and result in elasticity estimates within a range of -.1 to -.3 . Because of this, we have decided to use these as our low and high values, respectively. We chose our medium elasticity, which is -.2 , to be a midpoint between the low and high elasticity ranges. In practical terms, these values represent a decrease of $1 \%, 2 \%$, or $3 \%$ in employment per $10 \%$ increase in the minimum wage. We find the most pressing issue

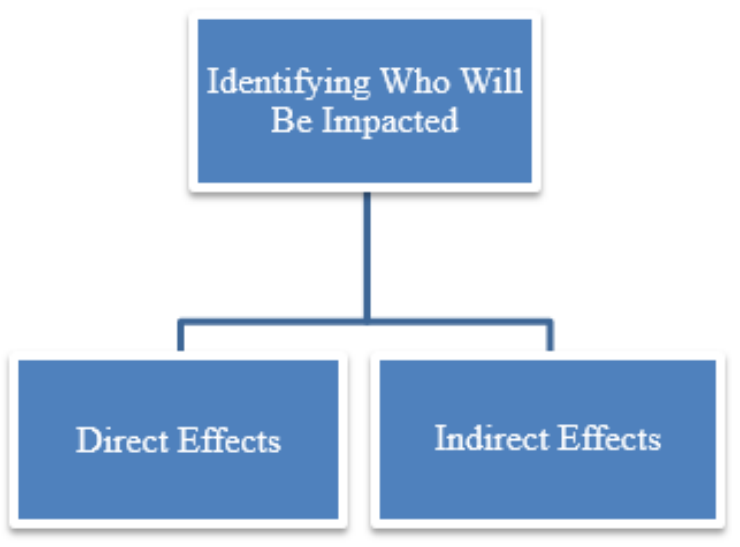

Figure 3. Tax revenues and social services are considered to be indirect effects; changes in employment are direct effects. to be the first jump of approximately $18 \%$ (from $\$ 8.46$ to $\$ 10.00$ ), thus we focus more closely on this. Similarly, our analyses relating to tax revenue and social services are also focused on the initial wage increase. We proceed with using the median elasticity of -.2 to estimate the economic impact of both the direct and indirect effects, working in conjunction with a dynamic multiplier model developed by Regional Economic Models, Inc. (REMI).

\section{Results}

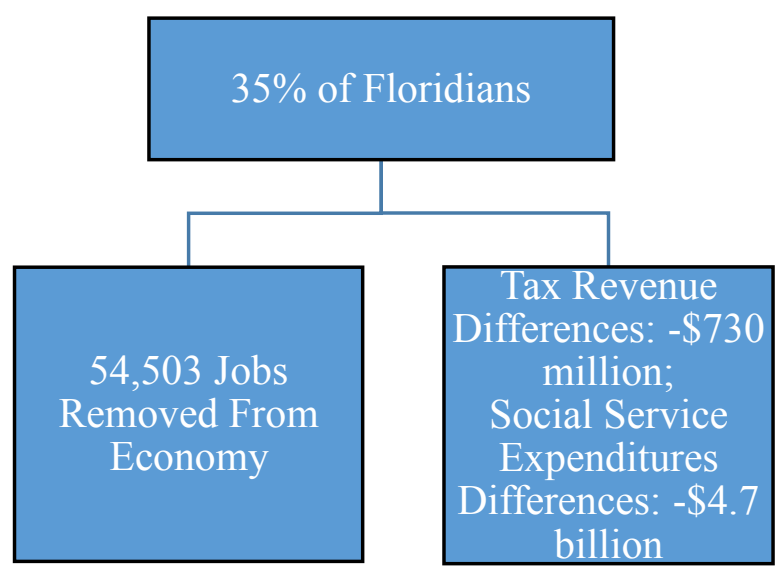

We estimate the numbers of jobs in Florida economy to decrease by 27,914 to 79,821 jobs on average annually over the duration of this amendment, according to our range of elasticities. Income and substitution effects would also take place, resulting in further disemployment. Our estimates for the differences in Florida's tax revenues and social services expenditures from the baseline forecast are presented in Figure 4.

Figure 4. Social service expenditures are composed of a variety of welfare programs in Florida. The graphic displays average differences from the control from 2020 to 2026. 


\section{Table of Contents}

\section{Estimating the Economic Impact of Increases in the Minimum Wage}

Introduction $\quad 3$

A History of the Minimum Wage $\quad 3$

Literature Review $\quad 5$

The "New" Economics of Minimum Wage $\quad 5$

A Closer Look at Florida Wages 19

Multiplier Software $\quad 36$

$\begin{array}{ll}\text { REMI } & 36\end{array}$

$\begin{array}{ll}\text { IMPLAN } & 37\end{array}$

Estimating Employment Effects $\quad 38$

The Increasing Affected Population 38

Selecting Appropriate Elasticities $\quad 39$

Spreading Effects between Industries $\quad 40$

$\begin{array}{ll}\text { Gradual Wage Adjustments } & 41\end{array}$

Direct Effects Estimation $\quad 42$

Differences from the Control 43

Induced Effects Analysis $\quad 44$

Total Effects Analysis $\quad 48$

$\begin{array}{ll}\text { Benefit Cliffs } & 50\end{array}$

Estimating Effects on Social Service Expenditures 56

Tax Revenue Impacts of Minimum Wage Increases $\quad 58$

$\begin{array}{ll}\text { Sales Tax } & 58\end{array}$

$\begin{array}{ll}\text { Property Taxes } & 60\end{array}$

Total State and Local Tax Revenue $\quad 61$

A Word on Productivity Changes due to Minimum Wage Increases 62

$\begin{array}{ll}\text { Non-Constant Elasticity Estimation } & 64\end{array}$

Increases in Wage and The Income Effect for Workers $\quad 65$

Assessing the Income Effect $\quad 65$

Leisure as a Good: The Income Effect $\quad 67$

A Review of the Schooling Effect as Substitution $\quad 68$

Channels of Adjustment: Education $\quad 71$ 
Quantifying the Schooling Effect $\quad 76$

Channels of Adjustment: Unemployment 77

Channels of Adjustment: Firm Spillover Effects 79

Channels of Adjustment: Automation $\quad 80$

Addressing Recent Research $\quad 82$

CBO: The Effects on Employment and Family Income of Increasing the Federal Minimum Wage

Final Thoughts

Appendix 1

Appendix 2

Appendix 3

Appendix 4

Appendix 5

Appendix 6

Appendix 7

Bibliography 


\section{Estimating the Economic Impact of Increases in the}

\section{Minimum Wage}

\section{Introduction}

In this paper, we will consider multiple facets of the widely debated minimum wage argument. First, we will assess the prior literature that analyzes and debates this topic in order to synthesize their estimated effects into a range. Second, and arguably most importantly, we will consider the key demographics affected by the minimum wage legislation. Included in this section will be an analysis of wage distributions in Florida. Third, we will attempt to estimate a range of low, medium, and high effects of increasing the minimum wage in terms of employment levels. Finally, we will estimate the secondary effects of an increased minimum wage - including but not limited to: income effects, substitution effects, and schooling effects - with an emphasis on tax revenue and social services expenditures.

\section{A History of the Minimum Wage}

Florida's minimum wage was initially created on November 2, 2004, after a constitutional amendment was approved by voters. The following year, the minimum wage was set to $\$ 6.15$ per hour - a dollar increase from the federal mandated minimum wage. ${ }^{1}$ By 2009 , the minimum wage of Florida reverted to the federal minimum wage of $\$ 7.25$ per hour. This

\footnotetext{
1 "Florida Minimum Wage History 2000 to 2019." Oct. 2018. Florida Department of Economic Opportunity. 09 July 2019, http://www.floridajobs.org/docs/default-source/business-growth-and-partnerships/for-employers/posters-andrequired-notices/2019-minimum-wage-poster/florida-minimum-wage-history-2000-2018.pdf?sfvrsn=4.
} 
remained constant until 2011, when a legal ruling was passed to increase the minimum wage to $\$ 7.31$ per hour. Over time, the wage has steadily increased to its current value of $\$ 8.46$ per hour. This wage includes the majority of employees with a couple of exemptions (tipped employees, student workers, and other exempt occupations). Typically, the minimum wage increases with the southern consumer price index on wages (CPI-W) and has, so far, only endured minor increases. The proposed minimum wage legislation, however, seeks to change that. The structure of the legislation, which seeks to increase the state-mandated minimum wage to $\$ 15$ per hour over six years beginning in 2020, is illustrated below in Table 1.

Table 1. Yearly Increases in the Minimum Wage

\begin{tabular}{|c|c|c|}
\hline Year & Minimum Wage & Percentage Change from Prior Year \\
\hline 2020 & $\$ 8.46$ & - \\
\hline 2021 & $\$ 10.00$ & $18.2 \%$ \\
\hline 2022 & $\$ 11.00$ & $10.0 \%$ \\
\hline 2023 & $\$ 12.00$ & $9.1 \%$ \\
\hline 2024 & $\$ 13.00$ & $8.3 \%$ \\
\hline 2025 & $\$ 14.00$ & $7.7 \%$ \\
\hline 2026 & $\$ 15.00$ & $7.1 \%$ \\
\hline
\end{tabular}

The initial wage hike from $\$ 8.46$ to $\$ 10.00$ is an $18.2 \%$ increase and represents the second largest percentage increase in the Florida minimum wage since its inception, rivalled only by the aforementioned increase from $\$ 5.15$ to $\$ 6.15$ in 2005 (an increase of 19.4\%). Additionally, the increases following 2021 dwarf previous adjustments based on CPI, which have been between $.02 \%$ and 3\% since 2013 (see Appendix 1 for full minimum wage table). Figure 1 graphically 
depicts the extreme separation from the gradual wage increases that we would see if the proposed legislation passes. We assume that the federal minimum wage would continue to be its current hourly wage of $\$ 7.25$, well into 2030 .

Figure 1 .

\section{Florida's Minimum Wage Would See Significant Increases}

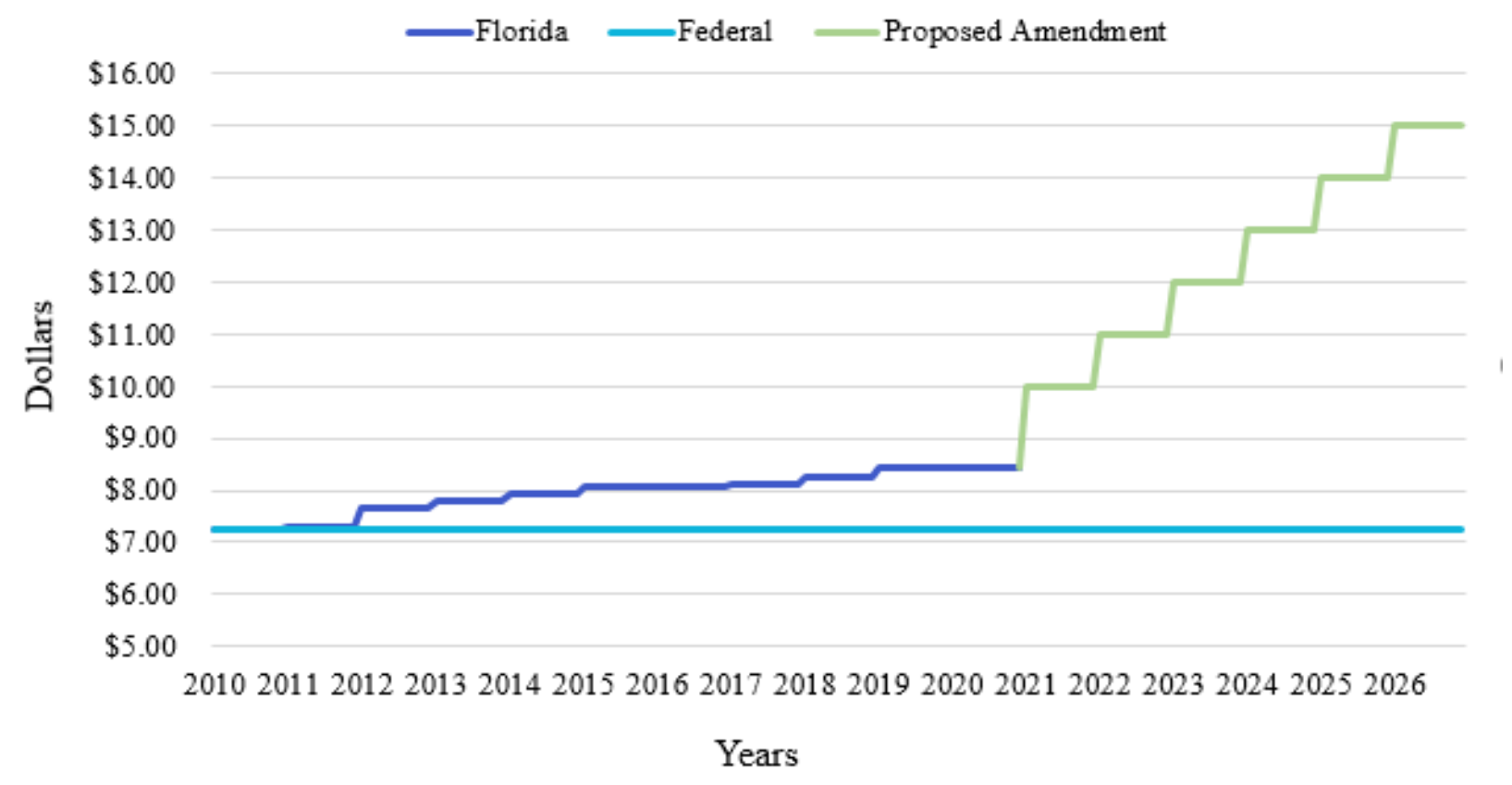

\section{Literature Review}

The "New" Economics of Minimum Wage

It was not until the mid-nineteenth century that somewhat reliable estimates of a theorized disemployment effect were reported. Brown, Gilroy, and Kohen's 1982 paper², which gathers and reviews most of the relevant literature up to that point, is a summary of prior

2 Brown, Charles; Gilroy, Curtis; and Kohen, Andrew. "The Effect of the Minimum Wage on Employment and Unemployment." Journal of Economic Literature, Vol. 20, No. 2 (June 1982), pp. 487-528. 
developments. They state that "time-series studies typically find that a 10 percent increase in the minimum wage reduces teenage employment by 1 to 3 percent", and cross-sectional studies usually "produce a wider range of estimated impacts, which are roughly centered on the range found in the time-series research". In both cases, the authors state that the lower end of the elasticity estimates, such as -.1 , are likely more realistic, and that there potentially is some small negative effect. Additionally, they note that, while there is a substantial lack of information regarding age groups aside from teenagers, the research on 20 to 24 year-olds leans toward an even smaller disemployment effect. Even though these results agree with the theory, there was concern that the prevailing methodology, which utilized national-level time-series data, had pitfalls. Neumark and Wascher note that "the minimum wage variable used in these studies exhibits relatively little variation over time, and what variation exists is correlated with changes in government social welfare and training programs". ${ }^{3}$ If this claim is true, any effect on employment might be confounded, and the minimum wage effect would be difficult to parse out. In order to avoid this, Neumark and Wascher employ state-level panel data, exploiting the fact that greater variation exists in the relative state-level minimum wages than in the federallymandated minimum wage (which has changed only ten times in the last forty years) ${ }^{4}$. Despite utilizing data and methodology that seems objectively better, their estimated elasticities remain essentially the same, with a range of -.1 to -.2 for teenagers aged 16 to 19 . Additionally, included in this paper is a mention of the sub-minimum wage, which had previously been untouched in the literature. Because service industry jobs - specifically retail and food service - play such a

\footnotetext{
${ }^{3}$ Neumark, David and Wascher, William, (1992), Employment Effects of Minimum and Subminimum Wages: Panel Data on State Minimum Wage Laws, ILR Review, 46, issue 1, p. 55-81, https://EconPapers.repec.org/RePEc:sae:ilrrev:v:46:y:1992:i:1:p:55-81.

4 "History of Federal Minimum Wage Rates Under the Fair Labor Standards Act, 1938 - 2009." Minimum Wage Wage and Hour Division (WHD) - U.S. Department of Labor, www.dol.gov/whd/minwage/chart.htm.
} 
large role in the Florida economy, we suspect that this insight will be particularly valuable to our analysis.

This comfortable consensus of a small negative effect went generally unchallenged until Card and Kreuger's 1994 book. ${ }^{5}$ Using a natural experiment-style empirical method, they compared employment in fast-food establishments in New Jersey and Pennsylvania before and after the minimum wage increased approximately $19 \%$ (from $\$ 4.25$ to $\$ 5.05$ ). Since Pennsylvania did not experience the wage change, it served as a proximate control group, which allowed for a simple difference-in-difference analysis. Using this methodology, they found positive employment effects of increasing the minimum wage. This result, and the accompanying indictment of the prior literature were the jumping-off point for much of the modern minimum wage debate. Card and Kreuger were cognizant of some of the drawbacks of their approach, however. Since natural experiments fail to ensure that each participant has a fair chance of being assigned to a given group, also known as random assignment, it deems impossible to infer a purely causal relationship. Also, there are ceteris paribus ${ }^{6}$ violations that occur in natural experiments, as it is not feasible that all characteristics of both groups continue to persist throughout the relevant time period. ${ }^{7}$ Whereas the authors themselves were confident that their methodology was better than the "traditional econometric approach", many economists since have questioned the validity of this assertion. The most common criticism levied against this study is that it is plagued by inferior data. Additionally, the results themselves seem misleading. The positive wage elasticity is not determined by an increase in New Jersey employment, but

\footnotetext{
${ }^{5}$ Card, David \& Krueger, Alan B, 1994. "Minimum Wages and Employment: A Case Study of the Fast-Food Industry in New Jersey and Pennsylvania," American Economic Review, American Economic Association, vol. 84(4), pages 772-793, September.

6 Latin, meaning "all else constant"

7 Thomas Leonard, (2000), “The Very Idea of Applying Economics: The Modern Minimum-Wage Controversy and Its Antecedents", History of Political Economy, 32, (5), 117-144
} 
rather by a stagnation of New Jersey employment, compared to decreased Pennsylvania employment. Even though the result is significant and positive, suggesting that this is a purely positive elasticity seems errant. John Kennan, in "The Elusive Effects of the Minimum Wage", provides a good metaphorical comparison, describing these results as "having a drug trial in which the drug has no effect but the placebo makes people sick". ${ }^{8}$

The recent revival in policy discussion around raising both state-mandated and federallymandated minimum wage has, in turn, sparked an influx of economics literature. The influx of recent literature involves criticism about econometric methods utilized by past researchers. In particular, Burkhauser et al.'s (2000a) study ${ }^{9}$ critiques Card and Krueger's technique using pooled cross-sectional CPS (Current Population Survey) data. As aforementioned, Card and Krueger conclude that a minimum wage increase yields a null effect in employment levels. Burkhauser et al. dispute this finding, stating that the "macroeconomic controls commonly included in models where no employment impact is found are inappropriate".

In order to effectively challenge Card and Krueger, Burkhauser et al. chose to re-estimate their data. They used CPS monthly data from the years 1979-1997, in contrast to Card and Krueger's use of annual data from the month of May during 1973-1989. An advantage of pulling monthly data rather than annual is a greater sample size, which is aggregated to a state-month level, due to the increase in the number of observations. This method produced 11,268 statemonth level observations - considerably more than Card and Krueger's 751 observations. The controls are kept the same for the purpose of re-estimating. Burkhauser et al. obtain auxiliary

\footnotetext{
${ }^{8}$ Kennan, John. “The Elusive Effects of Minimum Wages.” Journal of Economic Literature, vol. 33, no. 4, 1995, pp. 1950-1965. JSTOR, www.jstor.org/stable/2729319.

${ }^{9}$ Burkhauser, Richard V., Kenneth A. Couch, and David C. Wittenburg. 2000a. "A Reassessment of the New Economics of the Minimum Wage Literature with Monthly Data from the Current Population Survey." Journal of Labor Economics. Vol. 18, No. 4 (October), pp. 653-680.
} 
regression results in order to demonstrate the loss in variation in the minimum wage variable occurring when unsuitable macroeconomic controls, such as individual year effects, are used.

Burkhauser et al. argued that the inclusion of year fixed effects capture $93 \%$ of the variation in the variable for minimum wage. The auxiliary regression results show that year effects, also known as dummy variables for each of the years in the data, lead to an imprecise estimation of employment level effects because they only allow for $7 \%$ variation in state policies. With the use of equations estimated without year effects, they found elasticities around the range of -.45 , relative to the null effect found on employment after including year effects. Since year effects have the ability to control for changes in federal policy, any discrete change during a period of time is dismissed from the regression.

This leads to an enormous problem, as minimum wage increases occur incrementally year-by-year and typically do not happen more than once in a given calendar year. Though Burkhauser et al. were able to mitigate some of the problem by using monthly CPS data instead of annual CPS data, they were unable to fully resolve the problem created by the implementation of year effects. The year effects lull the possibility of obtaining negative effects on employment levels by disregarding gradual increases in the minimum wage. Thus, Burkhauser et al. argue that is not a phenomenon for Card and Krueger to find anything but a null effect on employment levels without excluding year effects. We suspect that this literature is essential in showing that including irrelevant macroeconomic variables when estimating Florida's employment levels may potentially be more hurtful than helpful.

Aside from year effects, researchers' curiosities about different demographics were also reinvigorated. In Zavodny's 2000 study $^{10}$, attention is turned toward teen hours of work and

10 Zavodny, Madeline. 2000. “The Effect of the Minimum Wage on Employment and Hours.” Labour Economics. Vol. 7, No. 6 (November), pp. 729-750. 
employment. This paper refutes a "growing set of papers [which] find that increases in minimum wage do not significantly lower employment among teens or fast-food workers.” Instead of simply looking at employment level changes, Zavodny offered another perspective revolving around the number of hours worked. She pointed out that "there are several reasons why employers may adjust hours as well as employment when the minimum wage is raised." Both state- and individual-level data are used to evaluate the effects on hours worked and teenage employment levels. State-level data has the advantage of aggregation, which means researchers can look at total effects more easily. On the other hand, the use of individual-level data assists Zavodny with more easily calculated probabilities of remaining teenage employees in the workforce.

The CPS data used by Zavodny consists of rotation groups for the years 1979-1993, ages 16 to 19 . Zadovny's analysis concentrated on the particular age group of 16 to 19 years because, according to the literature, these individuals are the ones most affected by a minimum wage increase. The results obtained in the study demonstrate that there may be a small effect on employment. Taking a look at the individual-level data, there seemed to be no significant decline in the hours worked by affected teens. However, the aggregated state-level data shows a slightly different picture: higher minimum wages may result in lower employment rates, but this is dependent on the choice of the minimum wage variable. According to Zavodny, her research paints an elusive picture pointing towards the reduction in the probability of workers becoming employed once minimum wages increase, rather than the probability of remaining employed, which would potentially explain the slight differentiation between individual-level and statelevel results. This study introduces a new aspect to the dynamic effects of wage increases, which causes us to investigate secondary effects of wage increases - mainly about the difficulties that 
Floridians might face when it comes to employment if firms choose to stop hiring or begin to start relying more on automation.

A different technique, discussed by Keil et al. in their 2001 study $^{11}$, considered lagged effects when estimating the effect on both aggregate and youth employment levels. Previously, minimum wage effects on employment were thought to appear quickly in industries, since previous economists believed firms were staffed and readily equipped to handle changes in labor. However, modern researchers disagree. Employment effects due to minimum wage increases may take longer to be felt, as firms often have to start assessing non-labor inputs to better assess who to fire or hire.

Lagged effects are included in regressions to explain the possibility of adjustment in the labor force taking longer than expected. Kiel et al. used lagged effects in conjunction with data from a panel of U.S. states. In order to account for adjustment costs, they decided to lag the dependent variable of their regression. By the introduction of a lagged dependent variable, their model became dynamic. The specified model output two ranges of elasticities in the short-run and long-run for aggregate and youth employment. In terms of youth employment, the model conveyed elasticities of -.37 in the short run and -.69 in the long run. Total employment's elasticities were in the range of -.11 in the short run and -.19 in the long run. This study is important for us to consider because the inclusion of lagged effects allow for the examination of gradual effects. Florida's proposed minimum wage increase is also gradual, which allows us to consider impacts in various domains (social services expenditures, tax revenues).

\footnotetext{
${ }^{11}$ Keil, Manfred, Donald Robertson, and James Symons. 2001. "Minimum Wages and Employment.” CEPR Working Paper No. 497.
} 
Apart from different techniques, past researchers have also returned to the topic of wage increases to re-examine established conclusions - notably, Neumark and Wascher in their 2003 study $^{12}$ examining schooling effects. The re-examination of evidence comes after criticism by Evans and Turner (1995) regarding their aforementioned 1992 study, stating that the effects of minimum wage increases on school enrollment may differ "depending on which definition of enrollment is used"13. To combat this, Neumark and Wascher re-estimate the model using a new minimum wage variable specific to October of each year from 1980 to 1998.

Their newly re-estimated results convey consistent negative effects of minimum wages on school enrollment. In particular, when the 1990s are added to the sample, Neumark and Wascher report a statistically significant elasticity of -.13 , indicating a strong negative effect of the minimum wage on school enrollment. The most interesting portion is that the results are consistent regardless of how enrollment is measured in the CPS data, and can sometimes be even stronger depending on using an enrollment measure that has been defined in recent research. This study is critical, as it shows consistency in negative effects even when the sample size increases, and could possibly influence future work revolving around state-specific high school and college enrollment when it comes to minimum wage policies.

The debate of adverse effects continued with Fiscal Policy Institute's (FPI) report in 2004. ${ }^{14}$ The report focused on the retail sector, since it employs the majority of workers at low wages. FPI aimed to analyze comparisons between states with a higher minimum wage than the

\footnotetext{
12 Neumark, David, and William Wascher. "Minimum wages and skill acquisition: Another look at schooling effects." Economics of Education Review 22.1 (2003): 1-10.

${ }^{13}$ Evans, W., \& Turner, M. (1995). Minimum wage effects on employment and school enrollment: comment. Mimeo. University of Maryland.

${ }^{14}$ Fiscal Policy Institute. 2004. "State Minimum Wages and Employment in Small Businesses." fiscalpolicy.org/wp-content/uploads/2004/04/minimumwageandsmallbusiness.pdf.
} 
federal minimum and all other states. At the time of the report, there were twelve states that had a higher prevalent wage than the federal wage. Four particular areas were focused on for the analysis: "total nonfarm employment, total retail employment, employment and average payroll per worker for all small businesses, and employment and average payroll per worker for small retail businesses.”

The conclusions drawn from FPI's research were contrary to most of the research discussed previously. Data from the CPS and U.S. Commerce Department's County Business Patterns (CBP) were used to evaluate the four areas mentioned earlier between the twelve states with state-specific minimum wages and the rest of the states. In terms of total nonfarm employment, FPI reports found that eleven of the minimum wage states (plus D.C), compared to the other thirty-nine states, increased aggregate employment by $6.14 \%$. Retail employment also grew "more than three times as great" compared to the rest of the states, increasing by a total of $6.11 \%$. The statistics for small businesses seemed to prevail against the rest of the states due to a number of factors increasing. The number of establishments, employment, total payroll, and average payroll for ten minimum wage states ${ }^{15}$ (including D.C) grew at least an average of $3 \%$ across the board. The last focus was on the prosperity of small retail trade businesses in the same ten states including D.C. Their findings are consistent with the others - small retail trade businesses seem to increase twice as quickly than in the other forty states, and the number of employees working for small employers increased by 3.7\%. Overall, FPI's goal of releasing this report was to provide another side to the argument that an increase in minimum wages will hurt small retail trade businesses and their employers and employees alike.

${ }^{15}$ Maine was excluded from the analysis since it did not raise its minimum wage above the federal minimum wage in 2002 . 
In 2006, Joseph Sabia refuted FSP's claim that there were no adverse effects on small businesses, citing FPI's disregard for statistical significance and use of only two time periods (2008 and 2001). ${ }^{16}$ Sabia re-estimated, using a much longer time period (1979-2004). Sabia also pointed out that FPI's incorporation of state-level socioeconomic and demographic characteristics could lead to attenuation bias - causing results to lean toward a null effect. This bias could potentially stem from states raising minimum wages in anticipation of wellperforming economic sectors employing a large number of hourly wage workers. This, in turn, would cause a failure to abide by the ceteris paribus assumption of economics.

Sabia begins by employing a fixed-effects model seen in both Card and Krueger and Burkhauser et al.'s approaches. Using the ratio of employment-to-population as the dependent variable is a common practice in the empirical framework observed in minimum wage literature. Along with estimating employment effects, Sabia also estimated changes in hours worked by teenagers in order to provide a picture of some of the byproducts of wages increasing. CPS Merged Outgoing Rotation Group data from January 1979 to December 2004 were applied to create a panel of states and months for the segment analyzing overall and retail employment. Each month contained about 22,000 to 23,000 observations comprised of individuals from age sixteen to sixty-four. These individual observations were then used to create state-month level observations, in favor of the "statistical power gained from the increase in the overall sample size". In regards to small business employment, a data set was constructed from CPS Outgoing Rotation Group data found containing March 1989 to March 2005. Instead of state-month level

\footnotetext{
16 Sabia, Joseph J. "The Effect of Minimum Wage Increases on Retail and Small Business Employment." Employment Policies Institute, May 2006, www.epionline.org/wp-content/studies/sabia_05-2006.pdf.
} 
data, Sabia was only able to create state-year level data and seemed to be cognizant of the weakened statistical power due to an enormous decrease in sample size.

The first estimations produced were in regards to overall retail and small business employment. The findings were consistent with the majority of minimum wage literature, indicating declines in retail employment when wages are increased. The range of elasticities were unwavering compared to past estimates for retail trade industries and were between -.1 and -.3. With regards to small business employment, a $10 \%$ increase in minimum wages is associated with a $1 \%$ decline in employment. As Sabia pointed out, a major drawback of FPI's analysis is the inability to distinguish between skilled and unskilled workers in order to examine the way both groups are affected. Grouping skilled and unskilled workers presents great challenges, as previous research has often stated unskilled, low-wage workers are more at risk than high wage, skilled workers. This can unintentionally lead to understating adverse effects.

To compare results to FPI's study, Sabia adamantly focused on the most at-risk group, according to modern literature: teenagers. Measuring overall teenage employment effects, a -2.2 to $-3.0 \%$ decrease in the ratio for employed teens is estimated as a result of an increase in minimum wage. What Sabia also found is that regardless of the controls (either macroeconomic controls or year effects), estimates in the range of -1.8 to $-3.0 \%$ in employed teen ratios are produced. Additionally, estimates show that there is indeed a reduction of teenage hours worked with an elasticity of $-2.9 \%$. Teenage retail sector employment decreases by a range of between 2.7 and $4.3 \%$ when a $10 \%$ increase in minimum wage is imposed, and among teens already employed in the retail sector, a 2.8\% decline in hours worked is estimated. Most surprisingly, a significant reduction between 4.9 and $9.0 \%$ in the ratio of teens employed in small businesses, 
and a reduction between 4.8 to $8.8 \%$ in hours worked by teens in the retail sector are associated with a $10 \%$ increase in hourly wage.

Overall, Sabia's results do not deviate from the majority of the literature we have reviewed. This study emphasizes that low-wage unskilled workers will be the demographic that is affected most by any increases to the hourly wage, contrary to FPI's report. The claims of the report are to "serve as a caution to legislators" and as a "reminder that there is no such thing as a free lunch". It also acts to confirm previous results in the counterproductive nature of minimum wage raising, as researchers believe it will hurt and push more people into poverty than it will help.

Fast forwarding to more recent literature, we observe Neumark and Wascher revisiting the topic with their study published in $2014 .{ }^{17}$ This is a response to Dube et al. (2010) and Allegro et al.'s (2011) attempt in constructing more reliable counterfactuals for estimation purposes. The researchers' counterfactuals "narrow the source of variation", focusing on statespecific and intra-regional trends. Because of this particular method, they find null effects on employment levels, and in turn, argue that negative employment effects often found in the literature are illegitimate and are caused by various geographic factors that researchers fail to control for.

Neumark and Wascher began their analyses by examining state-specific trends in California. They inspected the impact of including recessionary periods (i.e. the Great Recession and the early 1990s), in their regressions and concluded that the addition of the recessionary periods actually counter the employment effects estimates by biasing results away from longerterm factors not captured by the other controls. Instead, one of the approaches proposed is to

${ }^{17}$ Neumark, David, JM Ian Salas, and William Wascher. "Revisiting the Minimum Wage - Employment Debate: Throwing Out the Baby with the Bathwater?" ILR Review67.3_suppl (2014): 608-648. 
allow state-specific trends to deviate from linearity. This signifies that the state-specific trends might be better modeled using a polynomial function instead of a linear function, as it would capture variation and allow the function to have multiple inflection points. Taking their own advice, Neumark and Wascher apply a nonlinear function to the model, finding significant, negative effects on teen employment.

To address the complications that arise with concentrating on intra-regional trends, Neumark and Wascher estimate using control states in the same Census divisions. They reveal that the estimated effects vary significantly across the nine divisions, along with the ability to acquire precise estimations. Neumark and Wascher's results portray elasticity ranges from -.15 to -.64 for the New England, West North Central, West South Central, and Mountain divisions. For the East North Central, East South Central, and South Atlantic divisions, the estimates obtained are also negative, with the estimates obtained from East South Central doubtfully large. The estimates from the Mid-Atlantic region are positive, and the Pacific divisions have a null effect on employment. Neumark and Wascher believe these results contradict Dube et al.'s and Allegro et al.'s findings, as they believe Dube et al.'s and Allegro et al.'s elasticity ranges to be rather imprecise. Controlling for states within divisions rather than comparing states across divisions, contrary to previous literature, does not turn out to be helpful in achieving accurate estimations of employment effects. We believe this finding to be influential because it makes us inquire not only about Florida, but its surrounding states and industries - mentioned later in this paper.

In the past year, the growth in state legislation revolving around increasing wages has influenced researchers to home in on specific geographic locations when conducting analyses. Specifically, Jardim et al.'s 2018 Seattle study ${ }^{18}$ sparked debate on the impact of low-wage

${ }^{18}$ Jardim, Ekaterina, et al. "Minimum Wage Increases and Individual Employment Trajectories.” No. w25182. National Bureau of Economic Research, 2018. 
employment after changes to the minimum wage occurred. Much like Florida's proposed legislation, Seattle's increase in minimum wage was gradual, beginning in 2014. Every year after 2014 brought incremental changes until the final wage of $\$ 15.48 /$ hour was reached in 2018 .

Jardim et al. paid particular attention to the short-term effects on employment during the first two phase-in periods of 2015 and 2016.

Using administrative employment data from Washington State, Jardim et al. were able to capture quarterly payroll records for all workers in the state, as well as the number of hours worked. They then employed a difference-in-difference model - an economic technique commonly used to evaluate the difference before and after the policy change - in order to answer four key questions:

1) What is the difference in hourly wages for workers who remain employed?

2) What is the probability of workers being employed anywhere else in the state?

3) What is the impact on the hours worked?

4) Do low-wage workers benefit from an increase in wages?

The researchers found that while low-wage workers enjoy faster hourly wage growth over quarters following the wage increases, they experience a modest reduction in hours worked. This worked offset-their total gains, leading to essentially no change in earnings. Evidence also showed that employers responded by shifting the workforce toward more experienced workers, which could be a cause for concern when trying to use minimum wage as a poverty reduction policy. In fact, this could potentially displace low-wage workers and phase them out of the labor market completely - making it harder for these individuals to stay employed.

Prior literature is crucial in order to understand the true impact of a moderately-paced increase in Florida's minimum wage. Keeping in mind the elasticities we have found in the 
literature, the next segment of our paper focuses on the demographics associated with Florida's wages.

\section{A Closer Look at Florida Wages}

To explore how increasing the minimum wage would impact the state of Florida, our first step is to identify who this would directly impact. To do this, we need to answer the following four questions: Who makes the minimum wage? Where do they live? Where do they work? Who currently makes the final proposed minimum wage, and what will happen to them? The range of wages varies greatly between and within Florida's sixty-seven counties - influenced by the cost of living, industry prevalence, and various other factors. As a result of the factors contributing to the wage variation, assuming an increase would affect all Floridians equally would be inaccurate. Thus, we began to research the economic characteristics of Florida's different areas. However, concise data to answer these questions were very difficult to find, and, as such, we used multiple sources to assess the wage distribution across Florida.

Our first data source was the Current Population Survey (CPS), amassed by the University of Minnesota into the Integrated Public Use Microdata Series (IPUMS) database. The observation unit of the CPS is at the individual level, but the selection of individuals is done by household. Each person has a household identifier and a person identifier. For geographic purposes, the CPS data are coded by Public Use Microdata Areas (PUMAs). "PUMAs generally follow the boundaries of whole central cities, Metropolitan Statistical Areas, Primary Metropolitan Statistical Areas, or non-metropolitan places. If these areas exceed 200,000 residents, they are divided into as many PUMAs of 100,000+ residents as possible." ${ }^{19}$ By

\footnotetext{
${ }^{19}$ Steven Ruggles, Sarah Flood, Ronald Goeken, Josiah Grover, Erin Meyer, Jose Pacas, and Matthew Sobek. IPUMS USA: Version 9.0 [dataset]. Minneapolis, MN: IPUMS, 2019. https://doi.org/10.18128/D010.V9.0
} 
aggregating these PUMAs into areas (mostly at the county level), this gave us the ability to compare wage distributions between counties. However, there are several nuances to the data being that the self-reported survey is comprised of a small portion of a 200 question pool. This signals that although the data is very concise and detailed, it is also prone to inaccuracies and missing data due to the self-reporting bias. As an example, one of the inaccuracies we found involved an individual self-reporting that they usually worked forty hours per week, but their annual income was $\$ 4.00$. We discuss in detail how we deal with these inaccuracies in our data configuration section.

After aggregating the PUMAs into the county level, we were able to take a look at the descriptive statistics of Florida's counties. These descriptive statistics are detailed in Figure 2. We find that Martin County has the highest average annual income wage $(\$ 69,683)$ and Seminole County has the highest median annual income wage $(\$ 47,350)$. Suwannee County has the lowest average annual income wage $(\$ 38,665)$ and the Heartland Area has the lowest median annual income wage $(\$ 31,026)$. The median falling below the mean annual income wage indicates that there are some individuals on the highest end of the spectrum that pull the average up. We rely on the median as it is generally a more accurate depiction of distributions. 
Figure 2. Annual Income Distributions

\section{Annual Income Distributions}

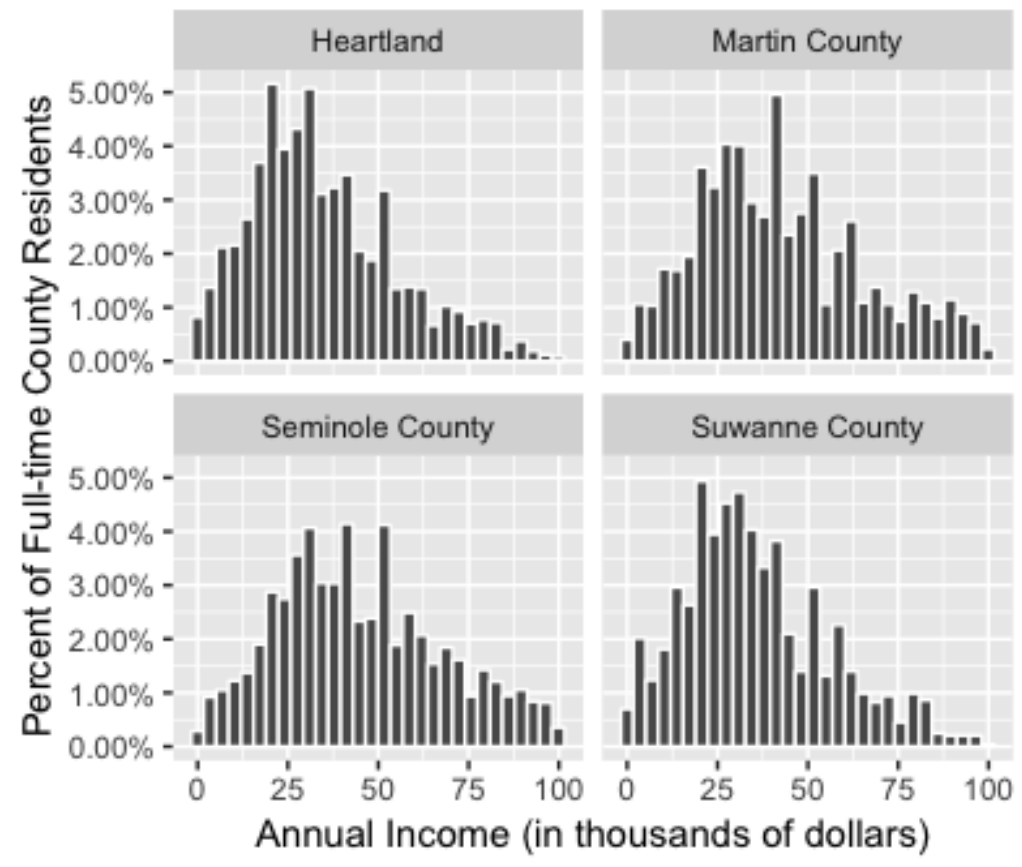

Our second source of data came from the U.S. Bureau of Labor Statistics (BLS) and contained much more succinct data. The data involved a simple list of the average weekly earnings for the third quarter of 2018 for each of Florida's sixty-seven counties. By multiplying these average weekly earnings by 50 , we determine that the three counties with the highest average annual income were Hillsborough $(\$ 52,468)$, Miami-Dade $(\$ 52,052)$, and Palm Beach $(\$ 51,272)$. The three counties with the lowest average annual income were Holmes $(\$ 30,567)$, Franklin $(\$ 30,680)$, and Calhoun $(\$ 31,512)$. The average weekly earnings of the highest-paid county is over $70 \%$ higher than the lowest-paid county. A visual representation of the differences in wages by county is below, as seen in Figure 3. As reported by their website:

“The data are derived from summaries of employment and total pay of workers covered by state and federal unemployment insurance (UI) legislation and provided by State 
Workforce Agencies (SWAs). The average weekly wage values are calculated by dividing quarterly total wages by the average of the three monthly employment levels of those covered by UI programs." 20

Because these data are derived from governmental agencies and reports, we assume they have some degree of accuracy and statistical integrity. However, this dataset only provides averages, which can be skewed due to outliers, and do not depict the whole story.

Our third data source is the U.S. Census' Small Area Income and Poverty Estimates (SAIPE). Using 2017 data, we find that the three counties with the highest median annual household income are St. Johns $(\$ 63,299)$, Clay $(\$ 54,867)$, and Nassau $(\$ 54,706)$. The three counties with the lowest annual household income are Hamilton $(\$ 29,482)$, Dixie $(\$ 30,801)$, and Putnam $(\$ 31,150)$. Their definition of "income" is:

'Income, defined as 'Total income,' is the sum of the amounts reported separately for: wage or salary income; net self-employment income; interest, dividends, or net rental or royalty income or income from estates and trusts; Social Security or Railroad Retirement income; Supplemental Security Income (SSI); public assistance or welfare payments; retirement, survivor, or disability pensions; and all other income... [and] is based on one year of survey data and is created using complex statistical modeling. Modeling generates more stable estimates for places with small numbers of residents or survey responses. There are also drawbacks to using modeled data. The smaller the population or sample

\footnotetext{
20“"County Employment and Wages in Florida - Third Quarter 2018: Southeast Information Office." U.S. Bureau of Labor Statistics, U.S. Bureau of Labor Statistics, 2 Apr. 2019, www.bls.gov/regions/southeast/newsrelease/countyemploymentandwages_florida.htm\#table1.
} 
size of a county, the more the estimates are derived from the model itself and the les s they are based on survey responses. Models make statistical assumptions about relationships that may not hold in all cases." 21

According to this dataset, the highest paid county earns more than twice of what the lowest county earns. Unfortunately, this dataset also only includes aggregated county data. Therefore, we cannot accurately determine the proportion of residents earning each wage.

Regardless of the data source, it is obvious that there are differences in the distributions of wages from county to county. The economic impact of the proposed minimum wage increases will affect some counties more adversely than others. By gradually increasing the minimum wage over several years, this will help mitigate adversities due to the changes, but some areas will likely have a more difficult time adapting than others.

\section{Data Configuration}

Because the IPUMS data set is the most detailed, this is the dataset chosen for further analyses. The IPUMS data generator allows analysts to choose from hundreds of variables and either five-year or one-year samples of the American Community Survey (ACS). According to the IPUMS description page, the one-year sample reflects a "1-in-100 national random sample of the population", and we choose this sample from 2017 (the latest year available). After filtering to include only Florida data, this sample contains 199,644 respondents. With an approximate state population of 22 million, this accounts for roughly one percent of Floridians. The definitions of variables collected from the IPUMS data dictionary, along with a simplistic

21 "SAIPE State and County Estimates for 2017." SAIPE State and County Estimates for 2017, US Census Bureau, 1 Mar. 2019, www.census.gov/data/datasets/2017/demo/saipe/2017-state-and-county.html. 
overview of any manipulations performed, is located in Appendix 2. Since this is only a onepercent sample, it is unrealistic to speak about the actual counts of Floridians. Hence, we will refer to the data as percentages or proportions of Floridians, until we have enough information to extrapolate our findings.

We begin our analysis by dissecting the state-wide data. The data were filtered to include only those who reported usually working between 30 and 80 hours per week, employed in industries other than the Military, and reporting an annual income of over $\$ 7,845$. This number was calculated for an individual making only tip wage thirty hours per week, for fifty weeks per year. We were left with a subset of 69,291 observations - or 34.7\% - from our initial sample of 199,644 observations as a result of filtering the data. After the data was imported, we used R statistical program to construct a distribution of hourly wages, as depicted in Figure 3, for the entire state. 
Figure 3.

More Than 35\% of Floridians Currently Earn Less Than \$15/Hour

$25 \%$

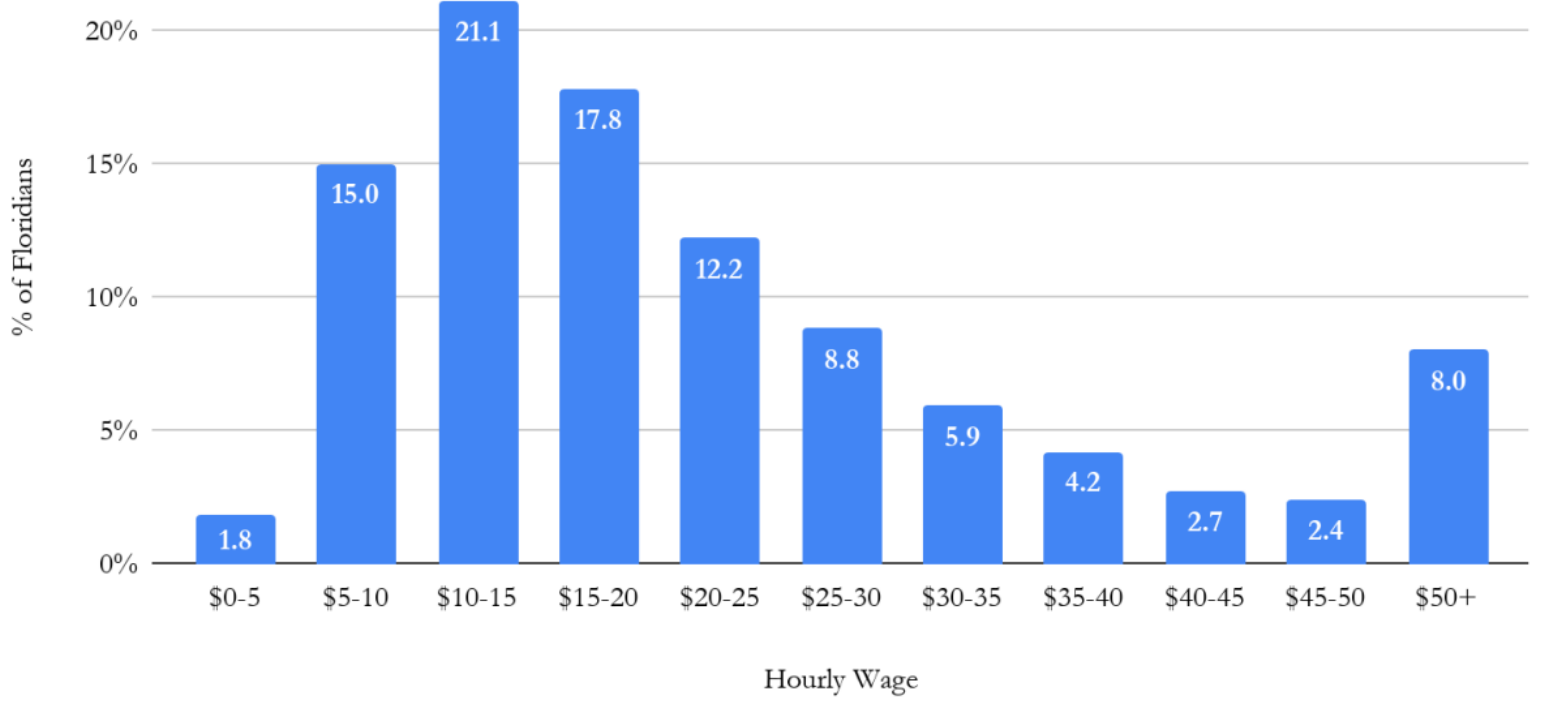

Next, we take a closer look at workers making less than $\$ 20 /$ hour. According to our calculations, $16.8 \%$ of our sample make ten dollars or less per hour, which is the proposed minimum wage in the year 2021. Those making between ten and eleven dollars - the proposed minimum wage in the year 2022 - comprise an additional $3.8 \%$, totaling $20.6 \%$ between the two groups. In the case of eleven to twelve dollars, we observe $3.6 \%$ of our sample earning this amount, totaling $24.2 \%$ when added to the other groups. Workers making twelve to thirteen dollars per hour accounts for $5.7 \%$ of our sample, comprising $29.9 \%$ in conjunction with the other wage groups. Those making thirteen to fourteen add an additional 3.3\%. Finally, $4.7 \%$ of workers earn between fourteen and fifteen dollars per hour, totaling $37.9 \%$ of our sample. Thus, we arrive to the conclusion that $37.9 \%$ of Floridians working thirty or more hours per week make fifteen dollars or less per hour. This is demonstrated in Figure 4 below. 
Figure 4.

\section{More Than $55 \%$ of Floridians Currently Earn Less Than $\$ 20 /$ Hour}

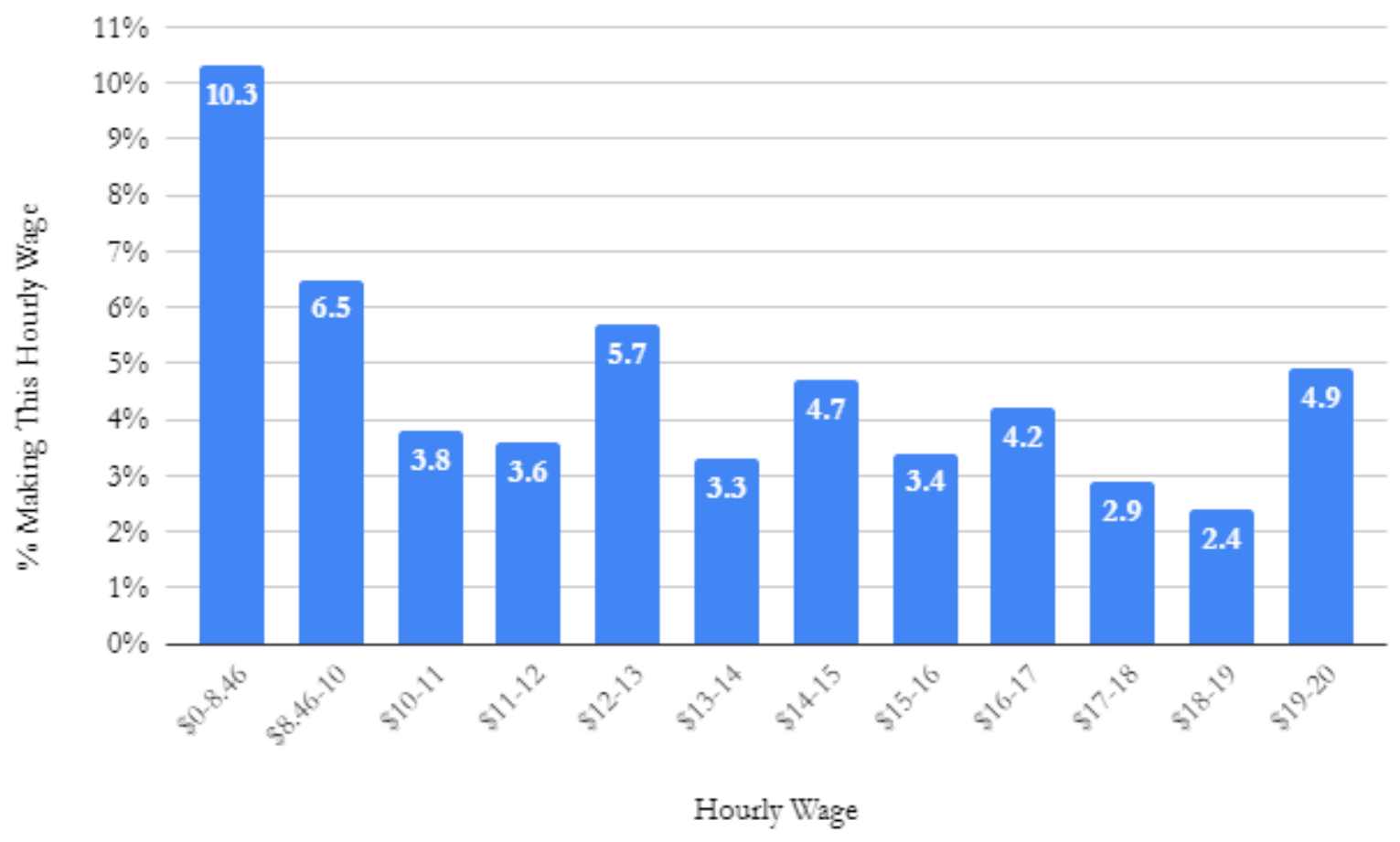

If we extrapolate these proportions to the population of roughly 20.6 million Floridians, we estimate that 7,146,583 Floridians meet our criteria: they are employed more than 30 but fewer than 80 hours per week, are not in the Military industry, and make at least $\$ 7,845$ annually. Continuing this extrapolation, we estimate - holding all else constant the number of Floridians that would be impacted each year following the passing of the proposed legislation. These estimations are shown in Table 2, followed by a graphical representation in Figure 5. 
Table 2. Floridians Who Will See Wage Changes

\begin{tabular}{|c|c|c|c|}
\hline Year & $\begin{array}{l}\text { Proposed } \\
\text { Minimum } \\
\text { Wage }\end{array}$ & $\begin{array}{l}\text { Additional Floridians } \\
\text { Directly Impacted Each Year }\end{array}$ & $\begin{array}{l}\text { Floridians Earning Less Than } \\
\text { the New Minimum Wage }\end{array}$ \\
\hline 2021 & $\$ 10 /$ hour & $1,202,185$ & $1,202,185$ \\
\hline 2022 & $\$ 11 /$ hour & 271,977 & $1,474,162$ \\
\hline 2023 & $\$ 12 /$ hour & 259,188 & $1,733,350$ \\
\hline 2024 & $\$ 13 /$ hour & 408,233 & $2,141,573$ \\
\hline 2025 & $\$ 14 /$ hour & 236,291 & $2,377,864$ \\
\hline 2026 & $\$ 15 /$ hour & 335,613 & $2,713,477$ \\
\hline
\end{tabular}


Figure 5.

\subsection{Million Floridians Currently Earn Less Than the Final Proposed Minimum Wage}

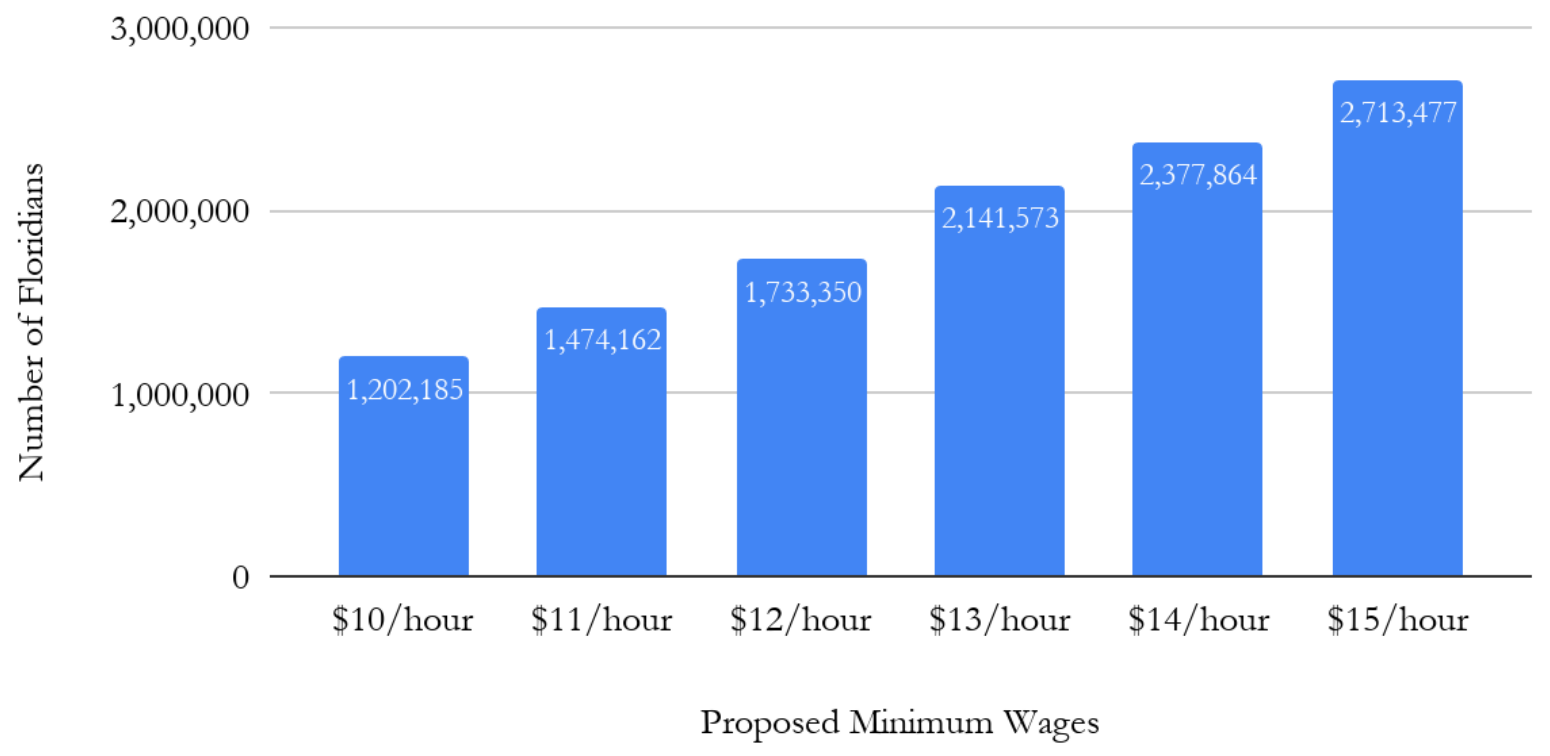

As illustrated by Table 2, the greatest impact will occur during the first year of the proposed legislation. This is to be expected, as the largest jump in wages would occur during this year. An increase in the current minimum wage of $\$ 8.46$ to $\$ 10$ per hour in 2021 would be an increase in magnitude of $18.2 \%$. While our estimation was done thoroughly, it is not without its pitfalls, which come as a result of our data rather than our methods. Our data contained many reports of wages that fell below the minimum wage, which will likely result in overestimation. However, if the reports of below-minimum wage incomes are in fact correct, they may be a byproduct of being paid "under the table", a worker being undocumented, or one of many other labor practices that have the potential to unlawfully pay workers less than $\$ 8.46$ per hour. One caveat to this is that employers who overlook the current employment guidelines are likely to continue doing so, regardless of whether or not the minimum wage increases. 
Once we completed our state-wide analysis, we began to take a closer look at county/area-specific data. According to the Office of Economic and Demographic Research, ${ }^{22}$ counties vary widely in both industrial makeup and wage distribution. The following five counties exemplify the aforementioned variety of industrial makeup and wage distributions that Florida counties have to offer: Escambia, Hillsborough, Martin, Miami-Dade, and Osceola Counties. Figure 6 exemplifies the comparisons between the five counties' industries.

Figure 6.

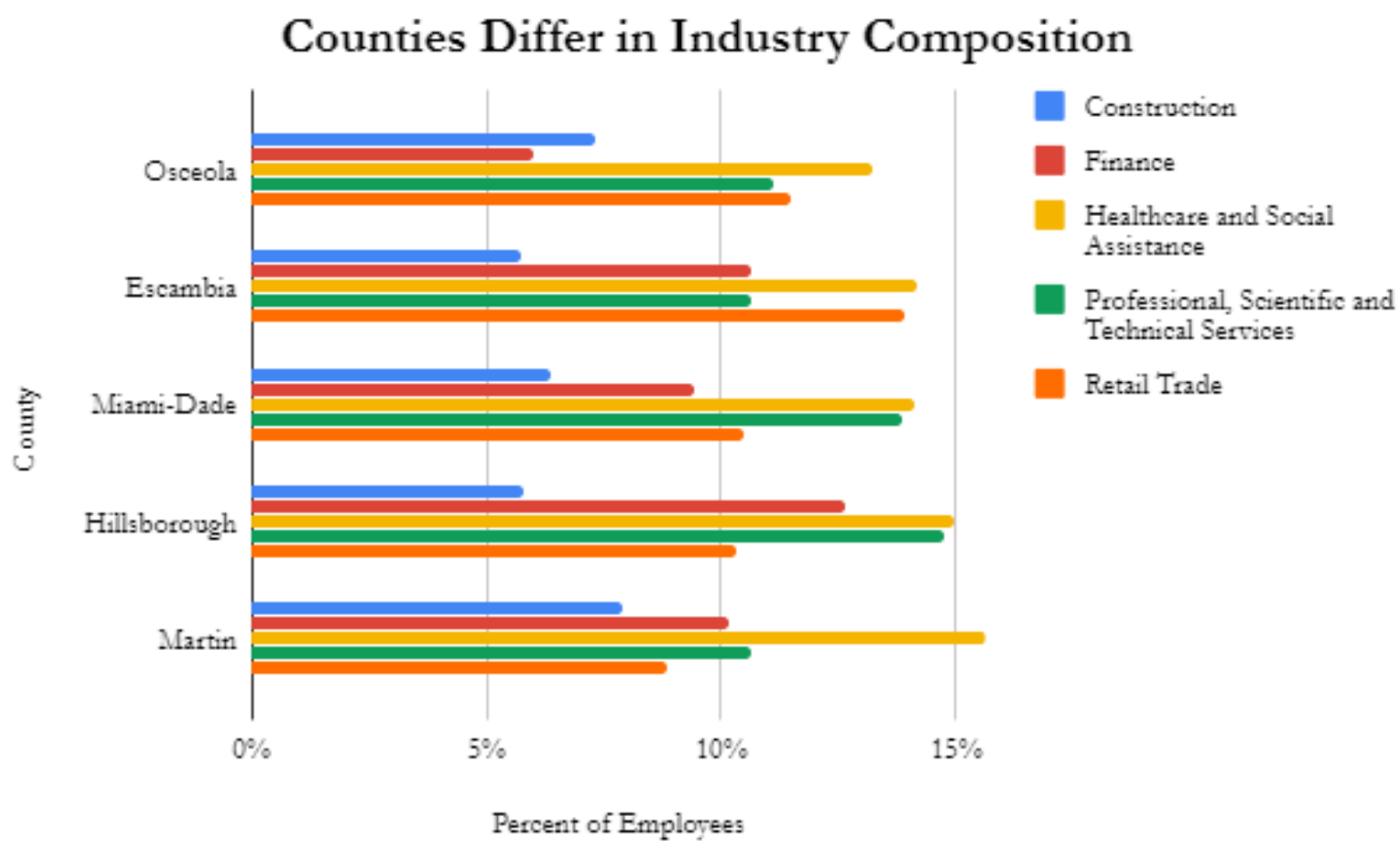

Figure 6, shown above, describes several similarities between the counties. First, each of these five counties' largest industry is Healthcare and Social Assistance (which is also overall the

22 "Florida County Profiles." Office of Economic \& Demographic Research The Florida Legislature, 25 June 2019, edr.state.fl.us/content/area-profiles/county/index.cfm. 
largest industry in the state). Second, each of these five counties has at least $10 \%$ employment in the Professional, Scientific, and Technical Services industry. Third, only Martin County has less than $10 \%$ of its employees in the Retail Trade industry. However, there are also several differences. First, Osceola has a relatively low portion of employees in the Finance industry. This is especially interesting when viewed in conjunction with Figure 7: Osceola has the lowest portion of workers earning more than $\$ 15$ per hour. Finance is one of the highest-paying industries in Florida. Also, Escambia and Osceola have the highest portion of Retail Trade workers of these five counties, which is a typically low-paying job. Those two counties have the higest portion of workers earning less than $\$ 15 /$ hour. The comparison of these five counties is just an illustration of how the counties in Florida vary widely in composition.

Looking at this from a different perspective, we are able to investigate the portions of each county's residents earning less than $\$ 10$ per hour, between $\$ 10$ and $\$ 15$ per hour, and above $\$ 15$ per hour, described in Figure 7. 
Figure 7.

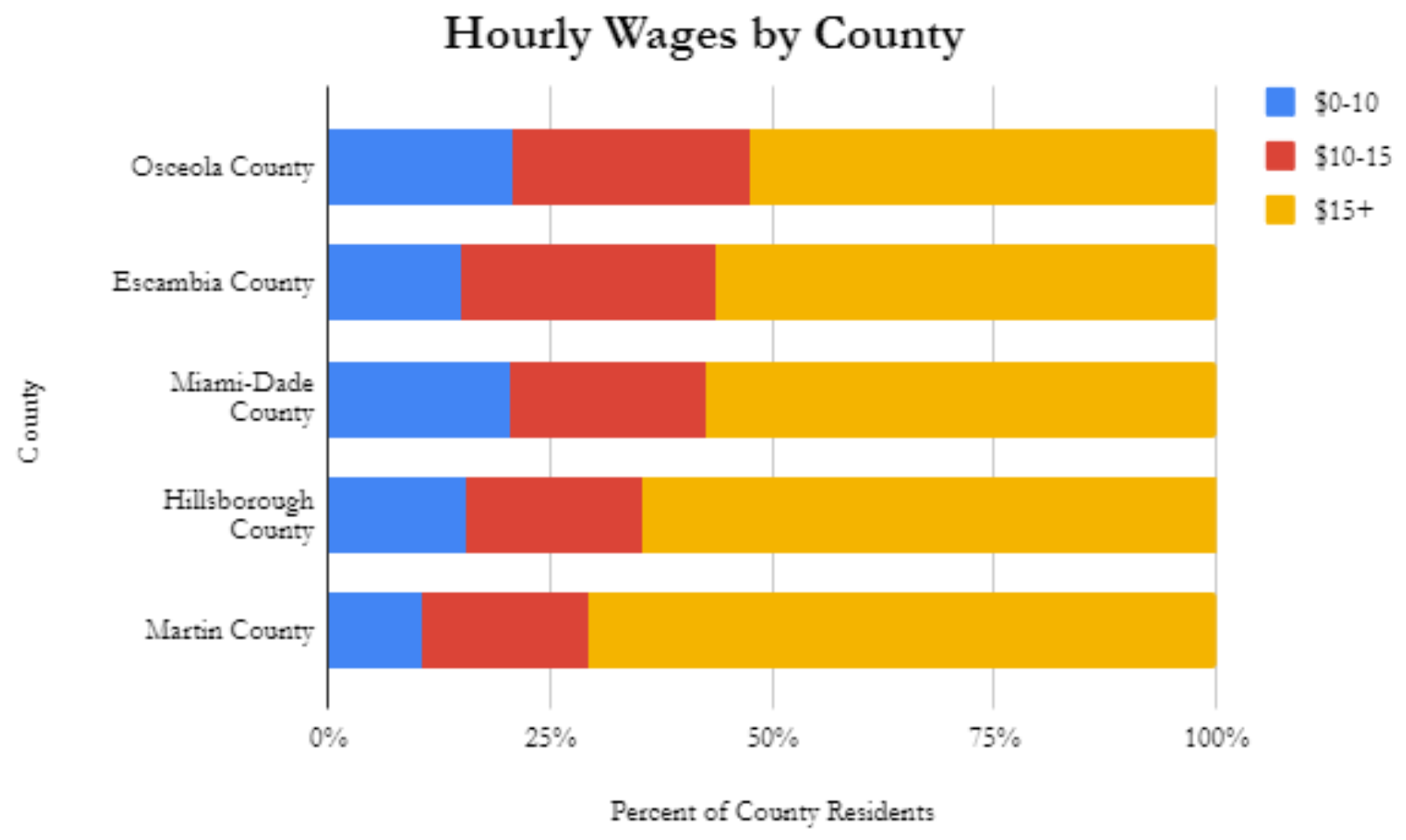

As revealed above, almost $50 \%$ of residents of Osceola County earn $\$ 15$ per hour or less, as opposed to Martin County, where nearly $70 \%$ of residents earn an excess of $\$ 15$ per hour.

This indicates that an increase in the minimum wage would affect a larger portion of residents in Osceola County than in Martin County.

Further differences can be found between rural and urban areas. ${ }^{23}$ As shown in Figure 8, over $48 \%$ of residents in rural areas earn less than $\$ 15$ per hour, while urban areas have over $60 \%$ of residents earning over $\$ 15$ per hour. With that being said, it is important to point out that we estimated that only $4.4 \%$ of Floridians live in areas that are considered to be rural.

23 “Rural Definition." Florida Department of Economic Opportunity, www.floridajobs.org/community-planningand-development/rural-community-programs/rural-definition. 
Figure 8.

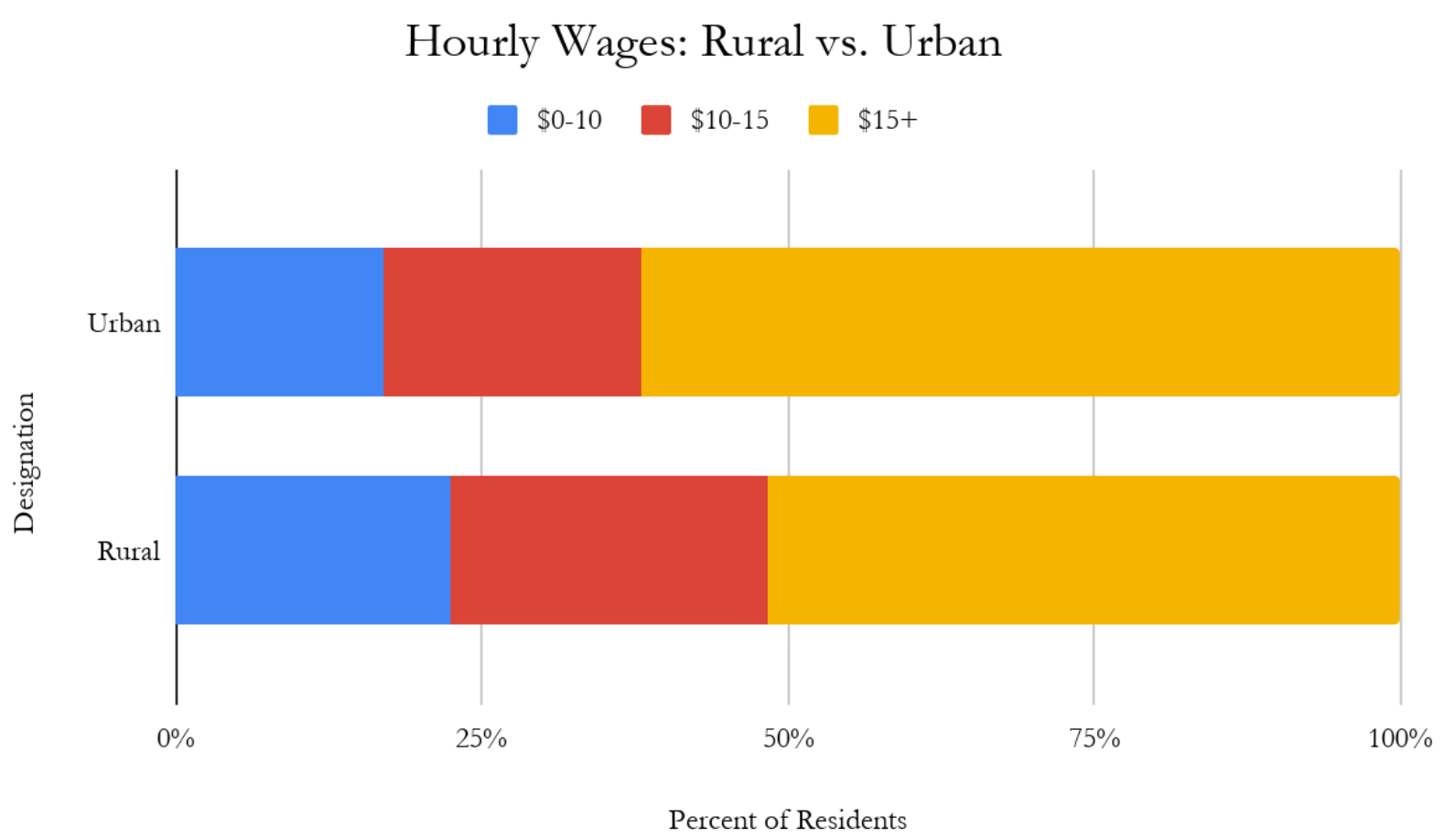

The most striking differences in wages appear when examining differences between industries. As you can see in Figure 9, the portion of employees earning less than $\$ 10$ per hour, $\$ 10-15$ per hour, and more than $\$ 15$ per hour vary greatly between industries. While nearly $75 \%$ of employees in the Accommodation and Food and in the Forestry, Fishing, and Hunting industry earn less than $\$ 15$ per hour, over $75 \%$ of employees in the Finance, Information, Administrative, Mining, and Utilities industries earn more than $\$ 15$ per hour. Since the combined number of employees in those five industries is less than $18 \%$ of the total employees in our sample, a significant number of Floridians will be affected. As illustrated in Figure 10, over 40\% of Floridians earn less than $\$ 15$ per hour. 
Figure 9.

Hourly Wage by Industry

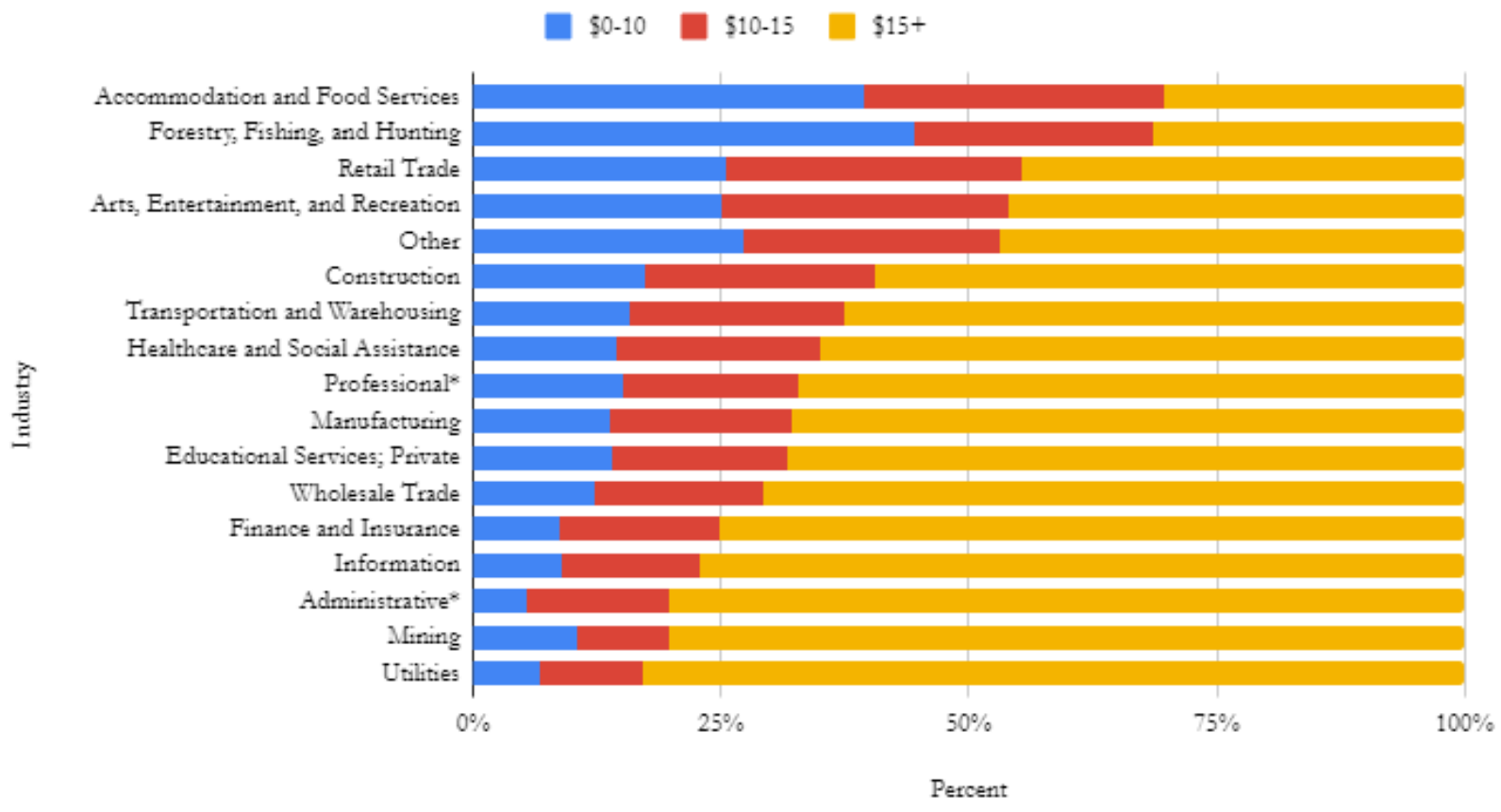

Figure 10.

\section{Hourly Wage for All Floridians}

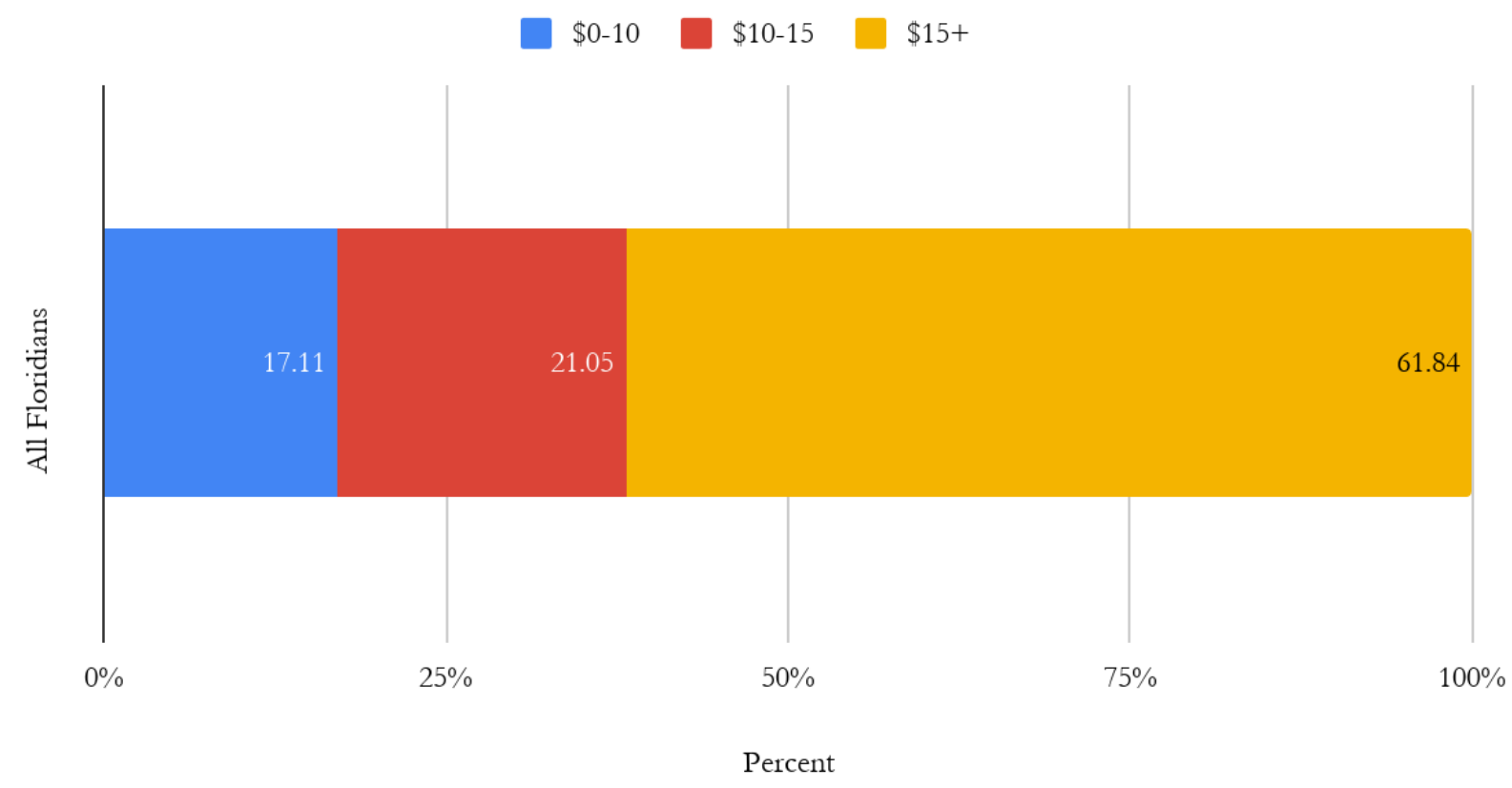


Even with all of this information, it is important to note that these changes will not occur in an invariable environment. The estimates we obtain are static estimates, meaning they do not take into account the dynamics of a changing workforce, industry composition, or preemptive hiring decisions due to the impending change in labor costs. That being said, it is difficult to predict how employment will respond to an increase in Florida's minimum wage. If employment leans toward being more receptive to the changes in wage, we would anticipate observing larger than expected declines in employment. On the other hand, if employment is slow to adapt to the changes in the minimum wage, then increases in the minimum wage would result in smaller declines in employment. However, we address both direct and induced effects as a result of the wage changes in an attempt to explain as much of the underlying forces involved as possible.

\section{A Word on Wage Compression}

In order to examine and estimate the workers that will be directly affected, it is equally important to look at those workers that potentially will be indirectly affected. Wage compression is defined as happening when a portion of the income distribution, often centered slightly above the minimum wage, begins to tighten. This occurs when increases in mandated wages make new hires or lower positioned workers earn wages that are comparable to the wages of those that have longer tenure or a higher position. If wages for those directly above the new minimum do not increase at a similar rate to the wages of those making the minimum, those above may risk substantial decreases in real wages, as inflationary pressures in the market will be exerted to push the workers' purchasing powers down.

The workers earning hourly wages that fall between the current minimum wage and just above the proposed minimum wage comprise the population that will be most directly affected by the proposed minimum wage bill. In addition, it is necessary to analyze wages above the 
proposed minimum wage because they are considered to be located in the "compression wage" zone. Take, for instance, a hypothetical employee named Sally, who began working at a business in 2017 when Florida's minimum wage was $\$ 8.10$ per hour. Suppose that the proposed minimum wage increase amendment passes. Due to Sally's good performance and tenure, she received a raise of $\$ 0.50$ per hour each year while employed there. She earned $\$ 8.60$ per hour in 2018 , $\$ 9.10$ per hour in 2019 , and $\$ 9.60$ per hour in 2020 . In 2019 , which is also the latest data we have available at this time - she is making \$.64 above the minimum wage, and enjoys feeling like a valued member of her company. If she were to leave this firm and find work at a new business, she would potentially have to begin back at the minimum wage of $\$ 8.46$ per hour (2019). In 2021, when she would expect to make $\$ 10.05$ per hour at her current firm, the minimum wage would be raised to $\$ 10.00$ per hour. While she is still making above the minimum wage, new hires to her place of employment would be starting off making only $\$ .05$ less per hour than her. After nearly five years of dedication and service to her employer, a person working there for only a few days could be making nearly the same amount as her. To demonstrate to tenured employees that their experience and loyalty is valuable, some employers will increase their employees' hourly wages to entice them to stay. However, some employers will not increase tenured employees' salaries, or may even forego regular raises to afford the new employees' salaries, leading to a spike in the distribution of wages on the low end of the spectrum.

Graphically, the area on the low end of the hourly wage distribution is pushed farther to the right, narrowing the distribution. We show this below in Figure 11. 
Figure 11.

\section{Hypothetical Hourly Wage Distribution}

2020

2021

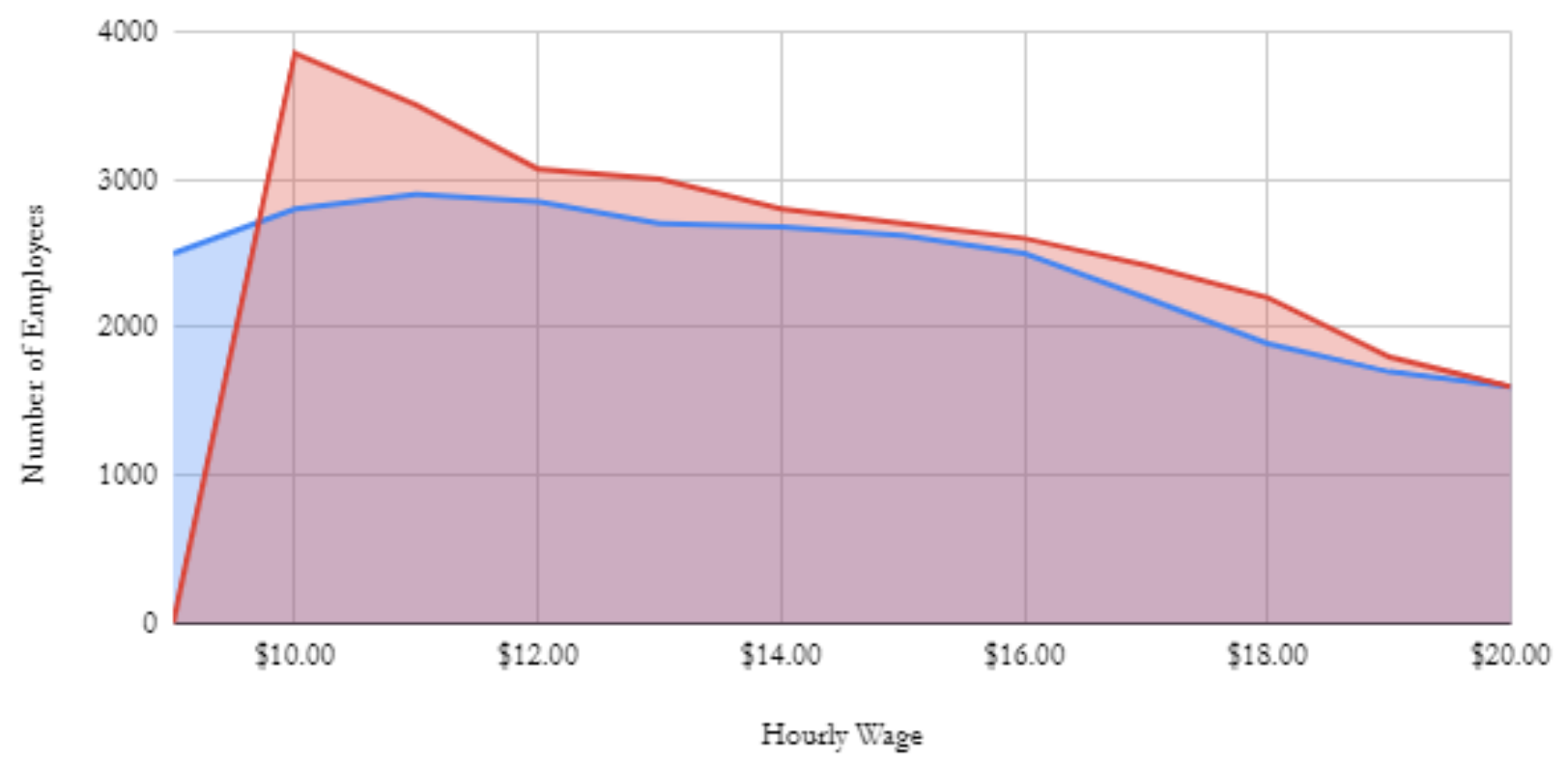

After we perform a concise overview of the labor market, the next step entails estimating the impacts an increase in the minimum wage would have on Florida's workers. To do so, we must utilize a dynamic modeling system. We chose to employ REMI as our dynamic modeling system, which is discussed in further detail below.

\section{Multiplier Software}

\section{REMI}

Regional Economic Models, INC. (REMI) is a software that uses a dynamic model aiming to assist researchers in answering questions that fall within the scope of several different subject areas - including the environment, energy, and for our purpose, economic development. 
REMI's approach to estimation includes four types of techniques: Econometric, General Equilibrium, Economic Geography, and Input-Output. The central component of REMI is the Input-Output model, which works to portray the relationships between industries within a region; for the purposes of our analyses, that region is Florida. REMI has the capability to portray a long-term general equilibrium in supply and demand accounting for several factors, including production, imports, exports, consumption, and prices. It also has the ability to portray both the economic and demographic effects caused by any given policy ${ }^{24}$.

REMI consists of four different types of models. For our analysis, we choose to employ the PI+ model as a way to mimic an Input-Output technique. This model adjusts for sub-national areas for policy and forecasting and can also be used for single and multi-area groupings. Each region that is incorporated into the model has their own set of demographic and economic variables. In addition, the $\mathrm{PI}+$ model can control for any economic policy specific to a region, giving ease to testing changes corresponding to the local economies. Appendix 4 displays a flow chart of REMI's model's structure. It is common practice for government agencies, firms, and universities to employ this model when analyzing policy impacts. Since we were tasked with conducting an economic impact analysis, the PI+ model was the best option for us to proceed with.

\section{IMPLAN}

In addition to using REMI, we employ a software known as IMPLAN to cover the fiscal impacts of the minimum wage legislation. Since IMPLAN is also an input-output (IO) model, we

24 “Regional Economic Models, Inc. (REMI) Model." Regional Economic Models, Inc. (REMI) Model |Open Energy Information, openei.org/wiki/Regional_Economic_Models,_Inc._(REMI)_Model. 
are able to use the same aggregated employment level shocks that we use in REMI. However, there are limitations to this model. For one, it does not include the type of dynamic analysis that REMI does. The effects are computed contemporaneously, and do not consider some micro-level changes that might be considered in other models (consumer behavior changes, elasticity changes). This means that IMPLAN is a static model and lacks REMI's ability to display dynamic effects. Additionally, IMPLAN has been found to have a tendency to overestimate some effects in the past. ${ }^{25}$ Despite these shortcomings, it is a widely used model for estimating large-scale impacts of legislation. Also, the sections which are estimated with this software will be one year shorter than the sections that are estimated otherwise. We are still able to estimate the entire duration of the amendment, but our inflation adjustment period after 2026 is curtailed at 2030 due to the ten year limit of the forecast.

\section{Estimating Employment Effects}

\section{The Increasing Affected Population}

After we have completed our industry analysis, we begin synthesizing the information we have obtained into a population. First, we use our distributional information to estimate the population of workers that falls into each of the affected groups. For purposes of estimating disemployment, we assume that as wages increase, the remainder of the employed population gets bumped up into the following tier to become a member of the next affected group. For example, a worker who was previously in the $\$ 0.00$ to $\$ 10.00$ group, who does not get pruned as a result of the first wage bump (from $\$ 8.46$ to $\$ 10.00$ ), subsequently become a member of the $\$ 10.00$ to $\$ 11.00$ group. Members of that group who remain employed through the next increase

\footnotetext{
${ }^{25}$ Rickman, Dan, and R Schwer. "A Comparison of the Multipliers of IMPLAN, REMI, and RIMS II: Benchmarking Ready-Made Models for Comparison." The Annals of Regional Science, vol. 29, no. 4, Dec. 1995, pp. 363-374., doi:https://doi.org/10.1007/BF01581882.
} 
then become members of the $\$ 11.00$ to $\$ 12.00$ group, and so on. The values that we use for these segments of the low-wage population can be found in Figure 5 in the section entitled "A Closer Look at Floridian Wages". Note that the numbers displayed in this table are merely the starting values; we adjust the cumulative numbers downward in our actual analysis, to account for prior period job losses.

\section{Selecting Appropriate Elasticities}

In our literature review, we discuss papers which estimate the disemployment effects caused by increases in the minimum wage. While most of the literature estimates are slightly negative elasticities, there are a few prominent papers that report increases in employment as a result of wage increases. Though most of the literature is centered around elasticities of -.1 to -.3 , the existence of estimates outside of this range convinced us that we should at least consider and analyze numbers outside of that range, if for no other purpose than to provide a more encompassing set of estimates. The inspiration for our final elasticity range is displayed in Table 3, alongside authors whose works they stem from. While a majority of these numbers made it to our estimation stage, the withering reputation of Card and Krueger's New Jersey study lead us to doubt the validity of the large positive effects they predict. For this reason, we decide to exclude this figure from our estimates. 
Author(s)

\begin{tabular}{l|l}
\hline $\begin{array}{l}\text { Neumark and Wascher } \\
\text { Kiel et al. }\end{array}$ & $-.1,-.2,-.6$ \\
Sabia et al. & $-.1,-.2$ \\
Card and Krueger & $-.2,-.3$ \\
Brown et al. & $.7, .9$ \\
Jardim et al. & $-.1,-.2,-.3$ \\
* References and further detail are located in the literature review.
\end{tabular}

With this in mind, our choice of elasticities to estimate is $-.1,-.2$, and -.3 Hereafter, we refer to -.1 as our low end, -.2 as our medium, and -.3 as our high end.

\section{Spreading Effects between Industries}

In order to estimate more realistic direct disemployment effects, we attempt to spread the effects throughout multiple sectors and industries. In its initial form, this analysis used a system of simple weights based on the percentage of low-wage workers in each sector, as dictated by the proportions extrapolated from our sample. While this seemed sensible, using these weights caused us to greatly overestimate the number of jobs removed from certain sectors, often estimating losses beyond the total number of low-skilled jobs. In order to correct this error, we changed our weighting to use the proportion of total low-wage workers that each industry accounts for. This new method fixes much of our initial problem, as industries with low employment but a large percentage of low wage workers in their pool would now be correctly 
counted. We settle on using this weighting method on 17 different prominent industries in Florida. Table 4 displays our chosen industries and the weights assigned to them. REMI also allows for the inclusion of federal employees, but since they are eligible for separate benefits through the government, we choose to only include non-federal, nonfarm sector jobs in our analysis.

Originally, we had estimated effects on only the top few industries, but since all industries have some form of low-wage worker, we decided to include all industries in our Table 4. analysis.

\begin{tabular}{|c|c|c|}
\hline Industry & $\%$ of $<\$ 15 /$ hour population & \multirow[b]{2}{*}{ Gradual Wage } \\
\hline Retail Trade & 15.82 & \\
\hline Healthcare & 13.48 & \multirow{3}{*}{ Adjustments } \\
\hline Professional & 11.37 & \\
\hline Food and Accommodation & 9.23 & \\
\hline Construction & 7.61 & In addition to \\
\hline Education; Private & 6.94 & \multirow{2}{*}{ estimating } \\
\hline Arts, Entertainment, and Recreation & 6.02 & \\
\hline Finance & 5.87 & \multirow{2}{*}{ employment } \\
\hline Other & 5.57 & \\
\hline Manufacturing & 5.28 & \multirow[t]{2}{*}{ reductions through the } \\
\hline Utilities & 4.65 & \\
\hline Transportation & 4.53 & \multirow[t]{2}{*}{ duration of the } \\
\hline Administrative & 2.87 & \\
\hline Wholesale Trade & 2.36 & proposed amendment, \\
\hline Forestry, Fishing, and Hunting & 1.39 & \multirow{2}{*}{ we also continue our } \\
\hline Information & 1.15 & \\
\hline Mining & 0.06 & analysis forward with \\
\hline
\end{tabular}

there will be inflation and a corresponding adjustment. While we initially considered basing our future period inflation adjustments on those of recent years, we adjust these numbers to reflect the fact that inflation has been unusually low. Appendix 1 contains a list of previous wage adjustments, wherein our point is illustrated: the difference in wages each year from 2013 to 
2018 was approximately $1.5 \%$ on average. Our projection supposes that inflation is only marginally higher beyond 2026, at 2\%, marking a return to a "normal" level.

\section{Direct Effects Estimation}

The actual process of estimating the direct disemployment effects was relatively simple. Using the range of elasticities that we have chosen to examine, we identify the magnitude of employment change in percentile form. For example, a -.1 elasticity, multiplied by an $18.2 \%$ increase in the minimum wage, would equate to a loss of $-1.82 \%$ of low-wage jobs. In much of this estimation, we assume that the elasticities remain the same over the initial six-year span. We also assume that these elasticities remain constant throughout the remainder of our analysis: through the year 2031. Per the proposed amendment, the minimum wage will be adjusted for inflation in the years following 2026. Table 5 below displays our estimates for our selected range of effects.

Table 5 .

\begin{tabular}{rlllllllllll} 
Elasticity & 2021 & 2022 & 2023 & 2024 & $\mathbf{2 0 2 5}$ & $\mathbf{2 0 2 6}$ & $\mathbf{2 0 2 7}$ & $\mathbf{2 0 2 8}$ & $\mathbf{2 0 2 9}$ & $\mathbf{2 0 3 0}$ & $\mathbf{2 0 3 1}$ \\
\hline-0.1 & $-21,218$ & $-14,081$ & $-14,958$ & $-16,8855$ & $-17,218$ & $-18,190$ & $-5,139$ & $-5,393$ & $-5,580$ & $-5,645$ & $-5,773$ \\
-0.2 & $-42,436$ & $-27,737$ & $-29,280$ & $-32,949$ & $-33,432$ & $-35,215$ & $-9,885$ & $-10,372$ & $-10,584$ & $-10,837$ & $-11,073$ \\
-0.3 & $-63,653$ & $-40,969$ & $-42,981$ & $-48,220$ & -48685 & $-51,137$ & $-14,260$ & $-14,964$ & $-15,255$ & $-15,607$ & $-15,931$
\end{tabular}

Understanding these initial estimates is critical to our analysis. Note the structure of these decreases: the largest wage increase, captured under the 2021 column, correctly coincides with the largest employment shock. However, there is a drop off following the first wage hike, after which the losses seem to ramp back up. While this might seem to contradict the fact that each wage change after the first represents a proportionally smaller change (an increase of $\$ 1$, over a larger base), there is a simple explanation for this phenomena. Recall from previous sections that 
our affected population spills over from the previous year. Estimating constant elasticities through the ten year period then only leaves variation from population and percentage of wage change. Population increases outweigh the decreasing percentage change in wage, resulting in an increasing disemployment effect through time.

\section{Differences from the Control}

While the estimates in Table 5 are required for utilizing a multiplier software for our other analyses, they don't have any meaningful interpretation by themselves. In order to have any meaning, we must input these numbers into REMI to "shock" the model of the economy, and allow REMI to do its complex calculations. This new model shows how the employment levels, income per capita, benefits per capita, and much more, would look if the amendment passes. We also run the model without any shocks - a baseline forecast - and can make direct comparisons by year between the two models. Table 6 displays our median forecast and the baseline.

We report these differences, between the baseline and shocked model, as jobs "missing" from the economy. We cannot say that these individuals are "losing" their jobs; they are just jobs that would otherwise likely exist if the amendment does not pass. Therefore, we calculate the difference from the control group, and present those in the table below.

Table 6.

\begin{tabular}{rllllllll} 
Elasticity & $\mathbf{2 0 2 1}$ & $\mathbf{2 0 2 2}$ & $\mathbf{2 0 2 3}$ & $\mathbf{2 0 2 4}$ & $\mathbf{2 0 2 5}$ & $\mathbf{2 0 2 6}$ & Average \\
\hline-0.1 & $-48,184$ & $-33,594$ & $-36,756$ & $-40,938$ & $-41,335$ & $-43,094$ & $-27,914$ \\
-0.2 & $-96,371$ & $-66,236$ & $-72,057$ & $-79,963$ & $-80,302$ & $-83,450$ & $-54,503$ \\
-0.3 & $-144,574$ & $-97,919$ & $-105,924$ & $-117,118$ & $-117,004$ & $-121,199$ & $-79,821$
\end{tabular}

Note that this table includes the averaged effect over the entire ten-year period, which is made up of six years of policy related-changes and four years of a supposed inflation adjustment. We expect that over the ten-year span, there will be an average of 27,914 to 79,821 jobs missing 
from the Florida economy. As the last few years of this estimation have wage increases substantially smaller than the first six years, the average over the ten-year period may be skewed to be smaller.

\section{Induced Effects Analysis}

As noted previously, our basic estimate of jobs missing from the economy comes from multiplying the percent increase in wages by the elasticities from the literature. However, once there are more unemployed members of society, there are trickle-down effects. For instance, if many members of a mining town are no longer employed, that area's residents' spending would likely decrease. The residents may stop spending money at local restaurants, forcing layoffs of workers in the Accommodation and Food Services industry. Those former food workers then may stop spending money in retail - with the trend continuing down the line. REMI is particularly useful to us because it accounts for population growth, economic trends, shifting industries, and other confounding factors, using complex models, to predict these trickle-down effects. Specifically, it is able to calculate how the loss of one job influences losses further down the line. These are known as "induced effects". Figure 12 shows the average number of missing jobs by industry, broken down into direct and induced effects. These numbers are the average number of missing jobs over the five years of proposed wage increases (2021-2026). 
Figure 12.

\section{Total Effects are Comprised of Direct and Induced Effects}

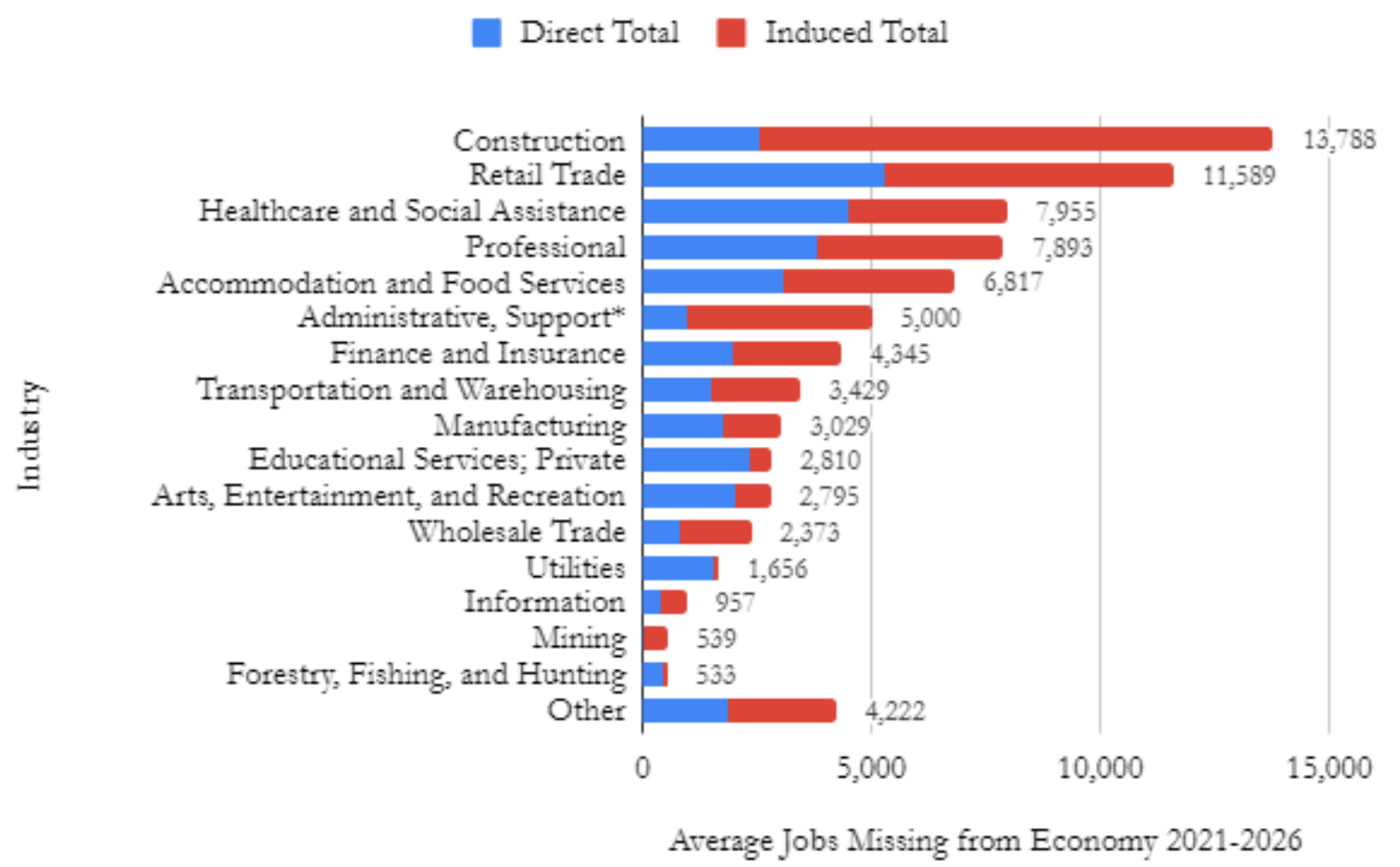

As you can see from the graph, many industries ${ }^{26}$ see more induced effects than direct effects. For each one job lost from direct effects, there are, on average, 0.06 jobs lost in the Utilities industry from induced effects. The Utilities industry has the smallest ratio of direct to induced effects. The largest ratio is in the Mining industry, where one direct loss is associated with 25.8 induced losses. Although this number sounds staggering, Mining is Florida's secondsmallest industry by number of jobs. Thus, this goes back to the point made earlier of how important it is important to speak in actual counts.

$26{ }^{*}$ Full name of industries in chart are Administrative, Support, Waste Management, and Remediation Services Professional, Scientific, and Technical Services. 
Over the years 2021 to 2026, there are 44,077 expected jobs missing due to direct effects, and 44,814 from induced effects. This results in an overall ratio of 1.02 induced losses for each one direct loss. Of these direct losses, Retail Trade is the largest contributor, with 5,301 jobs missing, on average, over the six years. Of the induced losses, Construction is the largest contributor, with 11,238 jobs missing, on average, over the six years.

Despite these insights, there is no evidence to support that the direct and indirect losses are linked within industries. It is entirely possible and probable that the industries are interconnected with their losses. For example, large losses in the Construction industry could impact Utilities workers down the line, as fewer buildings created would lead to smaller growth in utility usage.

A downfall to this is that there is also no conceivable way to account for lagged effects. If this amendment's passing devastates the Wholesale Trade industry in a town, causing all of the workers to relocate, the Accommodation and Food Service employees will likely be impacted soon after that as their customer base leaves the area. A longer term impact may appear in the Educational Services industry in the following school year. In the future, software may be able to map which industries induce losses in which other industries. However, at this time, we are only able to examine aggregate changes. These changes are displayed below in Table 7. 
Table 7.

\begin{tabular}{|c|c|c|c|c|c|c|c|c|c|c|c|}
\hline Ind & & & & & & & & & & & \\
\hline Forestry, fishing, and hunting & $\begin{array}{c}-696 \\
(-1.10)\end{array}$ & $\begin{array}{c}-448 \\
(-0.71)\end{array}$ & $\begin{array}{c}-467 \\
(-0.75)\end{array}$ & $\begin{array}{c}-520 \\
(-0.83)\end{array}$ & $\begin{array}{c}-521 \\
(-0.84)\end{array}$ & $\begin{array}{c}-542 \\
(-0.87)\end{array}$ & $\begin{array}{c}-124 \\
(-0.20)\end{array}$ & $\begin{array}{c}-131 \\
(-0.21)\end{array}$ & $\begin{array}{c}-136 \\
(-0.22)\end{array}$ & $\begin{array}{c}-143 \\
(-0.23)\end{array}$ & $\begin{array}{c}-149 \\
(-0.24)\end{array}$ \\
\hline Mining & $\begin{array}{c}-623 \\
(-2.02)\end{array}$ & $\begin{array}{c}-470 \\
(-1.53)\end{array}$ & $\begin{array}{c}-496 \\
(-1.61)\end{array}$ & $\begin{array}{c}-544 \\
(-1.76)\end{array}$ & $\begin{array}{c}-543 \\
(-1.76)\end{array}$ & $\begin{array}{c}-557 \\
(-1.80)\end{array}$ & $\begin{array}{c}-180 \\
(-0.58)\end{array}$ & $\begin{array}{c}-140 \\
(-0.45)\end{array}$ & $\begin{array}{c}-118 \\
(-0.37)\end{array}$ & $\begin{array}{c}-114 \\
(-0.36)\end{array}$ & $\begin{array}{c}-117 \\
(-0.36)\end{array}$ \\
\hline Utilities & $\begin{array}{l}-2,091 \\
(-5.17)\end{array}$ & $\begin{array}{l}-1,364 \\
(-5.54)\end{array}$ & $\begin{array}{l}-1,449 \\
(-6.28)\end{array}$ & $\begin{array}{l}-1,631 \\
(-6.28)\end{array}$ & $\begin{array}{l}-1,656 \\
(-6.40)\end{array}$ & $\begin{array}{l}-1,745 \\
(-6.77)\end{array}$ & $\begin{array}{c}-499 \\
(-1.94)\end{array}$ & $\begin{array}{c}-526 \\
(-2.05)\end{array}$ & $\begin{array}{c}-533 \\
(-2.08)\end{array}$ & $\begin{array}{c}-545 \\
(-2.12)\end{array}$ & $\begin{array}{c}-557 \\
(-2.17)\end{array}$ \\
\hline Construction & $\begin{array}{c}-14,504 \\
(-1.90)\end{array}$ & $\begin{array}{c}-12,903 \\
(-1.69)\end{array}$ & $\begin{array}{c}-13,529 \\
(-1.79)\end{array}$ & $\begin{array}{c}-14,286 \\
(-1.94)\end{array}$ & $\begin{array}{c}-13,871 \\
(-1.93)\end{array}$ & $\begin{array}{c}-13,632 \\
(-1.93)\end{array}$ & $\begin{array}{l}-4,733 \\
(-0.68)\end{array}$ & $\begin{array}{l}-2,219 \\
(-0.32)\end{array}$ & $\begin{array}{c}-863 \\
(-0.13)\end{array}$ & $\begin{array}{c}-372 \\
(-0.05)\end{array}$ & $\begin{array}{c}-374 \\
(-0.06)\end{array}$ \\
\hline Manufacturing & $\begin{array}{l}-3,870 \\
(-0.96)\end{array}$ & $\begin{array}{l}-2,617 \\
(-0.66)\end{array}$ & $\begin{array}{l}-2,738 \\
(-0.70)\end{array}$ & $\begin{array}{l}-2,991 \\
(-0.78\end{array}$ & $\begin{array}{l}-2,947 \\
(-0.78)\end{array}$ & $\begin{array}{l}-3,011 \\
(-0.81)\end{array}$ & $\begin{array}{c}-728 \\
(-0.20)\end{array}$ & $\begin{array}{c}-667 \\
(-0.19)\end{array}$ & $\begin{array}{c}-623 \\
(-0.18)\end{array}$ & $\begin{array}{c}-636 \\
(-0.18)\end{array}$ & $\begin{array}{c}-673 \\
(-0.19)\end{array}$ \\
\hline Wholesale Trade & $\begin{array}{l}-2,884 \\
(-0.65)\end{array}$ & $\begin{array}{l}-1,956 \\
(-0.44)\end{array}$ & $\begin{array}{l}-2,138 \\
(-0.49)\end{array}$ & $\begin{array}{l}-2,378 \\
(-0.55)\end{array}$ & $\begin{array}{l}-2,392 \\
(-0.55)\end{array}$ & $\begin{array}{l}-2,489 \\
(-0.58)\end{array}$ & $\begin{array}{c}-807 \\
(-0.19)\end{array}$ & $\begin{array}{c}-789 \\
(-0.19)\end{array}$ & $\begin{array}{c}-735 \\
(-0.17)\end{array}$ & $\begin{array}{c}-727 \\
(-0.17)\end{array}$ & $\begin{array}{c}-739 \\
(-0.18)\end{array}$ \\
\hline Retail Trade & $\begin{array}{c}-14,007 \\
(-0.97)\end{array}$ & $\begin{array}{l}-9,315 \\
(-0.65)\end{array}$ & $\begin{array}{c}-10,360 \\
(-0.72)\end{array}$ & $\begin{array}{c}-11,645 \\
(-0.82)\end{array}$ & $\begin{array}{c}-11,812 \\
(-0.84)\end{array}$ & $\begin{array}{r}-12,397 \\
(-0.88)\end{array}$ & $\begin{array}{l}-4,298 \\
(-0.31)\end{array}$ & $\begin{array}{l}-4,454 \\
(-0.32)\end{array}$ & $\begin{array}{l}-4,257 \\
(-0.31)\end{array}$ & $\begin{array}{l}-4,235 \\
(-0.30)\end{array}$ & $\begin{array}{l}-4,279 \\
(-0.31)\end{array}$ \\
\hline Transportation and warehousing & $\begin{array}{l}-4,376 \\
(-0.98)\end{array}$ & $\begin{array}{l}-2,853 \\
(-0.64)\end{array}$ & $\begin{array}{l}-3,044 \\
(-0.69)\end{array}$ & $\begin{array}{l}-3,385 \\
(-0.77)\end{array}$ & $\begin{array}{l}-3,387 \\
(-0.77)\end{array}$ & $\begin{array}{l}-3,529 \\
(-0.81)\end{array}$ & $\begin{array}{c}-890 \\
(-0.20)\end{array}$ & $\begin{array}{c}-921 \\
(-0.21)\end{array}$ & $\begin{array}{c}-907 \\
(-0.21)\end{array}$ & $\begin{array}{c}-937 \\
(-0.21)\end{array}$ & $\begin{array}{c}-982 \\
(-0.22)\end{array}$ \\
\hline Information & $\begin{array}{l}-1,224 \\
(-0.67)\end{array}$ & $\begin{array}{c}-772 \\
(-0.43)\end{array}$ & $\begin{array}{c}-850 \\
(-0.48)\end{array}$ & $\begin{array}{c}-949 \\
(-0.54)\end{array}$ & $\begin{array}{c}-952 \\
(-0.55)\end{array}$ & $\begin{array}{c}-996 \\
(-0.58)\end{array}$ & $\begin{array}{c}-300 \\
(-0.18)\end{array}$ & $\begin{array}{c}-330 \\
(-0.20)\end{array}$ & $\begin{array}{l}-325 \\
(-0.19)\end{array}$ & $\begin{array}{c}-331 \\
(-0.20)\end{array}$ & $\begin{array}{c}-339 \\
(-0.20)\end{array}$ \\
\hline Finance and insurance & $\begin{array}{l}-5,827 \\
(-0.82)\end{array}$ & $\begin{array}{l}-3,581 \\
(-0.50)\end{array}$ & $\begin{array}{l}-3,840 \\
(-0.54)\end{array}$ & $\begin{array}{l}-4,250 \\
(-0.60)\end{array}$ & $\begin{array}{l}-4,206 \\
(-0.59)\end{array}$ & $\begin{array}{l}-4,366 \\
(-0.61)\end{array}$ & $\begin{array}{l}-885 \\
(-0.12)\end{array}$ & $\begin{array}{l}-1,042 \\
(-0.15)\end{array}$ & $\begin{array}{l}-1,060 \\
(-0.15)\end{array}$ & $\begin{array}{l}-1,133 \\
(-0.16)\end{array}$ & $\begin{array}{l}-1,218 \\
(-0.17)\end{array}$ \\
\hline $\begin{array}{r}\text { Professional, scientific, and technical } \\
\text { services }\end{array}$ & $\begin{array}{l}-9,311 \\
(-1.02)\end{array}$ & $\begin{array}{l}-6,481 \\
(-0.71)\end{array}$ & $\begin{array}{l}-7,034 \\
(-0.77)\end{array}$ & $\begin{array}{l}-7,914 \\
(-0.87)\end{array}$ & $\begin{array}{l}-8,088 \\
(-0.89)\end{array}$ & $\begin{array}{l}-8,532 \\
(-0.93)\end{array}$ & $\begin{array}{l}-3,078 \\
(-0.34)\end{array}$ & $\begin{array}{l}-3,016 \\
(-0.33)\end{array}$ & $\begin{array}{l}-2,918 \\
(-0.31)\end{array}$ & $\begin{array}{l}-2,926 \\
(-0.31)\end{array}$ & $\begin{array}{l}-2,984 \\
(-0.32)\end{array}$ \\
\hline $\begin{array}{r}\text { Administrative, support, waste } \\
\text { management, and remediation services }\end{array}$ & $\begin{array}{l}-6,101 \\
(-0.61)\end{array}$ & $\begin{array}{l}-4,059 \\
(-0.40)\end{array}$ & $\begin{array}{l}-4,471 \\
(-0.44)\end{array}$ & $\begin{array}{l}-5,006 \\
(-0.50)\end{array}$ & $\begin{array}{l}-5,059 \\
(-0.50)\end{array}$ & $\begin{array}{l}-5,305 \\
(-0.53)\end{array}$ & $\begin{array}{l}-1,649 \\
(-0.16)\end{array}$ & $\begin{array}{l}-1,683 \\
(-0.17)\end{array}$ & $\begin{array}{l}-1,599 \\
(-0.16)\end{array}$ & $\begin{array}{l}-1,610 \\
(-0.16)\end{array}$ & $\begin{array}{l}-1,661 \\
(-0.16)\end{array}$ \\
\hline Educational services; private & $\begin{array}{l}-3,486 \\
(-1.39)\end{array}$ & $\begin{array}{l}-2,301 \\
(-0.91)\end{array}$ & $\begin{array}{l}-2,470 \\
(-0.98)\end{array}$ & $\begin{array}{l}-2,785 \\
(-1.10)\end{array}$ & $\begin{array}{l}-2,831 \\
(-1.12)\end{array}$ & $\begin{array}{l}-2,985 \\
(-1.18)\end{array}$ & $\begin{array}{c}-907 \\
(-0.36)\end{array}$ & $\begin{array}{c}-942 \\
(-0.37)\end{array}$ & $\begin{array}{c}-942 \\
(-0.37)\end{array}$ & $\begin{array}{c}-957 \\
(-0.37)\end{array}$ & $\begin{array}{c}-980 \\
(-0.38)\end{array}$ \\
\hline Health care and social assistance & $\begin{array}{l}-9,823 \\
(-0.69)\end{array}$ & $\begin{array}{l}-6,282 \\
(-0.43)\end{array}$ & $\begin{array}{l}-6,990 \\
(-0.48)\end{array}$ & $\begin{array}{l}-7,930 \\
(-0.54)\end{array}$ & $\begin{array}{l}-8,098 \\
(-0.55)\end{array}$ & $\begin{array}{l}-8,610 \\
(-0.58)\end{array}$ & $\begin{array}{l}-2,767 \\
(-0.18)\end{array}$ & $\begin{array}{l}-3,094 \\
(-020)\end{array}$ & $\begin{array}{l}-3,106 \\
(-0.20)\end{array}$ & $\begin{array}{l}-3,210 \\
(-021)\end{array}$ & $\begin{array}{l}-3,342 \\
(-021)\end{array}$ \\
\hline Arts, entertainment, and recreation & $\begin{array}{l}-3,659 \\
(-0.99)\end{array}$ & $\begin{array}{l}-2,287 \\
(-0.62)\end{array}$ & $\begin{array}{l}-2,450 \\
(-0.66)\end{array}$ & $\begin{array}{l}-2,740 \\
(-0.74)\end{array}$ & $\begin{array}{l}-2,750 \\
(-0.74)\end{array}$ & $\begin{array}{l}-2,884 \\
(-0.78)\end{array}$ & $\begin{array}{c}-691 \\
(-0.19)\end{array}$ & $\begin{array}{c}-789 \\
(-0.21)\end{array}$ & $\begin{array}{c}-809 \\
(-0.22)\end{array}$ & $\begin{array}{c}-849 \\
(-0.22)\end{array}$ & $\begin{array}{c}-891 \\
(-0.24)\end{array}$ \\
\hline Accommodation and food services & $\begin{array}{l}-7,901 \\
(-0.73)\end{array}$ & $\begin{array}{l}-5,327 \\
(-0.49)\end{array}$ & $\begin{array}{l}-6,035 \\
(-0.56)\end{array}$ & $\begin{array}{l}-6,890 \\
(-0.64)\end{array}$ & $\begin{array}{l}-7,132 \\
(-0.66)\end{array}$ & $\begin{array}{l}-7,621 \\
(-0.71)\end{array}$ & $\begin{array}{l}-3,041 \\
(-0.19)\end{array}$ & $\begin{array}{l}-3,182 \\
(-0.21)\end{array}$ & $\begin{array}{l}-3,081 \\
(-0.21)\end{array}$ & $\begin{array}{l}-3,071 \\
(-0.28)\end{array}$ & $\begin{array}{l}-3,098 \\
(-0.28)\end{array}$ \\
\hline $\begin{array}{r}\text { Other services (except public } \\
\text { administration) }\end{array}$ & $\begin{array}{l}-5,988 \\
(-0.67)\end{array}$ & $\begin{array}{l}-3,220 \\
(-0.36)\end{array}$ & $\begin{array}{l}-3,695 \\
(-0.42)\end{array}$ & $\begin{array}{l}-4,119 \\
(-0.46)\end{array}$ & $\begin{array}{l}-4,059 \\
(-0.46)\end{array}$ & $\begin{array}{l}-4,250 \\
(-0.48)\end{array}$ & $\begin{array}{c}-648 \\
(-0.07)\end{array}$ & $\begin{array}{l}-1,120 \\
(-0.13)\end{array}$ & $\begin{array}{l}-1,141 \\
(-0.13)\end{array}$ & $\begin{array}{l}-1,229 \\
(-0.14)\end{array}$ & $\begin{array}{l}-1,323 \\
(-0.15)\end{array}$ \\
\hline
\end{tabular}




\section{Total Effects Analysis}

Figure 13.

From 2021 to 2026, Employment Would Be Lower With the Amendment's Passing

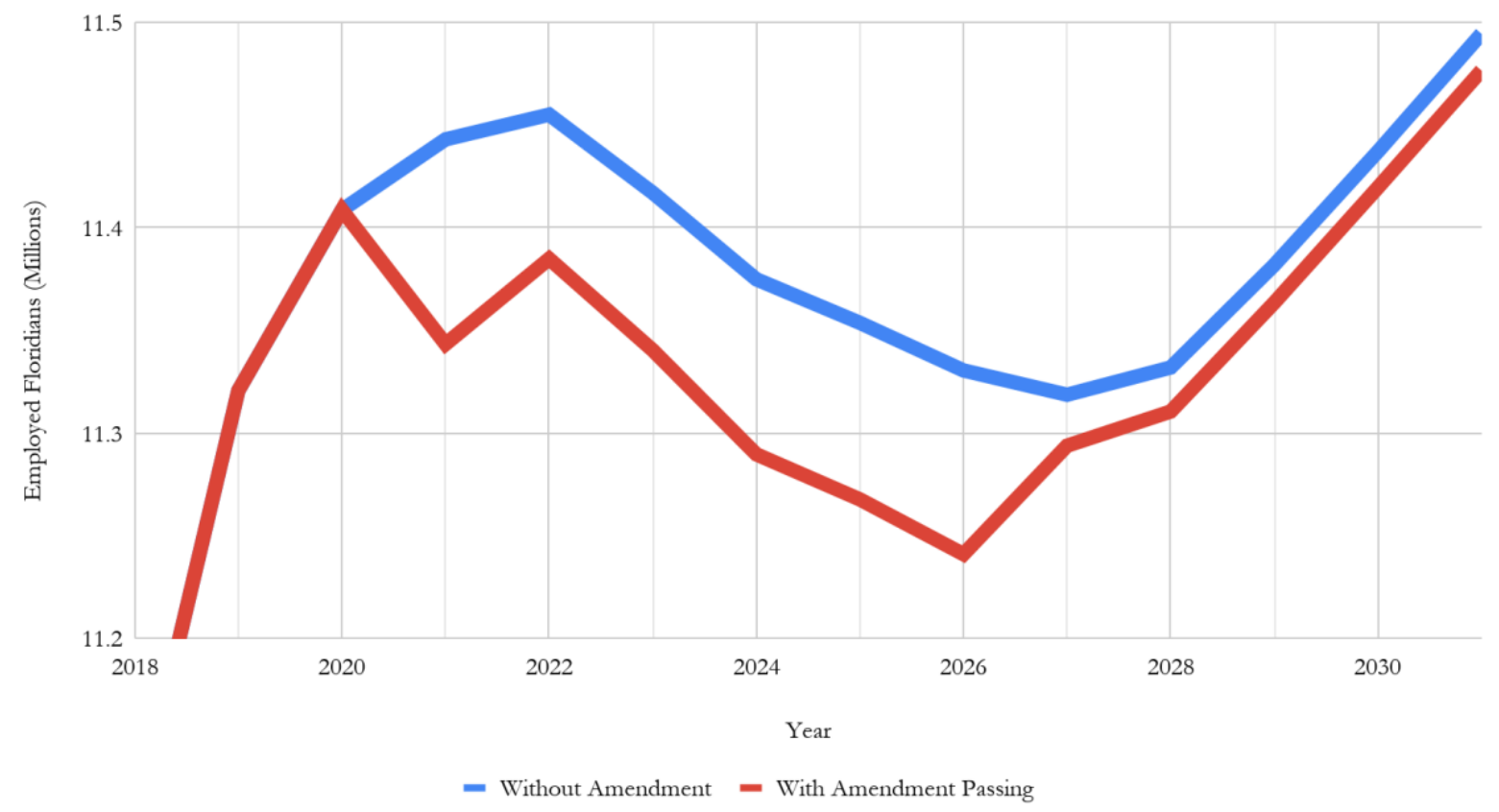

To discuss the total effects, otherwise known as the direct effects plus induced effects, it is important to note that the baseline forecast with no amendment predicts a downturn in employment beginning in 2022, and lasting until 2027. However, our model predicts an even larger downturn in employment if the proposed amendment passes. As you will see in Figure 13, there is a gap between the blue line, representing the baseline forecast, and the red line, which represents total employment if the amendment passes.

The largest difference between the two occurs in the first year of policy change, which is in 2021 . Because this year has the largest increase in wage of about $18.2 \%$, this is fairly selfexplanatory. Our model predicts there would be 96,372 fewer employees in Florida than if the amendment does not pass, which is a missing portion of $0.92 \%$. In 2022 , our model predicts that there will be 66,233 fewer employees in Florida, which is a difference of $0.63 \%$. Both the 
baseline model and our predicted values expect a decrease in total employment from 2022 to 2023: exemplified by a decrease of $0.35 \%$ in the baseline model, and a slightly larger decrease of $0.41 \%$ in our predicted model between the two years. The difference between the baseline model and the predicted model in 2023 is 72,053 employees, or $0.69 \%$. In 2024 , the difference is 79,958 , or $0.77 \%$. In 2025 , the difference is 80,301 , or $0.77 \%$. In 2026 , the difference is 83,448 , or $0.81 \%$.

In 2027, the story changes slightly: the predicted model indicates Florida coming out of its employment downturn one year earlier than if the amendment does not pass, with an increase in employment of 47,945 , or an increase of $0.47 \%$. The base model still shows that employment is decreasing from 2026, with a decrease of 9,270 or $0.09 \%$. The difference between the two models begins to decrease. The decrease is only 26,222 , or $0.25 \%$. From 2027 to 2028 , the baseline model also predicts an upswing, increasing employment by 14,916 , or $0.14 \%$. The difference between the models is only 25,047 , or $0.24 \%$. In the subsequent years, the gap generally gets smaller: in 2029 it is 23,154 , or $0.22 \%$; in 2030 it is 23,022 , or $0.22 \%$; in 2031 it is 23,703 , or $0.23 \%$. That last number is extremely important: despite an initial difference of $0.92 \%$ between the baseline and the predicted model, the two converge to within less than one quarter of one percent.

\section{Impact by Industry}

As mentioned in previous sections, not all industries would be impacted equally by this amendment's passing. For example, for the years 2021 to 2026, the Utilities industry would have $6.34 \%$ fewer jobs than the baseline forecast. However, this is Florida's smallest industry, so that $6.34 \%$ equates to only 1,655 jobs. Alternatively, the Retail industry - Florida's second-largest industry - would have an average employment of 1,425,272 without the amendment. With the 
amendment, that number decreases by a smaller percentage, $0.81 \%$, to $1,413,683$. That equates to 11,589 missing jobs, on average, each year.

We have previously stated that certain industries have larger portions of low-wage workers than others. These industries would see disproportionate impacts by a minimum wage increase. In 2017, 69.7\% of employees in the Accommodation and Food Services industry were earning less than $\$ 15$ per hour. Our model predicts a decrease of $0.63 \%$, or 6,818 jobs, from $1,077,065$ to $1,070,247$, on average. In contrast, Florida's largest industry, Healthcare Services, has only $35.3 \%$ of its employees earning less than or equal to $\$ 15$ per hour. It would see a decline of $0.55 \%$ in employment. Despite having 400,000 more employees than the Accommodation and Food Services industry, it would have only 1,138 more jobs missing from its industry, leaving 1,450,929 employees in the workforce.

The industries with the largest number of missing jobs are Construction and Retail Trade. We have already discussed the Retail industry, but our baseline model predicts that the Construction industry will employ an average of 740,996 Floridians from 2021 to 2026. Our shocked model predicts that the average number of Construction employees would decrease by $1.86 \%$ to 727,209 , leaving 13,788 jobs out of the economy. A full table of these industry-specific results is located in Appendix 3.

\section{Benefit Cliffs}

Much of the conversation surrounding the minimum wage debate pertains to how an increase in the minimum wage affects the unemployment rate, number of hours worked, tax revenue, and other economic concepts. Benefit cliffs are usually an area that tends to be less focused on. These cliffs occur when benefit programs cease disbursements, either immediately or gradually, as individual or family incomes increase and rise above each program's income 
threshold. They are also important when it comes to minimum wage legislation because, while the purpose of an increase in the minimum wage is to benefit people financially, it has the potential to do the opposite. For example: if a minimum wage worker is taking advantage of different benefit programs that add up to several thousand dollars' worth of assistance, and their wage goes up above those benefits' thresholds due to a minimum wage increase, they would lose their benefits. The addition of a few extra dollars per hour to their wage rate may fail to make up for the loss of thousands of dollars' worth of aid. The following paragraphs detail several programs with wage cliffs that people may lose access to if the minimum wage were to increase to $\$ 10$ per hour and gradually to $\$ 15$ per hour.

The first social service to focus on is the Child Care and Development Fund (CCDF), which helps provide child care subsidies to working parents. In determining eligibility for the program, states must follow specific federal guidelines. These guidelines include an income eligibility limit that is no higher than $85 \%$ of the state median income, along with work, education, and other requirements of that nature. For families with children, they establish that children cannot be older than 12 years of age, or no older than 18 years of age if the child has a disability. As of 2015, in order to receive this subsidy in Florida, individuals are required to work 15 to 20 hours per week. The monthly income threshold for a three-person family for this program falls between $\$ 838$ and $\$ 5,279$ monthly. In some cases, a monthly copayment of $\$ 1$ to $\$ 100$ needs to be paid in order to receive benefits. The maximum monthly reimbursement for childcare that a family of three in Florida can receive ranges from approximately $\$ 400$ to $\$ 600$, depending on the type of facility their child receives care from ${ }^{27}$.

27 "Child Care Subsidies under the CCDF Program." www.ccdf.urban.org/sites/default/files/CCDFDatabase2015PolicySummary.pdf. 
Additionally, The Supplemental Nutrition Assistance Program (SNAP) is a federallyfunded program that aims to aid people in purchasing food. Rather than SNAP benefits being distributed via paper food stamps, they are doled out monthly through an electronic benefits transfer (EBT) card, similar to a debit card. In Florida, several qualifications must be met before receiving SNAP benefits. ${ }^{28}$ It is required that applicants be employed or looking for employment (and have proof). Being eligible for SNAP benefits has an income component to it as well. ${ }^{29}$ If a one-person household meets the following income criteria, they will be eligible for a maximum of $\$ 505$ worth of SNAP benefits: $200 \%$ gross monthly income limit is $\$ 4,464$, the $130 \%$ gross monthly income limit is $\$ 2,252$, the $100 \%$ net monthly income limit is $\$ 1,732$. For each additional person added to a household, the $200 \%$ monthly income limit will increase by $\$ 720$, the $130 \%$ gross monthly income limit will increase by $\$ 468$, the $100 \%$ net monthly income limit will increase by $\$ 360$, and the maximum amount of SNAP benefits that can be received will increase by $\$ 144 .{ }^{30}$ Students who are enrolled in college or another form of higher education at least half time and are between the ages of 18-49 do not qualify for SNAP benefits - however, there are exceptions. These exceptions include: If a student is not fit mentally or physically, has to assist a dependent between the ages of 5 and 12 and does not have access to childcare, has to assist a dependent who is less than age 6 , is a single parent with a dependent under 12 years old while being a full time college student, a beneficiary of Temporary Cash Assistance benefits, in college due to taking part in a Job Opportunities and basic skills program under the umbrella of the Title IV of the Social Security Act, are a participant in a work-study program that is funded

\footnotetext{
28 "What Is SNAP?" What Is SNAP? | Www.gettingsnap.org, www.gettingfoodstamps.org/whatissnap.html.

29 "Eligibility for SNAP in FL." Florida, florida-assistance.org/florida-dcf/snap-in-florida/eligibility-for-snap-inflorida/.

${ }^{30}$ Food Assistance Program Fact Sheet. Oct. 2018, www.myflfamilies.com/programs/access/docs/fafactsheet.pdf.
} 
by the federal or state government, or work at least 80 hours every month, among more specific qualifications. SNAP benefits can only be used to purchase nutritious foods. Purchasing things like premade meals, alcohol, cigarettes, pet food, and medicines are prohibited.

The Low-Income Home Energy Program (LIHEAP) offers grants to both nonprofits and local governments to help provide low-income people with resources to pay their electricity bills. In addition to helping people pay their home energy bills, LIHEAP assists in paying fees associated with crises, as well as weather-related needs. A Florida resident living by themselves qualifies for LIHEAP if they do not make an excess of $\$ 18,735$ per year. For every additional member living in a household, $\$ 6,630$ is added to the maximum income level requirement to receive LIHEAP benefits ${ }^{31}$. Someone who partakes in SNAP, Supplemental Security Income (SSI), Temporary Assistance for Needy Families (TANF), or qualifies for certain Veteran benefits, among other programs are often automatically qualified to participate in LIHEAP. The SSI program, as mentioned above, is funded by all-purpose tax dollars rather than Social Security tax dollars as the name might suggest. The goal of SSI is to provide income assistance to blind and/or disabled individuals who are under 65 years of age and have either a very small income or no income at all. Children may also qualify for this program, depending on how much their disability affects their everyday lives ${ }^{32}$. As of January 2019 , for an individual to be eligible for SSI benefits, they can make no more than $\$ 9,259.67$ per year. Currently, an eligible individual can receive up to $\$ 771$ in SSI benefits. For a couple to be eligible, they can make no more than a combined $\$ 13,887.97$ annually. An eligible couple can receive up to $\$ 1,157$ in SSI benefits in $2019 .{ }^{33}$ SSI does not take into account SNAP benefits, the majority of

\footnotetext{
31 "Welcome to Benefits.Gov." Welcome to Benefits.Gov | Benefits.Gov, www.benefits.gov/benefit/1553.

${ }^{32}$ Geos Line. Employ Florida - Supplemental Security Income (SSI), www.employflorida.com/gsipub/index.asp?docid=50.

33 "Social Security." SSI Federal Payment Amounts for 2019, www.ssa.gov/oact/cola/SSI.html.
} 
programs like LIHEAP and other energy help, the first $\$ 20$ of income acquired monthly, $150 \%$ of the first $\$ 65$ earned monthly from working a job, or shelter provided to an individual or couple by a not for profit, when determining income eligibility for the program ${ }^{34}$.

A benefit program designed to aid low-income families with children under the age of 18 is the Temporary Assistance for Needy Families (TANF). The goals of this program are to help parents provide for their children, advocate for parents to be active in the workforce, get/remain married, and provide resources to people to help avoid out-of-wedlock pregnancies ${ }^{35}$. This program works similar to SNAP in that benefits are dispersed through an EBT card, but differs in that the benefits can be used for more than just food. In order to qualify for TANF in Florida, adults must fulfill a work requirement that ranges from 20 to 55 hours per week, depending on family composition and circumstances. Families must also have no more than $\$ 2000$ in countable assets and may not own vehicles that combine to be worth more than $\$ 8,500^{36}$. TANF monthly payments vary as well, but in addition to varying based on family makeup, payments also depend on each family's cost of shelter/rent. Shelter costs are broken up into three categories, more than $\$ 50$ per month, between $\$ 0.01$ to $\$ 50$ per month, and $\$ 0$ per month. Being that TANF is temporary, recipients are only eligible to receive TANF benefits for up to five years ${ }^{37}$.

Low-income individuals may qualify to receive an Earned Income Tax Credit (EITC). This tax credit helps reduce the number of tax dollars that low-income individuals owe to the government. For a single person without any qualifying dependents to qualify to receive an EITC in 2019 , they cannot make more than $\$ 15,570$ a year, and a single person with three or more

\footnotetext{
${ }^{34}$ Dickey, Elizabeth. "Income and Asset Limits for SSI Disability Eligibility." Www.nolo.com, Nolo, 19 Jan. 2017, www.nolo.com/legal-encyclopedia/income-asset-limits-ssi-disability-eligibility.html.

${ }^{35}$ Florida Temporary Assistance for Needy Families (TANF), www.welfareinfo.org/benefits/florida-temporaryassistance-for-needy-families-tanf- 1657.

36 "Florida TANF Application." TANF Program, www.tanfprogram.com/florida-tanf-application-ta9.

37 Temporary Cash Assistance Fact Sheet. www.myflfamilies.com/service-programs/access/docs/tcafactsheet.pdf.
} 
qualifying dependents cannot make an excess of $\$ 50,162$. For a married couple filing their taxes jointly and without any qualifying dependents, the most they can make and still receive an EITC is $\$ 21,370$. If a jointly-filing married couple has three or more qualifying dependents, the most they can make and still receive these benefits is $\$ 55,952$. The tax credit received ranges from $\$ 529$ for someone without any qualifying dependent children to $\$ 6,557$ for someone with three or more qualifying dependent children ${ }^{38}$. In order for a child to be considered qualified, they have to live with the person receiving the tax credit, must be the child of the person receiving the tax credit (biologically, adopted, step, foster, and grandchildren all count), and be below the age of 19 at the conclusion of the filing year. If the child is a full-time student and younger than 24 years old, they qualify. A disabled child qualifies regardless of age ${ }^{39}$. The EITC can be beneficial to people and families but is often not taken advantage of ${ }^{40}$.

38 "EITC Income Limits Maximum Credit Amounts Next Year: Internal Revenue Service." EITC Income Limits Maximum Credit Amounts Next Year | Internal Revenue Service, www.irs.gov/creditsdeductions/individuals/earned-income-tax-credit/eitc-income-limits-maximum-credit-amounts-next-year.

39 “Qualifying Child Rules.” Internal Revenue Service, www.irs.gov/credits-deductions/individuals/earned-incometax-credit/qualifying-child-rules.

40 “The Earned Income Credit." All Florida Tax \& Financial Solutions, 2 Jan. 2015, www.allfloridatax.net/blog/theearned-income-credit/4560. 


\section{Estimating Effects on Social Service Expenditures}

Table 8. Percent Difference from Baseline Estimation

\begin{tabular}{rlllllll}
\multicolumn{2}{c}{ Elasticity } & $\mathbf{2 0 2 1}$ & $\mathbf{2 0 2 2}$ & $\mathbf{2 0 2 3}$ & $\mathbf{2 0 2 4}$ & $\mathbf{2 0 2 5}$ & $\mathbf{2 0 2 6}$ \\
\hline-0.1 & 0.010 & -0.015 & -0.031 & -0.045 & -0.063 & -0.079 \\
-0.2 & 0.020 & -0.030 & -0.060 & -0.091 & -0.125 & -0.156 \\
-0.3 & 0.029 & -0.048 & -0.090 & -0.136 & -0.185 & -0.231
\end{tabular}

In addition to estimating the effect on employment, we also estimate how the proposed minimum wage increase would affect social service expenditures in Florida. Being that we estimate a sizeable decrease in employment, we expect a corresponding increase in benefit spending; the idea being that fewer people would be working and receiving a paycheck, which would lead to more people being in need of government aid. This presumption holds true in our estimation for 2021 across all elasticity levels, but the magnitude is much smaller than anticipated. As shown in Table 8, the percentage change from the baseline estimates range from $-0.231 \%$ to $0.029 \%$. Our estimation shows that, if the proposed minimum wage goes into effect, slightly more will be spent on social service benefits than if the bill does not pass. The small magnitude percent changes remain constant across years and elasticities, but after 2021, the percent changes become negative, denoting that we estimate that Florida will spend slightly less on benefits if the bill passes. 
Table 9. Percent Difference from Baseline Using -0.2 Elasticity

\begin{tabular}{|c|c|c|c|c|c|c|}
\hline Benefit Program & 2021 & 2022 & 2023 & 2024 & 2025 & 2026 \\
\hline Medicare & 0.015 & -0.024 & -0.046 & -0.071 & -0.097 & -0.123 \\
\hline Social Security & 0.015 & -0.025 & -0.047 & -0.071 & -0.098 & -0.123 \\
\hline $\begin{array}{r}\text { Earned Income } \\
\text { Tax Credit (EITC) }\end{array}$ & 0.029 & -0.043 & -0.085 & -0.140 & -0.181 & -0.233 \\
\hline $\begin{array}{r}\text { Supplemental } \\
\text { Nutrition } \\
\text { Assistance } \\
\text { Program }(\text { SNAP) }\end{array}$ & 0.020 & -0.040 & -0.099 & -0.136 & -0.172 & -0.226 \\
\hline $\begin{array}{r}\text { Education and } \\
\text { Training } \\
\text { Assistance }\end{array}$ & 0.029 & -0.044 & -0.091 & -0.142 & -0.187 & -0.231 \\
\hline $\begin{array}{r}\text { State } \\
\text { Unemployment } \\
\text { Insurance } \\
\text { Compensation }\end{array}$ & 0.000 & 0.000 & -0.123 & -0.115 & -0.217 & -0.309 \\
\hline
\end{tabular}

Table 9 shows the percent difference between our estimation and the baseline estimation with a -0.2 elasticity for several prominent benefit programs. When examining these programs, we see much of the same trends: positive, but miniscule changes for 2021, and small, negative changes for 2022 through 2026. The difference between our estimation and the baseline for State Unemployment Insurance Compensation is so small that the percent change is nearly zero. For more estimates regarding benefit programs, please Appendices 5 and 6.

As previously mentioned, after estimating such large decreases in the unemployment rate throughout the duration of the proposed legislation, we expected large, positive changes in social services spending, which wound up being far from what we estimated. To explain this, we need to take another look at benefit cliffs. It is plausible to conclude that, of the minimum wage workers who would remain employed after the implementation of the proposed legislation, many were benefiting from social service programs. Due to their increase in income, they will likely no longer qualify for many of the benefit programs they previously utilized. In turn, there would be a large decline in benefit spending in Florida. On the flip side, many of the workers who lose 
their jobs, pursuant to the minimum wage, hike will now require government assistance, thus increasing social service expenditures. The balancing act between people gaining access to benefits after losing their jobs, and minimum wage workers who priced out of receiving benefits, is likely to be at the root of the small estimated changes in Florida's spending on social services.

\section{Tax Revenue Impacts of Minimum Wage Increases}

Since there is no personal income tax in Florida, a majority of government income is collected in the form of ad valorem taxes. An ad valorem tax is a tax that is imposed in addition to the price of a good. Our analysis will be centered on the two forms of the ad valorem tax which yield the greatest revenue to the state. These are identified as being the sales tax (on general consumption) and property tax. We also consider how total tax revenue will be affected. For the calculation of tax revenue forecasts, we focus on our middle elasticity value and the corresponding employment changes.

\section{Sales Tax}

In large part, the damages or benefits caused by minimum wage changes are tied to changes in consumption. This effect is amplified substantially in Florida, since government income is so closely tied to consumption-based taxes. It is typically uncertain how consumption taxes will be affected by wage increases. For example, if one becomes unemployed, there are a few separate possible outcomes. Depending on how much they make, they may stand to only lose a small amount of actual spending power (via the benefits cliffs, as discussed in the prior section). In this case, consumption may be largely unaffected. Additionally, depending on the consumption smoothing habits of the person, they may have prepared for a period of little to no earnings, in which case their consumption may remain essentially constant. We expect that this is not the case for many low-income workers, as low-income is often tied to a higher marginal 
propensity to consume. ${ }^{41}$ Essentially, it is expected that many workers in the minimum wage earner category would be spending a larger portion of their transitory ${ }^{42}$ and permanent income than those in higher income categories. This also may serve to obscure some of the reduced consumption effects expected as a result of large scale disemployment. If those who remain employed still spend a large percentage of their income, as income increases across the board, they may cancel each other out.

Figure 14.

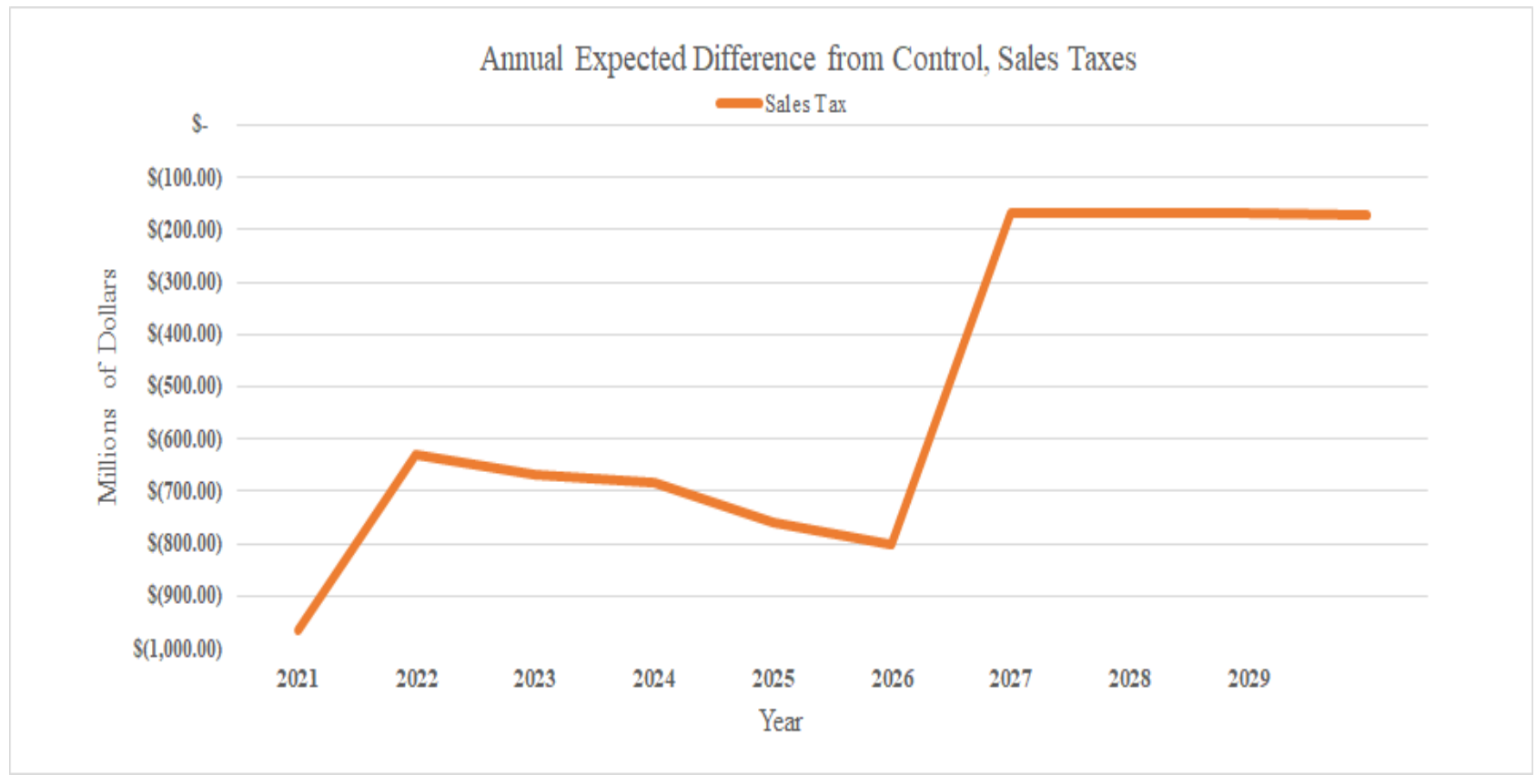

In Figure 14 shown above, we plot the sales tax difference from the baseline IMPLAN forecast until 2030. We expect that during the initial wage hike, sales tax revenue will be reduced by approximately 925 million dollars. However, we also predict a recovery in the following year. Despite this, the average differential over the 10-year span that we expect from the baseline

\footnotetext{
${ }^{41}$ Carroll, C., Slacalek, J., Tokuoka, K. and White, M. N. (2017), The distribution of wealth and the marginal propensity to consume. Quantitative Economics, 8: 977-1020. doi:10.3982/QE694

${ }^{42}$ Transitory (temporary) income was originally supposed to be saved, and permanent spent. This is being debunked, however, and an MPC of .2 to .4 is often tied to transitory income for low earning individuals.
} 
IMPLAN forecast is around 450 million dollars. The later year forecasts, although closer to the control, do not seem to be returning to the non-amendment values soon. While we are limited by IMPLAN's forecast range, disemployment effects due to the inflation adjustment period from 2026 onward would lead us to believe that even a more-extended forecast would fail to return to the control values.

\section{Property Taxes}

While property taxes still make up a large proportion of Florida's total tax receipts, they are not collected at the state level. Accordingly, the property tax figures that we predict using IMPLAN are essentially aggregated values that represent the total across all local governments in the state. In Figure 15, we show property tax estimates for Florida in the form of differences from the control group.

Figure 15.

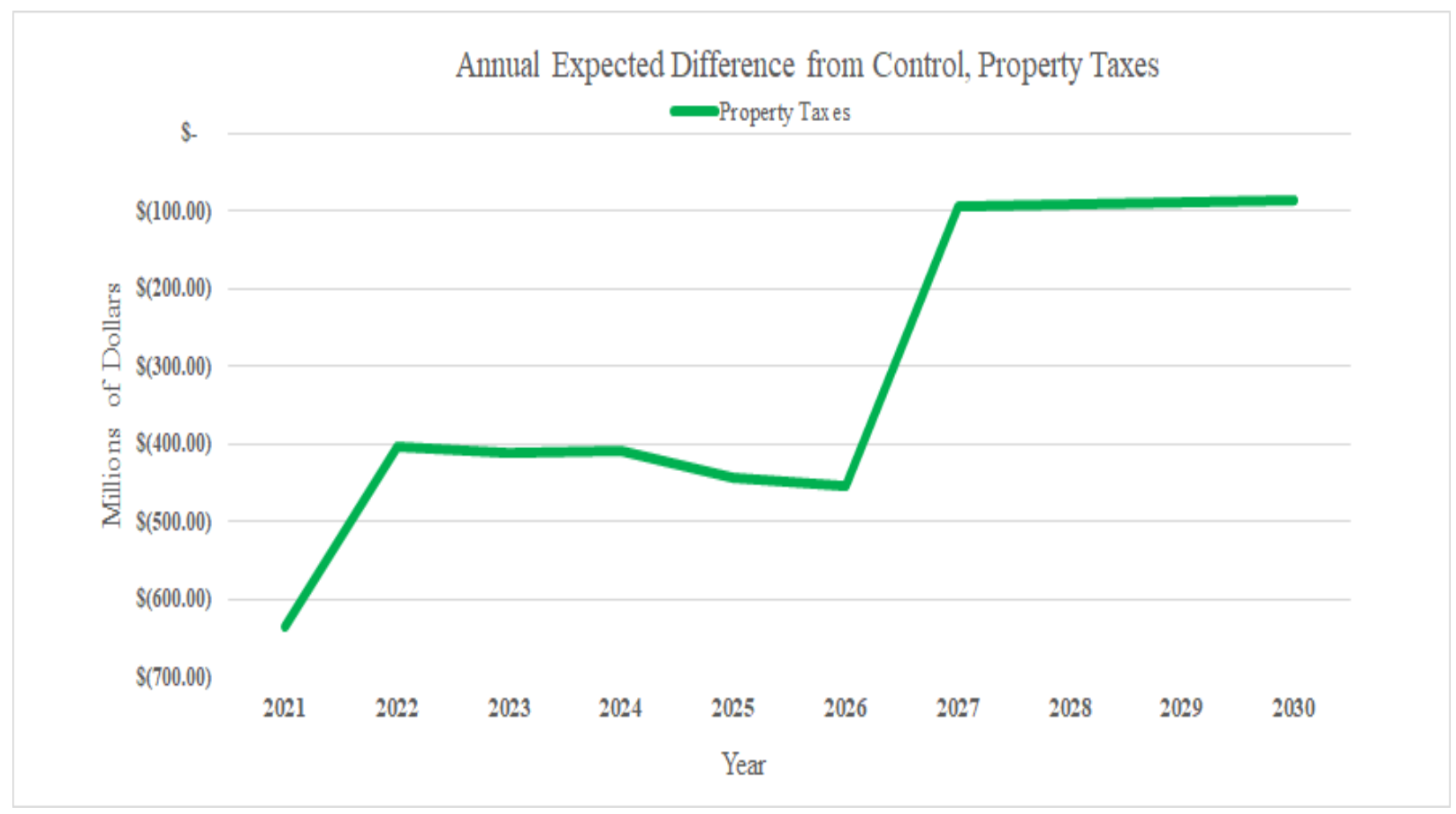


Note that the shape of this plot closely resembles the sales tax differences in Figure 14, with a fairly dramatic decrease resulting from the initial wage jump, and a stair-stepped structure ending with a plateau that begins in 2027 . We estimate that the total property tax revenue will be approximately 650 million dollars less than the control forecast. On average, there is a reduction of 300 million property tax revenue dollars if the amendment passes.

\section{Total State and Local Tax Revenue}

In Figure 16, we present a plot of the predicted tax revenue differences over the next ten years. While these figures may initially look jarring, it is critical to consider the proportion of total tax revenues that this represents. The United States Census Bureau calculates total receipts for Florida at around 165 billion dollars. A reduction of 2 billion would then be a $1.2 \%$ reduction in total tax revenues. On average, we expect that tax revenues will be reduced by one billion dollars annually. While we are unsure of what this equates to in terms of spending changes,

Figure 16.

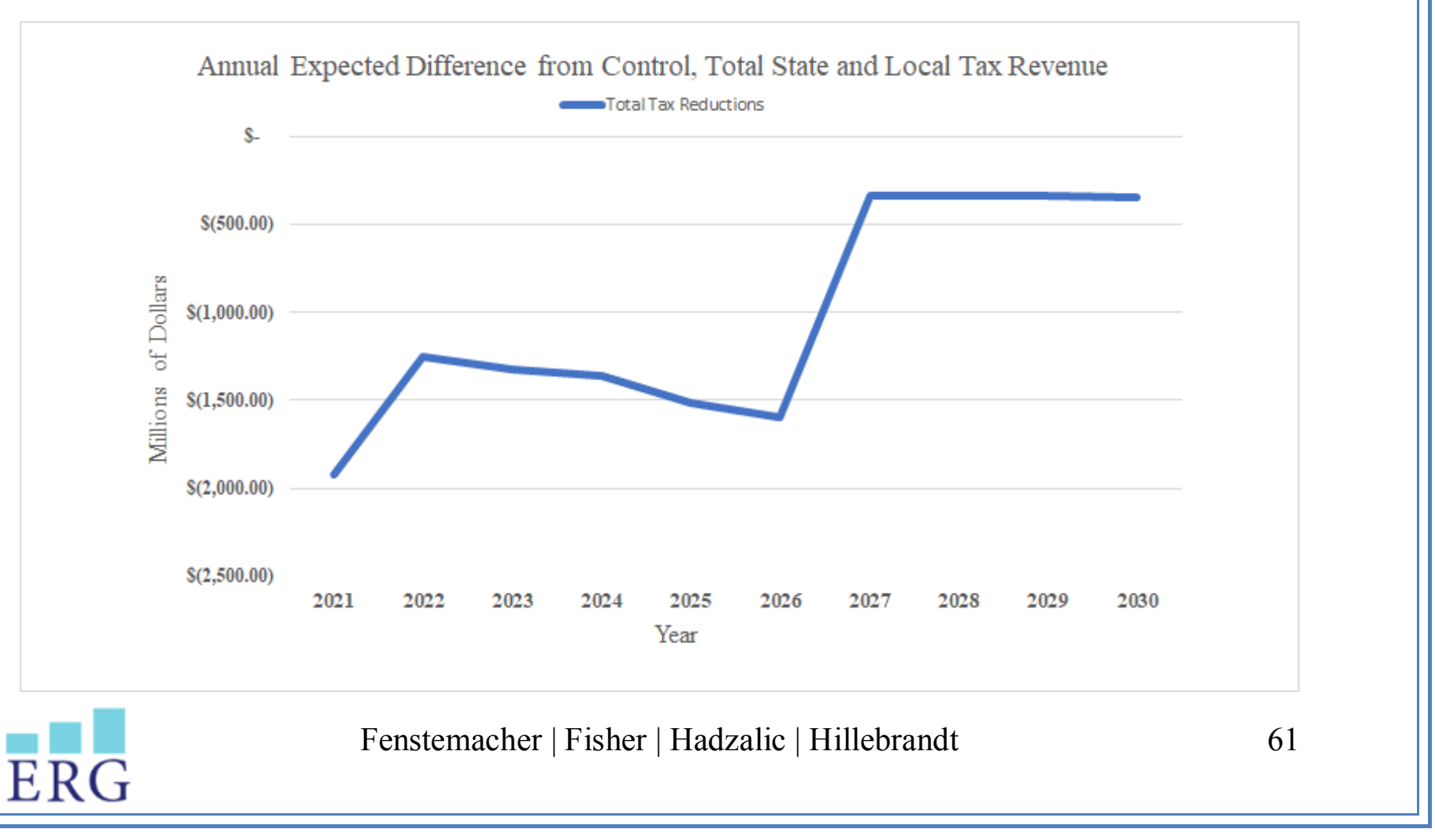


recent year spending increases lead us to believe that large revenue losses may damage Florida's government solvency sometime in the future.

\section{A Word on Productivity Changes due to Minimum Wage Increases}

One of the strongest cases made by proponents of increasing the minimum wage often relates to increases in productivity that are supposed to follow wage hikes. While equating productivity spikes to increases in an employee's hourly rate likely overstates the motivational effect of a marginal wage increase, it seems more reasonable that systematic changes in the hiring process and the composition of the workforce could result in productivity increases over time.

If employers are faced with rising costs of employees despite stagnant productivity, there will be an increased incentive to intensify the labor searching process and layoff the bottom tier of employees. Additionally, we expect that the market for low-skill jobs will be flooded with an increased supply of laborers, as their expected returns to labor increase. If the influx of laborers includes those who are more productive, the employer also stands to benefit, as the opportunity cost of searching for more highly skilled labor decreases. There are also proportional decreases in the relative cost of employing these higher-skilled employees as their lower-skilled counterparts begin to command higher wages. The end result of this process is a shift toward a more productive workforce, as those with higher productivity are increasingly employed over their less productive counterparts. Though there will likely be fewer workers employed in total, the net effect of this switch toward a smaller workforce might be essentially zero from a production standpoint. Figures 17 and 18 offer graphical representations of two possible outcomes. 
Figure 17.

Reduction in Force Typically Equates to

Decreased Total Output

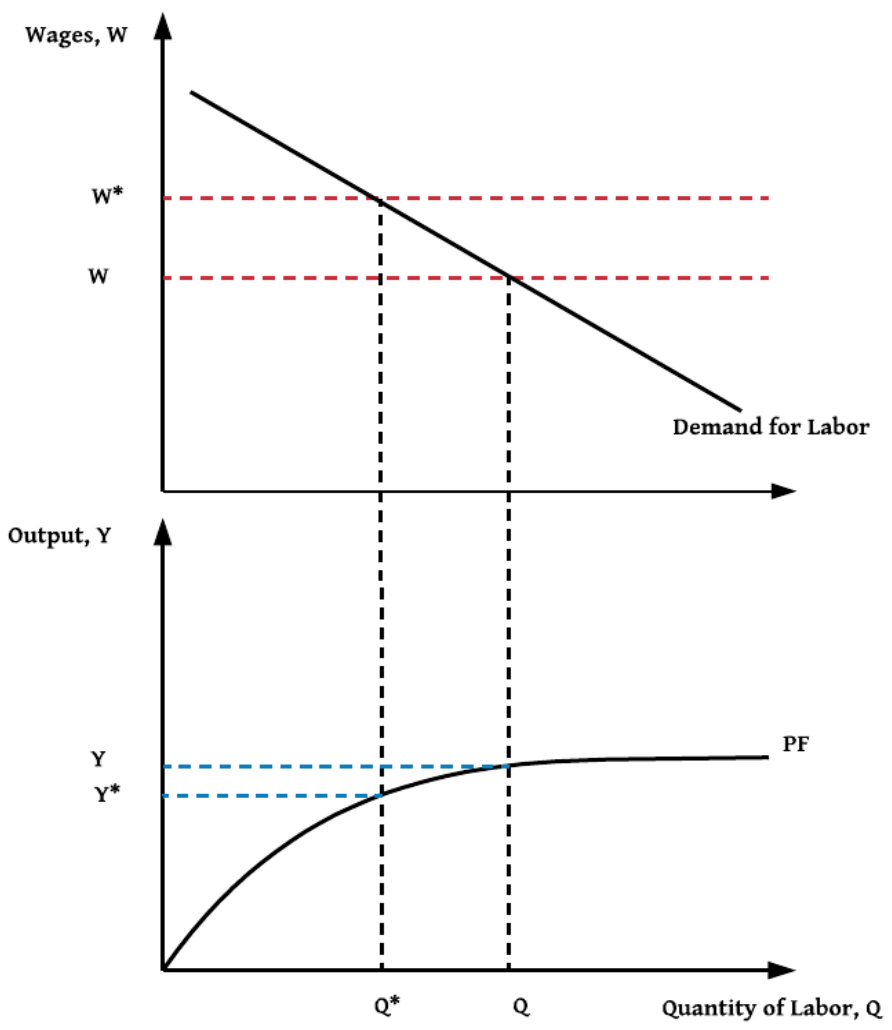

Figure 18.

Can Total Productivity Break Even?

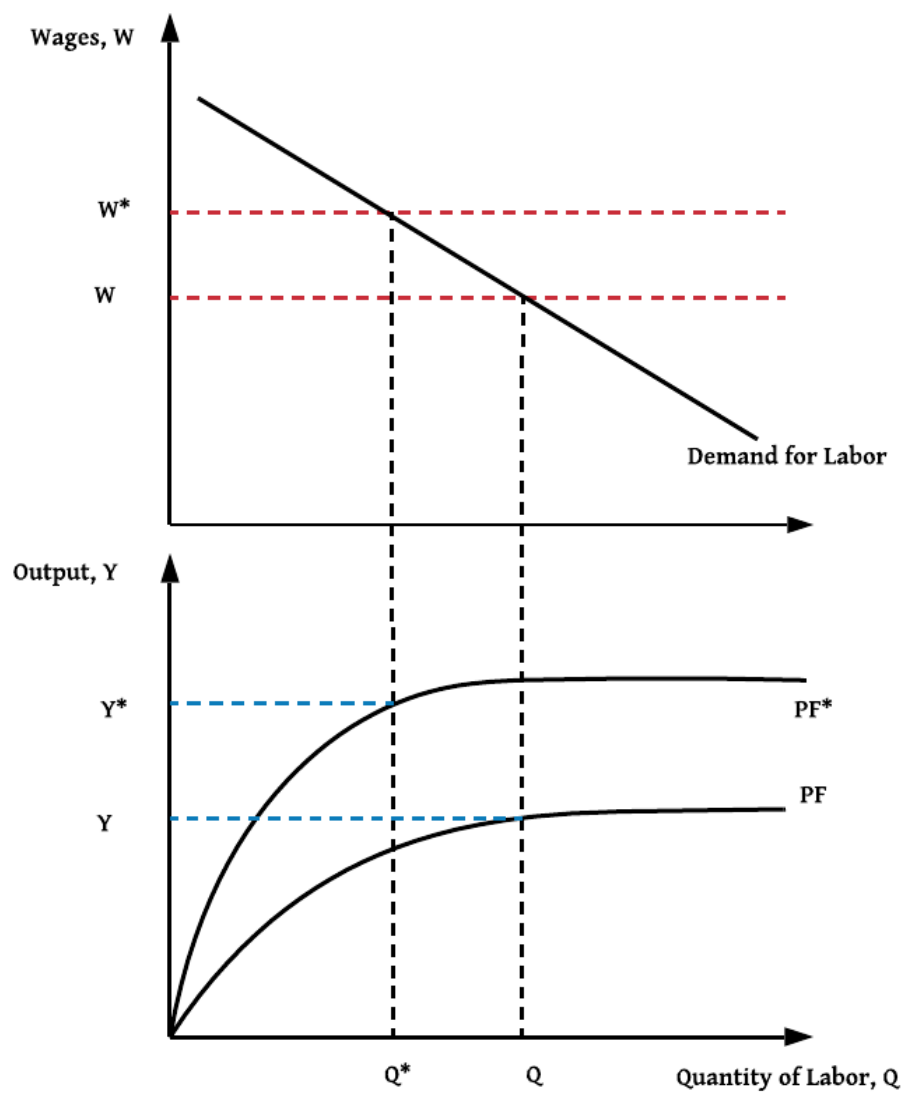

If productivity does not expand, such as in Figure 17, and quantity of labor decreases, we expect outright decreases in total productivity. However, Figure 18 paints a different picture, where the expanded production function, $\mathrm{PF}^{*}$, may actually eclipse total productivity lost from reducing the number of employed from $\mathrm{Q}$ to $\mathrm{Q}^{*}$. We expect that this will occur, but in a much lesser form. There are several reasons for these expectations. For one, it is unlikely that a shift toward a smaller base of marginally higher skilled employees will provide enough additional productivity to account for the loss of a number of less-productive employees. As an example, if two employees are laid off and replaced by one, would we expect that employee to produce twice as much output? Barring the expansion of increased/improved capital or employee training 
programs, it seems unrealistic to think that a sizable reduction in force wouldn't reduce productivity significantly.

\section{Non-Constant Elasticity Estimation}

Up to this point, all of our estimations have assumed that the elasticity for low-wage employment remains constant over our relevant period. In reality, we expect that the elasticity will change over time. Recall the previous section. For one, as the amendment pushes the cost of lower-wage workers higher, there is a corresponding decrease in the relative cost of employing higher-skilled workers that are above the mandated wage level. This pattern repeats for each year's wage hike, with every increase bringing wages of low-skill workers closer to those of high-skill workers (see wage compression). As the wage differential between skilled and unskilled workers becomes increasingly smaller, we expect that the aforementioned compositional employment change will hasten, increasing the disemployment effects for lowskilled workers.

Following these assumptions, we construct a final model using an elasticity that begins at our median value of -0.2 in 2021 and increases in magnitude by 0.025 every year following. Since we are uncertain of the actual magnitude of the elasticity change (there are essentially no papers that attempt to show how disemployment effects change over time), we will only briefly discuss these effects, limiting our analysis to employment changes. Figure 19 illustrates the control, the medium estimate, and our new model's forecast. 
Figure 19.

Non-Constant Elasticity Models Differ Notably in the Long Term

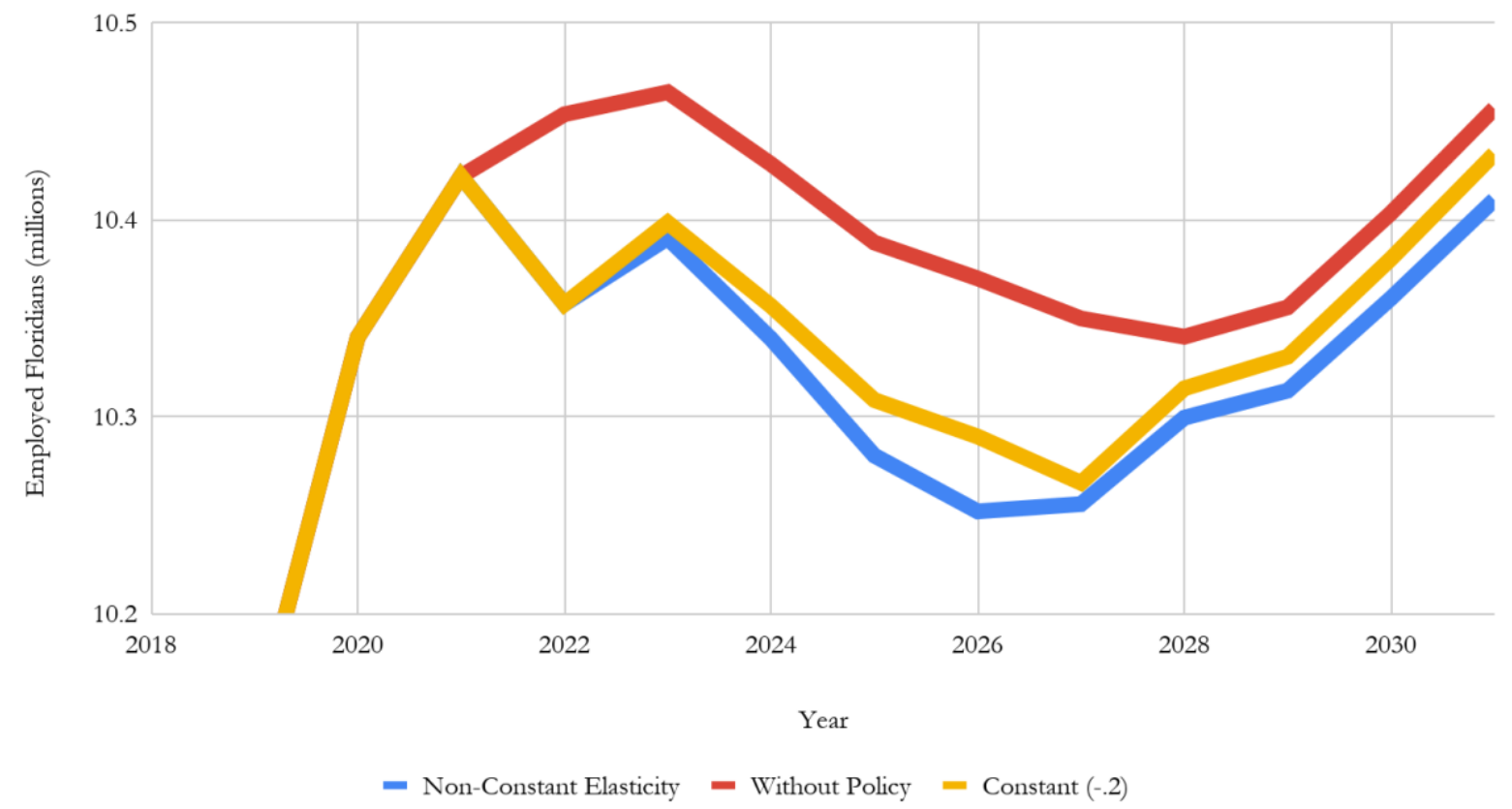

Using the same industry and population figures as our other models, we find that the nonconstant elasticity model predicts some sizable employment differences from our constant -0.2 forecasts. Most notably, employment in 2025 and 2026 is shown to be reduced by approximately 40,000 jobs when compared to our median estimate. Also, the inflation adjustment period after 2026 seems to have a lower level of employment, indicating that employment would struggle to return to the level of the control if the assumptions of this model are valid in reality.

Increases in Wage and The Income Effect for Workers

\section{Assessing the Income Effect}

In economics, we make the fundamental assumption that a consumer's objective is to maximize his/her level of utility, also known as the concept of utility maximization. In regards to this concept, consumer choice theory focuses on utility maximization by the consumption of goods. Market good consumption can be equally adversely and positively affected by the 
increase in minimum wages for individuals. The first effect we choose to focus on is known as the income effect, which describes the change in the consumption of goods as a result of a change in a consumer's purchasing power. Purchasing power increases as real income increases. If the market prices of goods are stagnant while nominal income increases, consumer demand for most goods will rise.

We say "most goods" because consumer goods are typically split into two categories: goods that are normal and goods that are inferior. Normal goods have a positive income elasticity of demand, signaling that the demand for these goods will increase parallel to the increase in consumer income. Inferior goods, on the other hand, are known to experience declines in consumer demand when consumer incomes increase. These goods are inferior because the demand for their substitutes, which are often costly, increases when consumer income increases. Inferior goods are usually of a lower quality, thus they are heavily impacted by substitute goods when income increases. Simply stated, consumer demand will rise as a result in an increase in consumer wages.

It is not uncommon to expect that an increase in the minimum wage would give lowwage workers more disposable income to buy market goods with. Generally, an increase in consumer spending would result in an economic boom. We decided to put this to the test and analyze worker incomes by comparing the dynamic multiplier model's baseline forecast to our forecast produced by the median elasticity estimate. The forecast produced by our elasticity estimate of -.2 denotes that there is an overall decline in incomes relative to the baseline forecast. In fact, we observe an average decrease in the incomes of workers to be about $.47 \%$ in the years 2021 to 2026 . We do, however, observe the decrease in workers incomes to shrink after 2027. This trend is observed in Figure 20. It is also important to note that although the declines in 
incomes get smaller as the years pass, workers would still be worse off after the passing of the amendments in regard to real income. When looking at the difference between our forecast and the baseline during the years 2027 to 2031 , we observe an average decline of about $.24 \%$.

Our analysis provides support to countering the income effect argument. Over time, we do perceive that the real incomes of workers will decline after the passing of the minimum wage amendment. Contrary to popular belief, this signifies the possibility that workers will not spend more money on consumer goods, perhaps limiting the benefits for Florida's economy.

Figure 20.

\section{Annual Expected Difference from Control, Total Income}

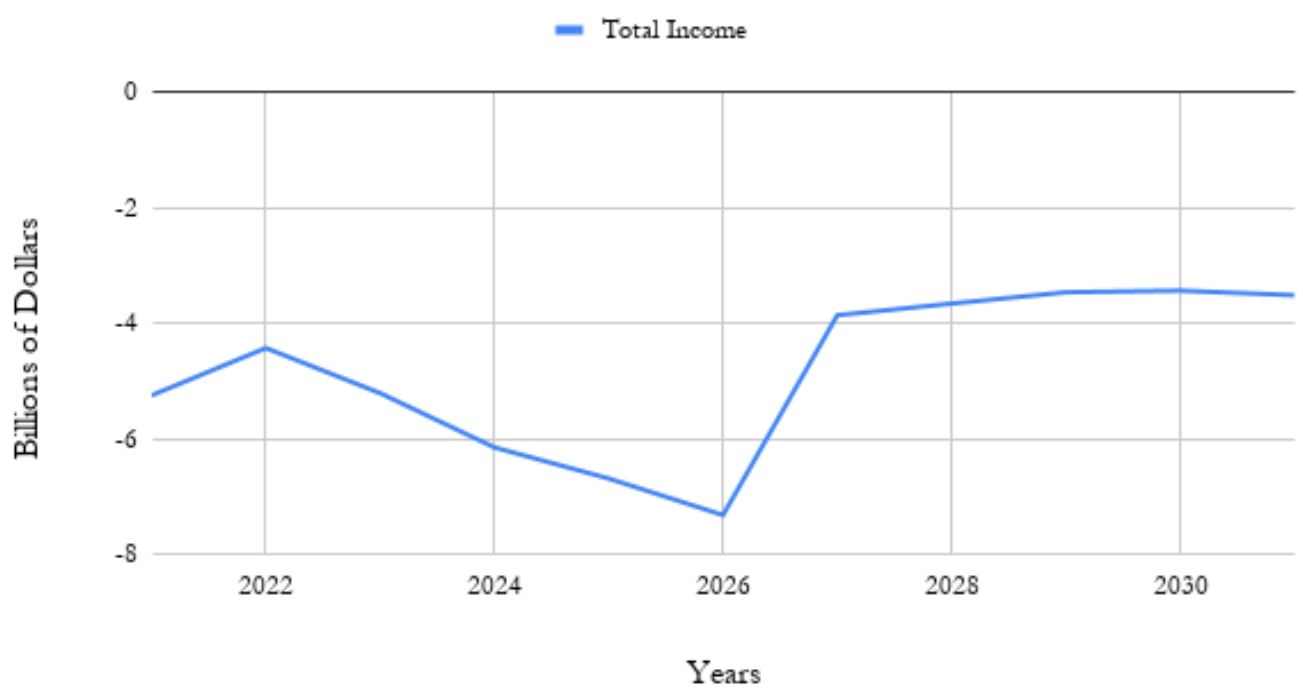

\section{Leisure as a Good: The Income Effect}

Though income effects primarily affect the demand for market goods, the demand for leisure can additionally be affected. This is where the substitution effect comes into play, depending on which effect takes dominance. Utility maximization for individuals can also derive 
from the availability of leisure time, which is defined to be any time away from work. If leisure is constructed as a normal good, an increase in income will ultimately lead to an increase in the demand for leisure. This concept also holds true for the labor market. For example: if an employee experiences an increase in income, the labor supply of a firm can potentially be negatively affected due to a greater inclination by the employee to take time off from work. Thus, the employee's total hours worked decreases, which could affect firms in the long run.

A decrease in total hours worked is one of the possible implications that arise due to an increase in wage. In this situation, it is vital to differentiate between a low-wage worker and a high-wage worker. This differentiation assists in the evaluation of how different types of earners react to the possibility of obtaining leisure time. For example, a worker earning $\$ 25$ per hour, whom we would consider being a high-wage worker, would associate giving up an hour of work in order to enjoy leisure time to be worth at least $\$ 25$ per hour. In the case of the low-wage worker, however, the costs are not as high to enjoy an hour of leisure time - resulting in a willing mindset to trade an hour of work for leisure.

Aside from leisure time, a minimum wage increase would also impact educational opportunities for Florida's population, often referred to as the schooling effect. Recent literature cites the population most affected by this, in particular to be a mixture of teenagers and those enrolled in post-secondary education, which results in large implications for the state of Florida. This will be discussed in detail below.

\section{A Review of the Schooling Effect as Substitution}

As discussed, raising the minimum wage will result in grand implications to the state of Florida. One of the major affected areas will be education - which will introduce some of the counterproductive byproducts of passing this legislation. For both current and future economic 
prosperity, education remains to be a vital source of skills and training for individuals entering the workforce. Often, the intentions of labor policymakers are benevolent; they are concerned with attempting to lift the less-prosperous out of poverty by raising worker incomes. However, we fear that this legislation may be counterproductive, as it may come at a cost to those it intends to help.

It is essential to begin by incorporating previous research on the topic, as there has been a rather contemporary uproar about the minimum wage and its effect on schooling. Neumark and Wascher first began to tackle this underlying complication in the 1990s, with their analysis of the minimum wage and school enrollment published in 1992. More recently, the duo revisited the topic in 2001, due to the importance of "reduced training opportunities or lowered educational attainment". ${ }^{43}$ They find that minimum wages reduce the acquisition of skills by the young. This conclusion has been criticized by the authors mentioned in the literature review, such as Evans and Turner (1995), who believe that the minimum wage variable used by Neumark and Wascher was misspecified in their model. The primary source of misspecification referenced by Evans and Turner comes from the definition of the school enrollment variable used in the model.

In order to refute the claims made, Neumark and Wascher utilize CPS data ranging from the late 1970s through the 1980s. They also choose to employ a broader definition of school enrollment suggested by critics, constructing it independently of employment. Their results are estimated in three different ways with data ranging from the months of May to October of each year. All three methods produce consistent results illustrating declining school enrollment. In addition to updating their estimation techniques, Neumark and Wascher decide to re-estimate through 1998 and still find a declining trend in school enrollment.

12 Neumark, David, and William Wascher. "Minimum Wages and Skill Acquisition: Another Look at Schooling Effects." Economics of Education Review 22.1 (2003): 1-10. 
To conclude their findings, Neumark and Wascher emphasize their persistent findings of negative effects of minimum wages on school enrollment; they appear to not differ much based on the definition of school enrollment as critics have mentioned. The prevalence of a minimum wage seems to decrease the proportion of enrolled teenagers in school, reducing skill acquisition among those who need it the most.

More currently, a researcher in the Department of Economics at the University of California, Santa Barbara released a paper analyzing the impact of the minimum wage and state college enrollment patterns. Chang Hyung Lee's 2018 study ${ }^{44}$ primarily focuses on data between 1990 and 2010. Lee emphasizes state college enrollment because most individuals enrolled are typically not as interested in pursuing the completion of a degree or certificate. The decision to enroll in state college is based on the availability or attractiveness of other alternatives, such as full-time employment.

Lee's estimation strategy involves looking at labor markets with various minimum wage setting authorities across boundaries. He pairs colleges located near state borders by distance in order to examine whether differing minimum wage policies in neighboring states result in any oddities in state college enrollment. State college enrollment can easily be influenced by a change in the minimum wage, as students are less likely to receive work-study or state-funded scholarships than their peers in universities. Thus, students are more likely to take out loans or pay their way through school, making the option to go to state college less affordable.

The data contains 914 state colleges and 16,021 school-by-year observations, concentrating on the Atlantic coast, Midwest, and South regions. The analysis also groups

\footnotetext{
44 Lee, Chang Hyung. "Minimum Wage Policy and Community College Enrollment Patterns." ILR Review, June 2019, doi:10.1177/0019793919855003.
} 
individuals based on their current and past work experience. Using the pair-by-year model, Lee finds a $10 \%$ increase in the minimum wage leads to a 4.4 to $5 \%$ decrease in the total enrollment of state college students. Moreover, in terms of part-time enrollment, Lee also finds a 10\% increase leads to a 5.2 to $6.1 \%$ decrease while the effect on full-time state college enrollments is insignificant and close to zero. These results suggest that part-time enrollments are primarily driving the results. The main finding might be the most surprising - as Lee comments that the negative correlation observed is only among individuals employed for at least 50 weeks prior to the survey.

His findings elicit discussion in regards to why a negative correlation between an increase in the minimum wage and a decrease in school enrollment exists. For one, individuals with stable employment pursuing part-time schooling might find it more cost-effective to return back to work after a hike in the minimum wage, as part-time students might perceive an opportunity cost in terms of lost income by deciding to enroll in school rather than work. However, it is quite possible that this effect might reverse when individuals returning back to the labor force are better informed of their abilities and desire additional schooling to attain better skills.

\section{Channels of Adjustment: Education}

The Florida Department of Education estimates the number of high schoolers in the state of Florida during the academic year of 2017-18 to have been 1,062,897, and the number of high schoolers during the 2018-19 academic year to be 1,065,948. ${ }^{45}$ The Annual Outcomes Report is also comprised of a section titled "Florida Continuing Education Data", which details the next

45 “Annual Outcomes Report.” Florida Department of Education, 2018, Florida Education and Training Placement Program. 
steps of high school graduates. The most recent year contributing to this section is the academic year of 2016-17, which includes responses from 124,645 high school graduates. Out of those, roughly $60 \%$ of respondents $(74,749)$ answered with the intention to continue their education. We believed the two most surprising differences to be between the amount of respondents enrolling in state college and the amount enrolling in Florida's university system. These differences, with the main categories in bold, are discussed in Table 10.

Table 10.

Florida Continuing Education Data In Florida College System AA Program In State University System
$\%$ of Respondents

44,849

31,712

$\mathbf{2 4 , 8 4 7}$

As outlined in Lee's study, we observe the majority of survey respondents from the 201617 academic year to be more drawn to state college rather than attending a university. The number of respondents going to state college after graduating from high school was roughly twice as much as those going to university, and out of those enrolling in state college, $70 \%$ were attending in pursuit of an AA degree.

Being that this is a survey, there are some potential drawbacks to take note of. Response bias - or the feeling to answer what is socially acceptable - might have skewed these answers. In practical terms, this signifies that respondents could have answered untruthfully to conform to societal norms. Additionally, nonresponse bias could have played a part in obtaining results. Nonresponse bias occurs when respondents do not answer, which is usually a problem of surveys, deeming them unreliable. Since the current academic year is $2018-19$, the survey results are outdated - signaling that answers could have changed in later years in favor of an increase in respondents attending universities or vice versa. Nevertheless, we assume that results would stay consistent in the years following the 2016-17 academic year, with little to no variation in the 
answers. We make this assumption because state college "is the primary access to higher education for Floridians, including recent high school graduates and returning adult students"46 and is a cheaper alternative for most students than attending a university. Access to a state college could similarly play a role in graduates deciding between the two types of schooling to pursue. Students that are geographically closer to one of the 28 community and state colleges might prefer to stay nearby and save money (i.e. living at home vs. renting an apartment) instead of moving to attend one of the 12 universities in the state of Florida.

Researchers like Lee continue to make strides towards understanding the true effect of wages increases on school enrollment. In the state of Florida, we believe this will lead to massive declines in the number of skilled workers in the long run. The population at stake will be those enrolled at the high school or state college level, as they have not yet entered into four-year universities, and thus, will have less to lose by going into the workforce immediately after the occurrence of a spike in the minimum wage. The decision by low-skilled workers to disregard education in the hopes of finding a job has many repercussions. Figure 21 demonstrates the labor market operating at equilibrium, with dotted lines representing the optimal wage and quantity of labor. As the higher minimum wage policy is implemented, market inefficiencies are exposed. These inefficiencies are represented by the triangle labeled deadweight loss in Figure 22.

46 “The Florida College System.” Home | The Florida College System, www.floridacollegesystem.com/. 
Figure 21 .

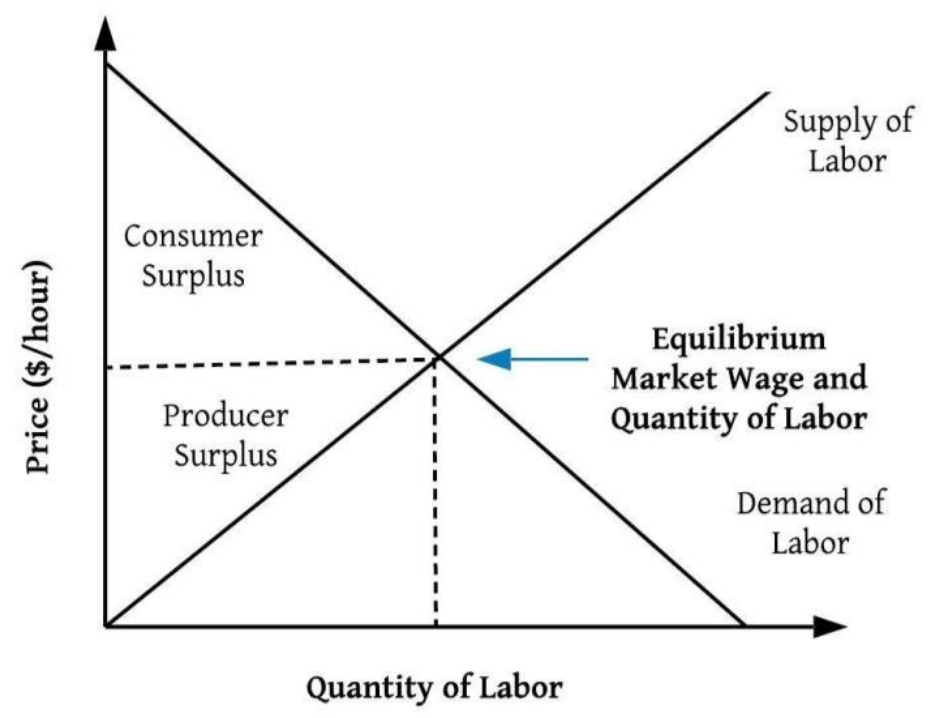

Figure 22.

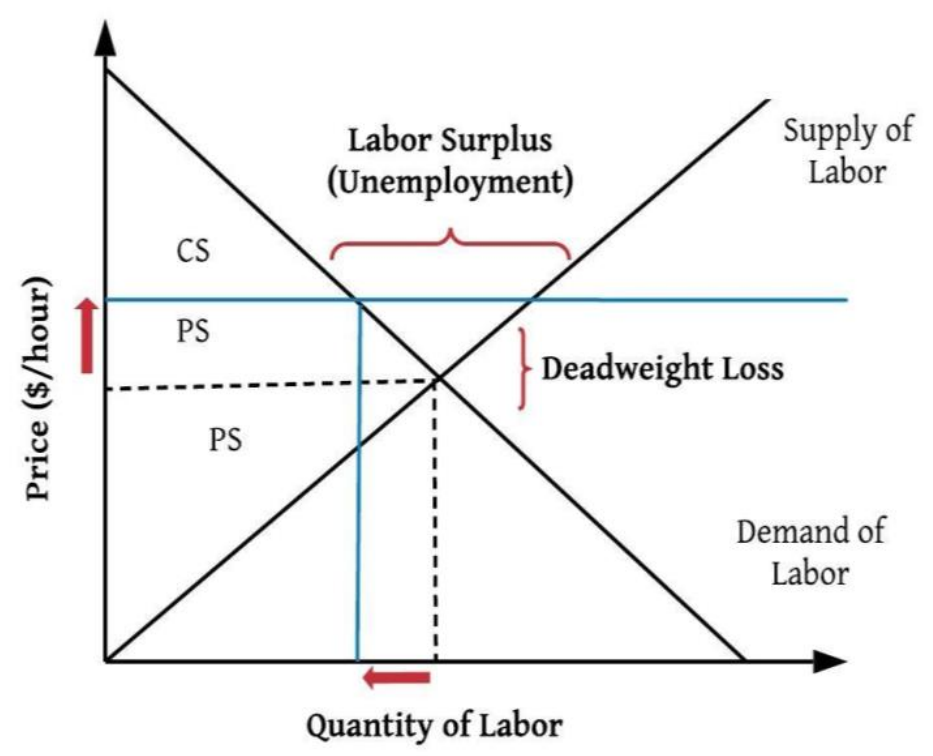

Fenstemacher | Fisher | Hadzalic | Hillebrandt 
Figure 22 also displays what happens to consumer surplus as the minimum wage increases. Consumer surplus (otherwise known as the employer's surplus) decreases as the producer surplus and deadweight loss grow to inhibit some of the original consumer surplus. Producer surplus (otherwise known as the employee's surplus) increases - but it also decreases by the small triangle of deadweight loss. The quantity demanded of labor, shown by the vertical blue line, decreases in comparison to the equilibrium quantity of labor demanded. The supply of labor, however, increases. This causes an excess in the supply of labor, as there are more lowskilled workers than demanded by firms. Unemployment is the main result of an excess supply in labor.

This is a major concern for Florida if the implementation of the minimum wage policy goes through. The effects on education will be detrimental, as individuals desiring to obtain more skills by going to school will turn to working as a result of being lured by the higher wage. As previously established, the majority of individuals attending college in the state of Florida are state college enrollees. This particular proportion of the school population is more susceptible to joining the labor force because they are usually paying out-of-pocket costs to attend college. If the minimum wage increases, these students will stop attending school due to the nature of the low costs associated with leaving a state college. In the short-run, more workers in the labor force might signal economic prosperity for Florida. However, in the long-run, the labor force will fall into the trap of continuing to be comprised of low-skilled workers with little to no educational training. An unskilled labor force will simply wreak havoc on the future of Florida's economy and will ultimately result in a less prosperous outcome for residents. In the worst case 
scenario, this will dissuade people from moving to Florida and encourage people to move out of Florida in search of new and better opportunities.

\section{Quantifying the Schooling Effect}

In order to appropriately describe the impact that the schooling effect would have on Florida, we choose to quantify the number of total state college students that would be affected by an increase in the minimum wage. Our first step in our methodology involves finding the total number of state college students enrolled in the state. We find there to be 733,000 students enrolled in Florida's state colleges, according to The Florida College System. ${ }^{47}$ Just as estimating changes in employment required elasticities, we deem elasticities necessary to calculate the affected schooling population. We gather the required elasticities from the paper previously mentioned, written by Lee. His method concentrated on the following three regions: the Atlantic coast, Midwest, and South regions. For this reason, we are able to estimate the changes due to the schooling effect, as the elasticity pertains to the specific coast Florida is located on.

Lee's study results in the conclusion that a $10 \%$ increase in the minimum wage will lead to between 4.4 to $5 \%$ decrease in total state college enrollments. Subsequently, we proceed to use the percent changes in the increase of the minimum wage from the years 2021-2026, demonstrated in the table found in Appendix 7. In order to find the percent decrease in state college enrollments with respect to both the 4.4 and $5 \%$ elasticity, we perform a point estimation and divide each numerical decrease by 100 to get them into percent form.

46،The Florida College System.” Home | The Florida College System, www.floridacollegesystem.com/. 
The penultimate step to finding the total number of state college enrollments affected by the amendment each year during 2021 to 2026 is to take the percent decrease and multiply it to the original number of state college enrollments reported by The Florida College System. For instance, if interested in the $4.4 \%$ elasticity in conjunction with the number of college enrollments affected in 2021, we simply take the reported percent decrease (0.08) and multiply it by the initial number of enrollments $(733,000)$. This results in a numerical decrease of 58,640 state college enrollments during the year of 2021. We then subtract this numerical decrease from the starting point of state college enrollees, which is 733,000 , to get 674,360 total state college enrollments for the year 2021. In order to calculate 2022's change in total state college enrollment, we use the new number mentioned earlier $(674,360)$ as our baseline. Each year follows this-method. We follow this method for the 5\% elasticity as well.

As a result, we predict a decline of total state college enrollment to occur throughout the course of the six years, both during and after the passing of the amendment. Specifically, in terms of the $4.4 \%$ elasticity, we expect a decrease of 175,111 total state college enrollments. The $5 \%$ elasticity results in a decrease of 209,446 total state college enrollments. Both of these numbers factor in part-time and full-time enrollment. The implications of these results are tremendous, as they foreshadow a potential danger for the future of the Florida economy. An increase in the amount of Floridians leaving state college for the possibility of earning a higher minimum wage will hurt them in the long run, as they may forego higher earnings in the future and will miss out on necessary skills needed for career development.

\section{Channels of Adjustment: Unemployment}

As illustrated in Figure 21, the labor surplus that can primarily be attributed to the influx of individuals in pursuit of employment will eventually lead to unemployment through various 
mechanisms in Florida and is our main concern. In addition to the introduction of unskilled workers, employment in Florida will also be heavily affected. Unemployment will be presented in many forms for workers - such as a loss of hours or a loss of employment benefits.

Our economic impact study revolves around the impacts on employment. With the research that has already been conducted (which has been detailed in our literature review), we find unemployment effects to be a cause for concern for Floridians. Previous research outlines unemployment elasticities which we use to reach a conclusion about the loss of jobs for the state of Florida. Likewise, research has also been conducted to study the changes in employee hours. Conducted in a state with similar economic conditions, Jardim et al. $(2017)^{48}$ examined unemployment as a result of raising the minimum wage in Seattle. Evidence demonstrates that the hours of low-skilled workers fell by $6.9 \%$ during the three quarters when the minimum wage was raised from $\$ 9.47$ to $\$ 13$ per hour in 2016 . This resulted in a loss of around 3 million hours worked per calendar year and approximately 5,000 jobs. More importantly, Jardim et al. report that though wages were increased, the monetary value of the hours lost outweighed the increase in wages. The researchers calculated the monthly salary of a low-wage worker, which was $\$ 1,900$. Reducing employee hours resulted in a loss of $\$ 130$ per month, while the increase in wage would only recover $\$ 56$ of this loss. The net loss would then be $\$ 74$, which is quite sizable for the low-wage worker.

Taking into consideration the current research, we emphasize the impacts that raising the minimum wage will have on Florida's workers. A low-wage worker might not necessarily lose

\footnotetext{
${ }^{47}$ Jardim, Ekaterina, et al. "Minimum Wage Increases, Wages, and Low-wage Employment: Evidence from Seattle." No. w23532. National Bureau of Economic Research, 2017.
} 
their job, but they would see either a reduction in hours worked or a loss in benefits.

Additionally, an increase in the minimum wage will create barriers to entry in the labor market for workers, making it harder to find a job for those that are not yet in the labor force and will cause an increase in unemployment for the state. Going back to the Seattle studies, an update to Jardim et al.'s (2017) paper published in October 2018 which was mentioned in the literature review claims 'Seattle's minimum wage ordinance appears to have delivered higher pay to experienced workers at the cost of reduced opportunity for the inexperienced." ${ }^{49}$ Extending this to Florida, we fear that an increase in wages will induce hardships when finding jobs among lowskilled workers. This will contribute to the overall increase in the unemployment rate in Florida, and will not be conducive to building a flourishing economy.

\section{Channels of Adjustment: Firm Spillover Effects}

Spillover effects are known to be secondary effects coming from primary effects. In this context, we relate spillover effects to be concerned with firms in Florida. To evaluate any spillover effects that increasing the minimum wage might have on firms, it is vital to examine any neighboring states. Florida's neighboring state is Georgia, which has their state minimum wage set at $\$ 5.15$ per hour. ${ }^{50}$ Since the state minimum wage is less than the federal minimum wage, workers covered by the federal Fair Labor Standards Act (FLSA) are subject to being paid the federal minimum wage, which is $\$ 7.25$ per hour.

The fact that a neighboring state has a lower mandated minimum wage might be problematic for firms in Florida. If the legislation of increasing the minimum wage passes, firms

\footnotetext{
47 Jardim, Ekaterina, et al. “Minimum Wage Increases and Individual Employment Trajectories.” No. w25182. National Bureau of Economic Research, 2018.

${ }^{49}$ Brainerd, Jackson. "State Minimum Wages: 2019 Minimum Wage by State." State Minimum Wages | 2019 Minimum Wage by State, 7 Jan. 2019, www.ncsl.org/research/labor-and-employment/state-minimum-wagechart.aspx\#Table.
} 
would be required to pay their low-skilled employees up to $\$ 15$ per hour - even if they feel as though their employees are not worth as much. If a firm believes they can find cheaper labor elsewhere - like in the state of Georgia - this will pose as a good opportunity for firms to relocate in search of the alternative, which is cheaper labor. This could potentially drive firms out of the state of Florida into neighboring states. Moreover, Florida's state government will have to spend more money to design incentive packages in order to make firms reconsider staying in the state.

An increase in the minimum wage would lead to unintended consequences, making both firms and employees suffer. Florida's future would also be at stake, as firms would view this state as being less attractive to stay in or move to. As a result, this would lead to the loss of jobs and opportunities for lower-skilled workers to enter the labor force. If firms choose to relocate, Florida's tax revenues would substantially decrease. Just in the year of 2018, businesses generated 2.2 billion dollars in corporate income taxes. Thus, when imposing legislation aimed to increase the minimum wage, we caution to think about the spillover effects that could occur and the long-lasting effects they would have on Florida.

\section{Channels of Adjustment: Automation}

The final adjustment channel to be discussed is relatively new but is becoming a large threat to jobs. The advancement of technology in recent years has spurred automation. We see evidence of this already happening, with restaurants and grocery stores incorporating self-order and check-out machines. The emergence of automation in these low-skilled labor industries is a threat, as technology is typically of much lower cost relative to employees of a firm. It might also be easier for firms to substitute a portion of low-skilled jobs with self-service machines which are able to operate on their own. 
In particular, Grace Lordan and David Neumark $(2018)^{51}$ study the effect of minimum wage increases on automatable jobs, focusing on low-skilled labor. Using CPS data from 19802015, Lordan and Neumark distinguish between occupations that are intensive in automatable tasks. They, in addition, account for urban and non-urban areas in each state. Their results find that increasing the minimum wage significantly declines the share of automatable jobs held by low-skilled labor. The manufacturing sector has the largest effects on the share of automatable tasks, of which the elasticity is -0.18 . To add to that, they find that the largest effects occur for the oldest and youngest workers, for females, and for African-Americans. Though the impact on low-skilled workers is investigated, Lordan and Neumark also suggest that the increases in the minimum wage will shape the type of jobs low-skilled workers will hold in the future, and will also generate employment hardships for them. Similarly, they find that some of the adverse effects felt by low-skilled workers will be offset by increased employment opportunities for higher-skilled workers. This implies that most of the low-skilled workers will suffer in the long run, as businesses will turn to automation to gradually phase out manual labor tasks.

Automation is yet another unintended consequence of raising the minimum wage. We fear that this would phase out the jobs that are predominantly comprised of low-skilled workers. The hospitality and food service industries could in fact make a quick and easy switch to choosing technology over employing workers - which would be unfortunate for the future of Florida's workers and needs to be put into consideration when proposing a legislative change concerning an increase in the minimum wage.

${ }^{50}$ Lordan, Grace, and David Neumark. "People Versus Machines: The Impact of Minimum Wages on Automatable Jobs." Labour Economics 52 (2018): 40-53. 


\section{Addressing Recent Research}

CBO: The Effects on Employment and Family Income of Increasing the Federal Minimum Wage

While we were concerned with studying the impact on Florida due to increasing the minimum wage, the Congressional Budget Office (CBO) also seemed to share the same concern. In July of 2019, the CBO released their own study regarding the effects of employment and family income after increasing the federal minimum wage ${ }^{52}$. In order to analyze the impacts of increasing the minimum wage by the year 2025, they focused on three minimum wage points in comparison to the federal mandated minimum wage of $\$ 7.25$ per hour: $\$ 10$ per hour, $\$ 12$ per hour, and \$15 per hour. These wage points are referred to as "options" by the CBO; an overview of the results for each option can be viewed in Table 11 below.

Table 11.

\begin{tabular}{|c|c|c|c|c|c|}
\hline Options & $\begin{array}{l}\text { Number of } \\
\text { Workers } \\
\text { Whose } \\
\text { Wages } \\
\text { Would } \\
\text { Increase }\end{array}$ & $\begin{array}{l}\text { Number of } \\
\text { Workers } \\
\text { Indirectly } \\
\text { Affected }\end{array}$ & $\begin{array}{l}\text { Number of } \\
\text { Workers } \\
\text { Who Would } \\
\text { Become } \\
\text { Jobless }\end{array}$ & $\begin{array}{l}2 / 3 \text { Certainty } \\
\text { of Results }\end{array}$ & $\begin{array}{l}\text { Number of } \\
\text { People } \\
\text { Moving Out } \\
\text { of Poverty } \\
\text { Threshold }\end{array}$ \\
\hline$\$ 10$ & 1.5 million & 2 million & $\begin{array}{l}\text { Decrease of } 0 \\
\text { to } 0.1 \text { million }\end{array}$ & $\begin{array}{l}\text { Decrease of } 0 \\
\text { to } 0.1 \text { million }\end{array}$ & $*$ \\
\hline$\$ 12$ & 5 million & 6 million & 0.3 million & $\begin{array}{l}\text { Decrease of } 0 \\
\text { to } 0.8 \text { million }\end{array}$ & 0.4 million \\
\hline$\$ 15$ & 17 million & 10 million & 1.3 million & $\begin{array}{l}\text { Decrease of } 0 \\
\text { to } 3.7 \text { million }\end{array}$ & 1.3 million \\
\hline
\end{tabular}

Source: Congressional Budget Office.

51 "The Effects on Employment and Family Income of Increasing the Federal Minimum Wage." Congressional Budget Office. 8 July 2019. 16 July $2019<$ https://www.cbo.gov/publication/55410>. 
Because our economic impact study involved us devising an estimation method to estimate changes in Florida's employment levels, we were particularly interested in how the CBO went about estimating employment changes in the entirety of the United States. Similar to one of our steps, the $\mathrm{CBO}$ utilized a range of elasticity estimates found in the academic literature to generate their own lowend, medium-, and high-end estimates. The range of elasticity estimates $\mathrm{CBO}$ found can be seen in Table 12. As you can see, CBO's medium estimate of -0.25 only differs from our mid-range employment elasticity estimate by 0.05 .

\section{Table 12.}

\begin{tabular}{|c|c|c|}
\hline Study & $\begin{array}{l}\text { Short-Run } \\
\text { Elasticities }\end{array}$ & $\begin{array}{l}\text { Ratio of Long-Run to Short- } \\
\text { Run Elasticities }\end{array}$ \\
\hline Cengiz and others (2019) & 0.4 & 1.0 \\
\hline Cengiz (2019) & 0.3 & 1.0 \\
\hline Derencourt and Montialoux (2018) & 0.2 & 1.0 \\
\hline Bailey, DiNardo, and Stuart (2018) & -0.1 & 2.0 \\
\hline Aaronson, French, and Sorkin (2018) & -0.2 & 2.0 \\
\hline Neumark, Schweitzer, and Wascher (2004) & -0.2 & n.a. \\
\hline CBO's Median Estimate & -0.25 & 1.5 \\
\hline Gopalan and others (2018) & -0.9 & n.a. \\
\hline Monras (2019) & -1.0 & 1.5 \\
\hline Meer and West (2015) & -1.2 & 1.7 \\
\hline Jardim and others (May 2018) & -1.7 & n.a. \\
\hline Clemens and Wither (2016) & -1.7 & n.a. \\
\hline
\end{tabular}

In terms of the methodology, the $\mathrm{CBO}$ analysis encompasses a wide range of the U.S. population. For example, the demographics of the population they were concerned with were teenagers, part-time workers, adults without a high school education, non-workers, and children. For the purpose of our study, we placed a greater emphasis on low-wage workers ages 18 to 64 . They gathered information on these demographics from the CPS, using sample weights as each observation in the survey respectively represents a number of people. Our approach differs with 
respect to theirs - instead of using sample weights to represent a number of people, we used industry codes and found the proportion of low-wage workers in each industry to use as our sample weights. Florida's data was a bit messy, as we were missing data from certain PUMAs. This resulted in the inability to correctly assign weights to each observation, leading us to use the industry weight strategy. It appeared as though the CBO also ran into the same difficulty as we did, with many of the survey respondents choosing to not report their hourly wages. We encountered this difficulty with workers tending to under-report their hourly wages in conjunction to sometimes neglecting to report any wages at all. To fix this, the CBO calculated the hourly wages as usual, defining it to be the earnings per week divided by the usual hours. They, in addition, moved non-reported wages closer to the mean wages of workers with similar characteristics. Our way of addressing these discrepancies in the data were to exclude low-wage workers that did not earn, at the bare minimum, the tipped wage in Florida. Our weights were distributed differently across our central populations; nevertheless, the ideology between both us and the $\mathrm{CBO}$ remains consistent.

The next comparison we were most interested in was a comparison of results between our study and the CBO's. Their medium estimate reports a job loss for 1.3 million workers in the United States. Using a report by the U.S. Department of Labor detailing the labor force status of the civilian non-institutional population for both Florida and the United States ${ }^{53}$, we are able to find out if our results align. To obtain an average of Florida's civilian labor force in 2018, we add up the seasonally adjusted population and divide by 12 . This results in 9,864,083 workers. In

\footnotetext{
52"Labor Force Status of the Civilian Noninstitutional Population." 21 June 2019. U.S. Department of Labor, Bureau of Labor Statistics, Local Area Unemployment Statistics Program, in cooperation with the Florida Department of Economic Opportunity, Bureau of Workforce Statistics and Economic Research. 16 July 2019

$<\mathrm{http}$ //lmsresources.labormarketinfo.com/library/press/fl-us.pdf $>$.
} 
order to obtain the average for the United States civilian labor in 2018, we follow the same method to get a total of $1,869,169,000$ workers. This signals that Florida's civilian labor force comprises $5 \%$ of the country's total labor force. Instrumenting this logic, we then apply Florida as $5 \%$ of the CBO's estimated job loss due to the median elasticity estimate. We find that in terms of the CBO's estimate, Florida's civilian labor force contributes 65,000 jobs to the United States civilian labor force. This is good news, as it shows that indeed our estimates do align. Our economic impact analysis results in a job loss of 43,461. Although the CBO's estimate is roughly 22,000 greater than our estimate, it is also important to keep in mind that the elasticity they use to calculate job loss is $0.05 \%$ greater than ours, which would explain the differences in estimates between our studies.

The CBO concludes that although the earnings and incomes of most low-wage workers would increase, this increase in income would certainly come at a steep price. They fear other low-wage workers would become jobless, causing a drastic decrease in family income. In some cases, the fall in family income would push workers and their families below the poverty threshold, which would demonstrate how the increase in the federal minimum wage could be counterproductive for some of the workers it desperately attempts to help. Overall, our results appear to mimic the findings that the $\mathrm{CBO}$ estimates and draws a similar conclusion.

\section{Final Thoughts}

In conclusion, there are several key takeaways from our analysis. For one, the academic literature most commonly estimates effects that coincide with the conceptual framework laid out in classical theory. We suppose that there is merit to using the most frequently occurring estimates, as they result from independently identified models across many 
papers. Secondly, our distribution and industry analyses warn us that Florida may be particularly vulnerable to mandated wage increases, as there are high numbers of low-wage workers all around the state. More specifically, there are 2.7 million Floridians that earn an hourly rate at or below $\$ 15$ per hour. Thirdly, we expect that there will be fairly sizable reductions in employment over the duration of the amendment, and during the adjustment period that follows. Our central models using elasticities of -0.1 to -0.3 predict reductions of 40,650 to 117,289 jobs on average. Finally, we consider some of the numerous indirect effects that we may see as a result of these wage increases.

Our models predict that there will be a reduction in total social services expenditures on average over the six years of the policy, with only the first wage hike eliciting an increase in expenses. While we did not expect these results, they likely come as a result of reduced benefits paid to those who have risen above the income threshold for certain programs. Regardless, the magnitude of these reductions represents an average reduction of $.01 \%$ to $.03 \%$ of total benefits expenditures in Florida. We also estimate total tax receipts for state and local governments would be reduced by approximately one billion dollars on average annually over the duration of the policy. The social services and tax revenue effects are critical to understanding the total impact of this legislation, but they do not complete the picture. Last but not least, our final sections discuss some of the lesser-known, more-nuanced risks of raising minimum wages. Amongst these are reduced education level, increased automation, and compositional shifts in the labor force. The former of which threatens future earning power in exchange for current earnings, and the latter two potentially damaging employment opportunities for low-skill workers in general. Overall, the results presented in this report indicate that we should expect net adverse effects if the proposed minimum wage amendment passes. 
Appendix 1

\begin{tabular}{|c|c|c|}
\hline Year & Minimum Wage & Percent Change from Prior year \\
\hline 2005 & 6.15 & $19.4 \%$ \\
\hline 2006 & 6.40 & $4.1 \%$ \\
\hline 2007 & 6.67 & $4.2 \%$ \\
\hline 2008 & 6.79 & $1.8 \%$ \\
\hline 2009 & 7.21 & $6.2 \%$ \\
\hline 2010 & 7.25 & $0.6 \%$ \\
\hline 2011 & 7.31 & $0.8 \%$ \\
\hline 2012 & 7.67 & $4.9 \%$ \\
\hline 2013 & 7.79 & $1.6 \%$ \\
\hline 2014 & 7.93 & $1.8 \%$ \\
\hline 2015 & 8.05 & $1.5 \%$ \\
\hline 2016 & 8.08 & $0.4 \%$ \\
\hline 2017 & 8.10 & $0.2 \%$ \\
\hline 2018 & 8.25 & $1.9 \%$ \\
\hline 2019 & 8.46 & $2.5 \%$ \\
\hline
\end{tabular}




\section{Appendix 2}

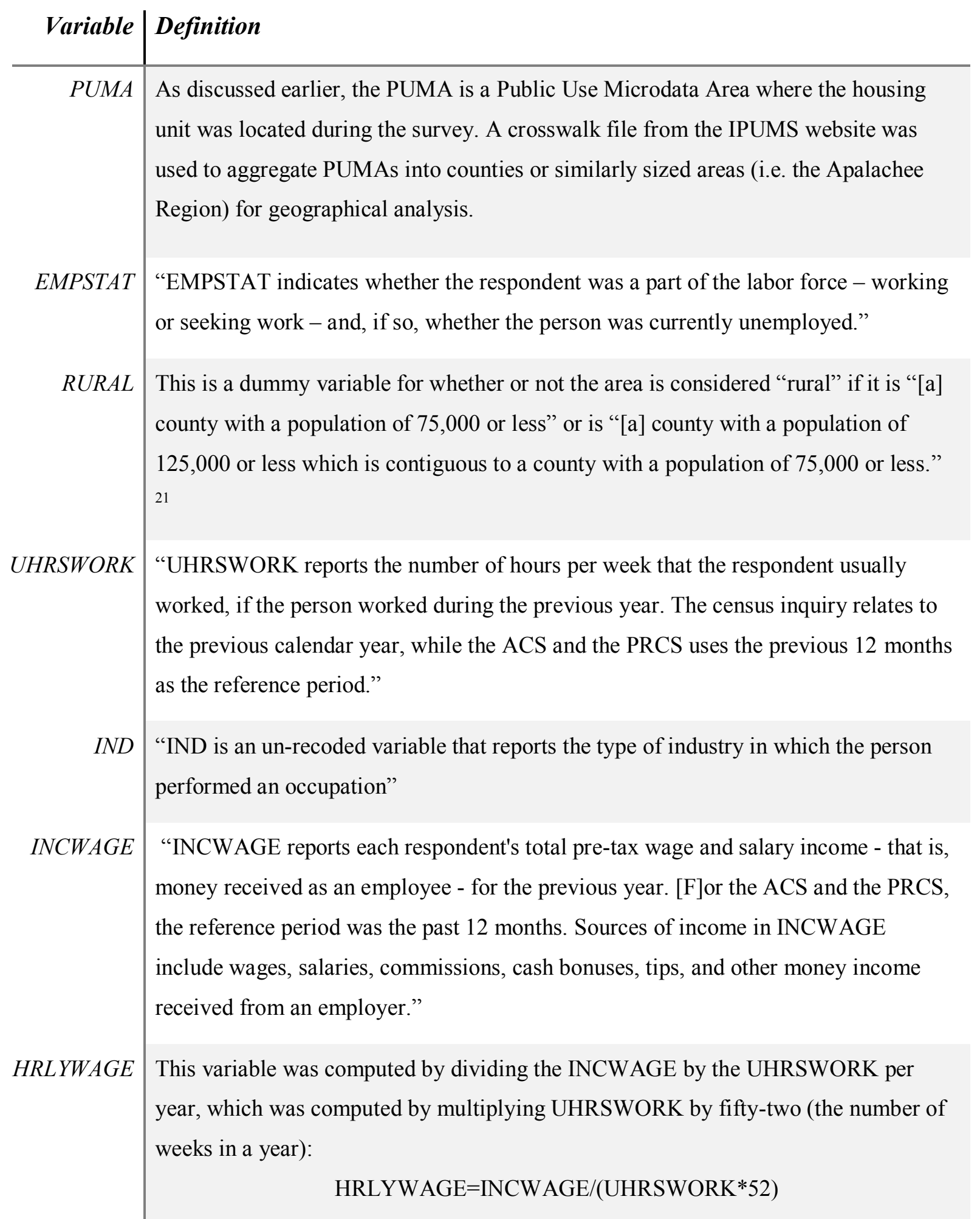




\section{Appendix 3}

\begin{tabular}{|c|c|c|c|c|c|c|}
\hline Industry & $\begin{array}{l}\text { Baseline } \\
\text { Avg 2021- } \\
2026\end{array}$ & $\begin{array}{l}\text { Forecasted } \\
\text { Avg 21-26 }\end{array}$ & Difference & $\begin{array}{l}\% \\
\text { Different }\end{array}$ & $\begin{array}{l}2017 \\
\text { Median } \\
\text { Wage }\end{array}$ & $\%<\$ 15 /$ hour \\
\hline Utilities & 26,119 & 24,464 & $-1,655$ & -6.336 & 27.4 & 17.06 \\
\hline Mining & 30,885 & 30,346 & -539 & -1.745 & 24.04 & 18.3 \\
\hline $\begin{array}{r}\text { Administrative, } \\
\text { Support, Waste } \\
\text { Management, and } \\
\text { Remediation Services }\end{array}$ & $1,006,847$ & $1,001,847$ & $-5,000$ & -0.497 & 23.08 & 20.03 \\
\hline Information & 176,801 & 175,844 & -957 & -0.541 & 24.04 & 23.26 \\
\hline Finance and Insurance & 712,382 & 708,037 & $-4,345$ & -0.610 & 22.65 & 25.17 \\
\hline Wholesale Trade & 437,922 & 435,549 & $-2,373$ & -0.542 & 20.51 & 29.56 \\
\hline $\begin{array}{r}\text { Educational Services; } \\
\text { Private }\end{array}$ & 252,094 & 249,284 & $-2,810$ & -1.115 & 19.23 & 31.91 \\
\hline Manufacturing & 387,542 & 384,513 & $-3,029$ & -0.782 & 20.83 & 32.91 \\
\hline $\begin{array}{r}\text { Professional, } \\
\text { Scientific, and } \\
\text { Technical Services }\end{array}$ & 912,527 & 904,634 & $-7,893$ & -0.865 & 21.15 & 33.24 \\
\hline $\begin{array}{r}\text { Healthcare and Social } \\
\text { Assistance }\end{array}$ & $1,458,885$ & $1,450,929$ & $-7,956$ & -0.545 & 19.23 & 35.32 \\
\hline $\begin{array}{r}\text { Transportation and } \\
\text { Warehousing }\end{array}$ & 441,977 & 438,548 & $-3,429$ & -0.776 & 19.23 & 37.77 \\
\hline Construction & 740,996 & 727,209 & $-13,787$ & -1.861 & 17.31 & 41.03 \\
\hline $\begin{array}{c}\text { Other Services (Except } \\
\text { PublicAdministration) }\end{array}$ & 889,419 & 885,197 & $-4,222$ & -0.475 & 14.42 & 53.45 \\
\hline $\begin{array}{r}\text { Arts, Entertainment, } \\
\text { and Recreation }\end{array}$ & 369,671 & 366,876 & $-2,795$ & -0.756 & 14.42 & 54.64 \\
\hline Retail Trade & $1,425,272$ & $1,413,683$ & $-11,589$ & -0.813 & 14.33 & 55.76 \\
\hline $\begin{array}{r}\text { Forestry, Fishing, and } \\
\text { Hunting }\end{array}$ & 62,591 & 62,058 & -533 & -0.852 & 11.54 & 63.05 \\
\hline $\begin{array}{r}\text { Accommodation and } \\
\text { Food Services }\end{array}$ & $1,077,065$ & $1,070,247$ & $-6,818$ & -0.633 & 11.54 & 69.65 \\
\hline
\end{tabular}




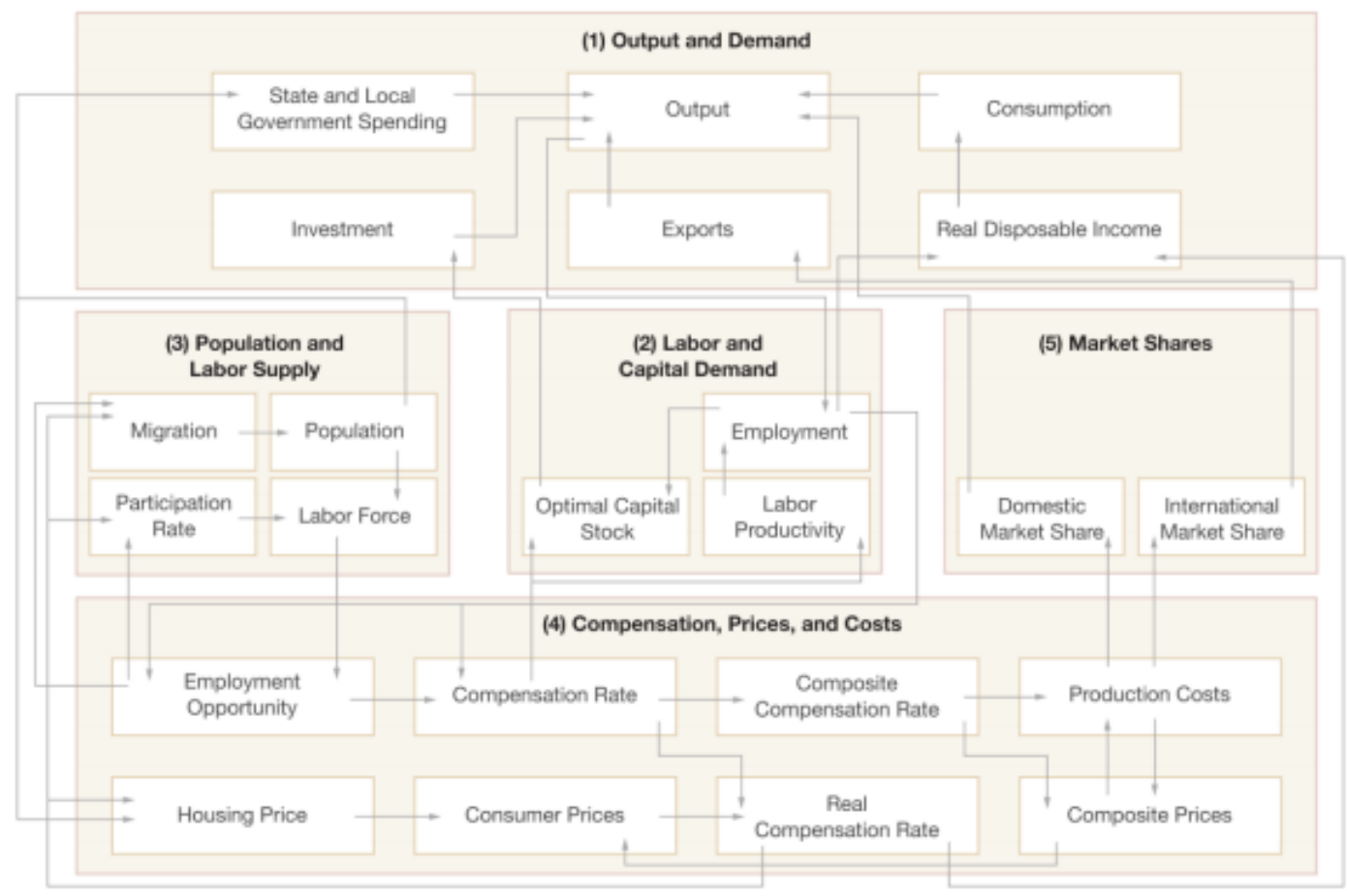

Source: http://www.remi.com/wp-content/uploads/2018/06/Model-Equations-v2_2.pdf 


\section{Appendix 5}

Percent Difference from the Baseline Estimate for a -0.1 Elasticity

\begin{tabular}{r|llllll} 
Benefit Program & $\mathbf{2 0 2 1}$ & $\mathbf{2 0 2 2}$ & $\mathbf{2 0 2 3}$ & $\mathbf{2 0 2 4}$ & $\mathbf{2 0 2 5}$ & $\mathbf{2 0 2 6}$ \\
\hline Medicare & 0.007 & -0.012 & -0.022 & -0.035 & -0.049 & -0.063 \\
Social Security & 0.008 & -0.030 & -0.023 & -0.036 & -0.049 & -0.062 \\
$\begin{array}{r}\text { Earned Income } \\
\text { Tax Credit } \\
\text { Supplemental }\end{array}$ & 0.014 & -0.048 & -0.043 & -0.070 & -0.097 & -0.109 \\
$\begin{array}{r}\text { Nutrition } \\
\text { Assistance }\end{array}$ & 0.000 & -0.020 & -0.059 & -0.058 & -0.096 & -0.113 \\
$\begin{array}{r}\text { Program (SNAP) } \\
\text { Education and }\end{array}$ & 0.015 & -0.015 & -0.046 & -0.079 & -0.093 & -0.108 \\
$\begin{array}{r}\text { Training } \\
\text { Assistance }\end{array}$ & & & & & & \\
State & 0.000 & 0.000 & -0.123 & -0.115 & -0.109 & -0.103 \\
Unemployment & & & & & & \\
$\begin{array}{r}\text { Insurance } \\
\text { Compensation }\end{array}$ & & & & & &
\end{tabular}

This chart shows the percent difference between out estimation the baseline forecast for several different benefit programs with a -0.1 elasticity. 


\section{Appendix 6}

Percent Difference from the Baseline Estimation for a -0.3 Elasticity

\begin{tabular}{r|llllll} 
Benefit Program & 2021 & 2022 & 2023 & 2024 & 2025 & 2026 \\
\hline $\begin{array}{r}\text { Medicare } \\
\text { Social Security }\end{array}$ & 0.022 & -0.037 & -0.070 & -0.105 & -0.145 & -0.182 \\
Earned Income & 0.043 & -0.037 & -0.070 & -0.106 & -0.146 & -0.182 \\
$\begin{array}{r}\text { Tax Credit } \\
\text { Supplemental }\end{array}$ & 0.040 & -0.071 & -0.128 & -0.211 & -0.278 & -0.342 \\
$\begin{array}{r}\text { Nutrition } \\
\text { Assistance }\end{array}$ & & & -0.138 & -0.195 & -0.268 & -0.339 \\
$\begin{array}{r}\text { Program (SNAP) } \\
\text { Education and }\end{array}$ & 0.044 & -0.074 & -0.137 & -0.204 & -0.280 & -0.338 \\
$\begin{array}{r}\text { Training } \\
\text { Assistance } \\
\text { State }\end{array}$ & 0.000 & -0.133 & -0.123 & -0.230 & -0.217 & -0.412 \\
$\begin{array}{r}\text { Unemployment } \\
\text { Insurance }\end{array}$ & & & & & & \\
Compensation & & & & & &
\end{tabular}

This chart shows the percent difference between out estimation the baseline forecast for several different benefit programs with a -0.3 elasticity. 


\section{Appendix 7}

\begin{tabular}{|c|c|c|c|c|c|}
\hline Year & $\begin{array}{c}\% \text { Change in } \\
\text { Wage by } \\
\text { Year }\end{array}$ & $\begin{array}{c}\text { College } \\
\text { Enrollment } \\
\text { According to } 4.4 \% \\
\text { Elasticity }\end{array}$ & $\begin{array}{c}\text { College } \\
\text { Enrollment } \\
\text { According to } \\
5 \% \text { Elasticity }\end{array}$ & $\begin{array}{l}\text { \% Decrease in } \\
\text { College } \\
\text { Enrollees for } \\
\text { Elasticity of } 4.4\end{array}$ & $\begin{array}{c}\text { \% Decrease in } \\
\text { College } \\
\text { Enrollees for } \\
\text { Elasticity of } 5\end{array}$ \\
\hline 2021 & 18.2 & 733,000 & 733,000 & 0.080 & 0.091 \\
\hline 2022 & 10.0 & 674,360 & 666,297 & 0.044 & 0.050 \\
\hline 2023 & 9.1 & 644,688 & 696,350 & 0.040 & 0.046 \\
\hline 2024 & 8.3 & 618,901 & 699,649 & 0.037 & 0.042 \\
\hline 2025 & 7.7 & 596,001 & 670,613 & 0.034 & 0.039 \\
\hline 2026 & 7.1 & 575,737 & 644,794 & 0.031 & 0.036 \\
\hline
\end{tabular}

This chart demonstrates how we've come up with the schooling effect estimates based off of the number of state college enrollments provided by The Florida College System. 


\section{Bibliography}

Title Page Image: Jackson, Lucas. Reuters, https://slate.com/business/2019/02/new-research-15dollar-minimum-wage-good-for-workers.html.

1."Florida Minimum Wage History 2000 to 2019." Oct. 2018. Florida Department of Economic Opportunity. 09 July 2019, http://www.floridajobs.org/docs/default-source/business-growth-andpartnerships/for-employers/posters-and-required-notices/2019-minimum-wage-poster/floridaminimum-wage-history-2000-2018.pdf?sfvrsn=4.

2. Brown, Charles; Gilroy, Curtis; and Kohen, Andrew. "The Effect of the Minimum Wage on Employment and Unemployment." Journal of Economic Literature, Vol. 20, No. 2 (June 1982), pp. 487-528.

3. Neumark, David and Wascher, William, (1992), "Employment Effects of Minimum and Subminimum Wages: Panel Data on State Minimum Wage Laws”, ILR Review, 46, issue 1, p. 55-81, https://EconPapers.repec.org/RePEc:sae:ilrrev:v:46:y:1992:i:1:p:55-81.

4. "History of Federal Minimum Wage Rates Under the Fair Labor Standards Act, 1938 - 2009." Minimum Wage - Wage and Hour Division (WHD) - U.S. Department of Labor, www.dol.gov/whd/minwage/chart.htm.

5. Card, David \& Krueger, Alan B, 1994. "Minimum Wages and Employment: A Case Study of the Fast-Food Industry in New Jersey and Pennsylvania," American Economic Review, American Economic Association, vol. 84(4), pages 772-793, September.

7. Thomas Leonard, (2000), The Very Idea of Applying Economics: The Modern MinimumWage Controversy and Its Antecedents, History of Political Economy, 32, (5), 117-144

8. Kennan, John. "The Elusive Effects of Minimum Wages.” Journal of Economic Literature, vol. 33, no. 4, 1995, pp. 1950-1965. JSTOR, www.jstor.org/stable/2729319.

9. Burkhauser, Richard V., et al. "A Reassessment of the New Economics of the Minimum Wage Literature with Monthly Data from the Current Population Survey." Journal of Labor Economics, vol. 18, no. 4, 2000, pp. 653-680. JSTOR, www.jstor.org/stable/10.1086/209972.

10. Zavodny, Madeline. 2000. "The Effect of the Minimum Wage on Employment and Hours." Labour Economics. Vol. 7, No. 6 (November), pp. 729-750.

11. Keil, Manfred, Donald Robertson, and James Symons. 2001. "Minimum Wages and Employment." CEPR Working Paper No. 497.

12. Neumark, David, and William Wascher. "Minimum wages and skill acquisition: Another look at schooling effects." Economics of Education Review 22.1 (2003): 1-10. 
13. Evans, W., \& Turner, M. (1995). "Minimum Wage Effects on Employment and School Enrollment: Comment." Mimeo. University of Maryland.

14. Fiscal Policy Institute. 2004. "State Minimum Wages and Employment in Small Businesses." fiscalpolicy.org/wp-content/uploads/2004/04/minimumwageandsmallbusiness.pdf.

16. Sabia, Joseph J. "The Effect of Minimum Wage Increases on Retail and Small Business Employment”. Employment Policies Institute, May 2006, www.epionline.org/wpcontent/studies/sabia_05-2006.pdf.

17. Neumark, David, JM Ian Salas, and William Wascher. "Revisiting the Minimum Wage Employment Debate: Throwing Out the Baby with the Bathwater?." ILR Review67.3_suppl (2014): 608-648.

18. Jardim, Ekaterina, et al. "Minimum Wage Increases and Individual Employment Trajectories". No. w25182. National Bureau of Economic Research, 2018.

19.Steven Ruggles, Sarah Flood, Ronald Goeken, Josiah Grover, Erin Meyer, Jose Pacas, and Matthew Sobek. IPUMS USA: Version 9.0 [dataset]. Minneapolis, MN: IPUMS, 2019. https://doi.org/10.18128/D010.V9.0

20. "County Employment and Wages in Florida - Third Quarter 2018: Southeast Information Office.” U.S. Bureau of Labor Statistics, U.S. Bureau of Labor Statistics, 2 Apr. 2019, www.bls.gov/regions/southeast/news-release/countyemploymentandwages_florida.htm\#table1.

21. "SAIPE State and County Estimates for 2017." SAIPE State and County Estimates for 2017, US Census Bureau, 1 Mar. 2019, www.census.gov/data/datasets/2017/demo/saipe/2017-stateand-county.html.

22. "Florida County Profiles." Office of Economic \& Demographic Research The Florida Legislature, 25 June 2019, edr.state.fl.us/content/area-profiles/county/index.cfm.

23. "Rural Definition." Florida Department of Economic Opportunity, www.floridajobs.org/community-planning-and-development/rural-community-programs/ruraldefinition.

24. "Regional Economic Models, Inc. (REMI) Model." Regional Economic Models, Inc. (REMI) Model | Open Energy Information, openei.org/wiki/Regional_Economic_Models,_Inc._(REMI)_Model.

25. Rickman, Dan, and R Schwer. "A Comparison of the Multipliers of IMPLAN, REMI, and RIMS II: Benchmarking Ready-Made Models for Comparison." The Annals of Regional Science, vol. 29, no. 4, Dec. 1995, pp. 363-374., doi:https://doi.org/10.1007/BF01581882. 
27. "Child Care Subsidies under the CCDF Program."

www.ccdf.urban.org/sites/default/files/CCDFDatabase2015PolicySummary.pdf.

28. "What Is SNAP?" What Is SNAP? | Www.gettingsnap.org,

www.gettingfoodstamps.org/whatissnap.html.

29. "Eligibility for SNAP in FL." Florida, florida-assistance.org/florida-dcf/snap-inflorida/eligibility-for-snap-in-florida/.

30. "Food Assistance Program Fact Sheet." Oct. 2018, www.myflfamilies.com/programs/access/docs/fafactsheet.pdf.

31. "Welcome to Benefits.Gov." Welcome to Benefits.Gov | Benefits.Gov, www.benefits.gov/benefit/1553.

32. Www.geosolinc.com. Employ Florida - Supplemental Security Income (SSI), www.employflorida.com/gsipub/index.asp?docid=50.

33. "Social Security." SSI Federal Payment Amounts for 2019, www.ssa.gov/oact/cola/SSI.html.

34. Dickey, Elizabeth. "Income and Asset Limits for SSI Disability Eligibility." Www.nolo.com, Nolo, 19 Jan. 2017, www.nolo.com/legal-encyclopedia/income-asset-limits-ssi-disabilityeligibility.html.

35. "Florida Temporary Assistance for Needy Families (TANF)", www.welfareinfo.org/benefits/florida-temporary-assistance-for-needy-families-tanf-1657.

36. "Florida TANF Application.” TANF Program, www.tanfprogram.com/florida-tanf-application-ta9.

37. Temporary Cash Assistance Fact Sheet. www.myflfamilies.com/serviceprograms/access/docs/tcafactsheet.pdf.

38. "EITC Income Limits Maximum Credit Amounts Next Year: Internal Revenue Service." EITC Income Limits Maximum Credit Amounts Next Year | Internal Revenue Service, www.irs.gov/credits-deductions/individuals/earned-income-tax-credit/eitc-income-limitsmaximum-credit-amounts-next-year.

39. "Qualifying Child Rules." Internal Revenue Service, www.irs.gov/creditsdeductions/individuals/earned-income-tax-credit/qualifying-child-rules.

40. "The Earned Income Credit.” All Florida Tax \& Financial Solutions, 2 Jan. 2015, www.allfloridatax.net/blog/the-earned-income-credit/4560. 
41. Carroll, C., Slacalek, J., Tokuoka, K. and White, M. N. (2017), The distribution of wealth and the marginal propensity to consume. Quantitative Economics, 8: 977-1020.

doi:10.3982/QE694

44. Lee, Chang Hyung. "Minimum Wage Policy and Community College Enrollment Patterns." ILR Review, June 2019, doi:10.1177/0019793919855003.

45. "Annual Outcomes Report." Florida Department of Education, 2018, Florida Education and Training Placement Program.

46. "The Florida College System." Home | The Florida College System, www.floridacollegesystem.com/.

47. Jardim, Ekaterina, et al. Minimum Wage Increases, Wages, and Low-Wage Employment: Evidence from Seattle. No. w23532. National Bureau of Economic Research, 2017.

49. Brainerd, Jackson. "State Minimum Wages: 2019 Minimum Wage by State." State Minimum Wages | 2019 Minimum Wage by State, 7 Jan. 2019, www.ncsl.org/research/labor-andemployment/state-minimum-wage-chart.aspx\#Table.

50. Lordan, Grace, and David Neumark. "People Versus Machines: The Impact of Minimum Wages on Automatable Jobs." Labour Economics 52 (2018): 40-53.

51. "The Effects on Employment and Family Income of Increasing the Federal Minimum Wage." Congressional Budget Office. 8 July 2019. 16 July 2019

$<$ https://www.cbo.gov/publication/55410>.

52. "Labor Force Status of the Civilian Noninstitutional Population." 21 June 2019. U.S. Department of Labor, Bureau of Labor Statistics, Local Area Unemployment Statistics Program, in cooperation with the Florida Department of Economic Opportunity, Bureau of Workforce Statistics and Economic Research. 16 July 2019

$<$ http://lmsresources.labormarketinfo.com/library/press/fl-us.pdf $>$.

Appendix 4. "What Does REMI Say?” REMI, www.remi.com/. 